\title{
LIFE CYCLE OF VALVATA PISCINALIS (O. F. MÜLLER, 1774) (GASTROPODA: HETEROBRANCHIA) IN THE LABORATORY
}

\author{
STANISŁAW MYZYK
}

\begin{abstract}
Sąpolno 14, 77-320 Przechlewo, Poland
ABSTRACT: Laboratory and field observations in 1994-2004 made it possible to ascertain the following parameters of life cycle of Valvata piscinalis (O. F. Müller, 1774). In favourable food conditions (filamentous diatoms) female maturity was attained in 42-85 days from hatching (mean 59 days) at the body whorl diameter of 3.45-4.65 mm (mean $4.10 \mathrm{~mm}$ ) and the number of whorls 3.25-3.75 (mean 3.53). In slightly less favourable food conditions (periphyton) the maturity was attained later at a somewhat lower mean shell size. The number of cocoons and eggs produced during lifetime by snails kept in pairs was 18-113 and 387-2,862, respectively; the number of eggs per cocoon ranged from 0 to 76 . Among singly kept snails only half laid cocoons (maximum 7 cocoons $/ 6$ eggs during lifetime), and the eggs failed to develop. The mean life span of snails fed mainly with periphyton was ca. 1 year (maximum 641 days); it was distinctly shorter in snails fed with filamentous diatoms (usually 5-7 months, rarely more than 11 months). In very unfavourable food conditions (small quantities of periphyton) female maturity was attained only after 1-2 years and the life span was not much longer: maximum 830 days. In natural conditions (lake Sosnowe near Sapolno) reproduction started in the second half of April and lasted till half of July; the cocoons contained 10-37 eggs.
\end{abstract}

KEY WORDS: Gastropoda, Heterobranchia, Valvata, life cycle, reproduction

\section{INTRODUCTION}

Valvata piscinalis (O. F. Müller, 1774) occurs mainly in permanent water bodies of various kinds: lakes, ponds, rivers, oxbows, drainage ditches, etc. Its shell is conical (from conical-spherical to turret-like), with a rather narrow umbilicus. The shell height and width are up to $5-7 \mathrm{~mm}$. The whorls are usually strongly convex, and their surface is covered by radial striae and sometimes also delicate spiral lines. The shell structure (e.g. shape, proportions, surface sculpture) shows a considerable variation which resulted in numerous forms being described (FALNIOWSKI 1989a).

\section{MATERIAL AND METHODS}

Adult snails for the laboratory culture were collected in lake Sosnowe near Sapolno (NW. Poland). They were placed in the laboratory culture tempor-
The species was hitherto the best known member of the genus with respect to its biology (WESSENBERG-LUND 1939, CLELAND 1954, FRÖMMING 1956, FRETTER \& GRAHAM 1962, PIECHOCKI 1979, GIROD et al. 1980, RATH 1986, 1988, FALNIOWSKI 1989a). Illustrations and detailed descriptions of shell structure and internal organs are contained in FALNIOWSKI (1989a, b, 1990). A part of information given in my earlier papers on life cycles of $V$. cristata and $V$. macrostoma (MYZYK 2002, 2004) pertains also to this species (e.g. variation in egg and cocoon structure, course of embryonic development).

arily, to obtain cocoons and to observe various activites (copulation, cocoon laying, feeding). In 1994, 24 snails were used to start the culture; they 


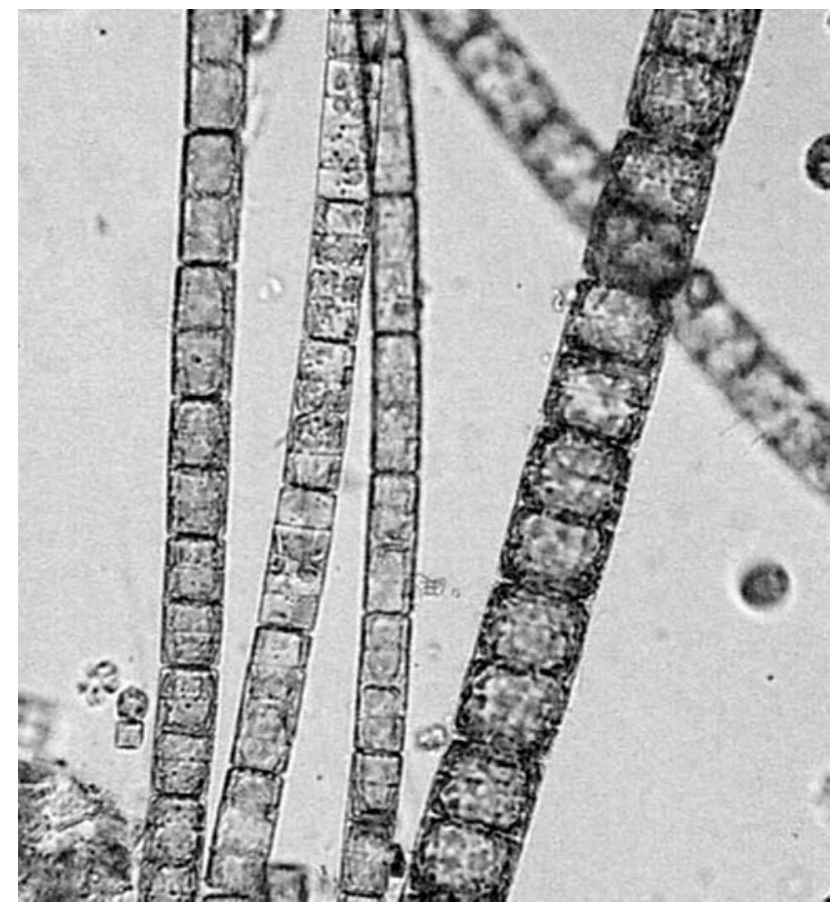

Fig. 1. Light microscope, filamentous diatoms added as food, $300 \times$

were kept in small containers $25 \mathrm{~mm}$ in diameter, filled with water to the depth of ca. $25 \mathrm{~mm}$. In spite of being constantly provided with food (periphyton) they grew very slowly and most died as juveniles. Only four of them reached maturity and the number of deposited cocoons and eggs was very small. Thus further in the text the results will be presented only briefly and referred to as "culture in very unfavourable food conditions". In 1996 the culture was started in small containers (as above), but with growth the snails were transferred to inreasingly larger containers. Adult snails were kept in containers of $80 \mathrm{~mm}$ diameters and filled with water to the depth of 55-60 $\mathrm{mm}$. In 1996-2001 a total of 148 snails were placed in the culture, 64 died as juveniles and three reached only male maturity (partly excluded from the analysis). Adults were kept in pairs (52) or singly, with no possibility to copulate (29). When one of the snails kept in pairs died, the remaining partner was placed with another snail (usually for 24 hours) to copulate.

Snails hatched in 1996-1998 during their lifetime were given mainly leaves of trees from lake Sosnowe, covered with a layer of periphyton. From spring till autumn fresh food was provided usually every 10 days. In winter every few weeks a small quantity of dead leaves of sweet rush and manna grass from the Brda river was added. In subsequent years the quantity of food was increased. Newly hatched snails in 1999-2001 were fed with a thin layer of periphyton covering tree leaves. When they were larger, from June till October, colonies of filamentous diatoms of the genus Melosira (Fig. 1) collected in the Brda River were added to the containers. In consecutive years the quantity of provided diatoms was increased gradually, while the quantity of leaves was decreased. Snails hatched in 2001 were given large quantities of diatoms already when their shells were ca. $1.5 \mathrm{~mm}$ in diameter. In winter and spring large quantities of dead leaves of sweet rush and manna grass, covered mainly by various species of diatoms, were added to the containers. Water in the containers was changed according to need, e.g. at temperatures above $23^{\circ} \mathrm{C}$ every 12 hours and below $15^{\circ} \mathrm{C}$ usually every $3-5$ days. From May till September the temperature in the culture was usually $15-25^{\circ} \mathrm{C}$, during the remaining period it was $8-18^{\circ} \mathrm{C}$ (rarely slightly less or more).

After concluding the laboratory observations, in 2003 and 2004 observations in lake Sosnowe were continued (periods of cocoon deposition, number of

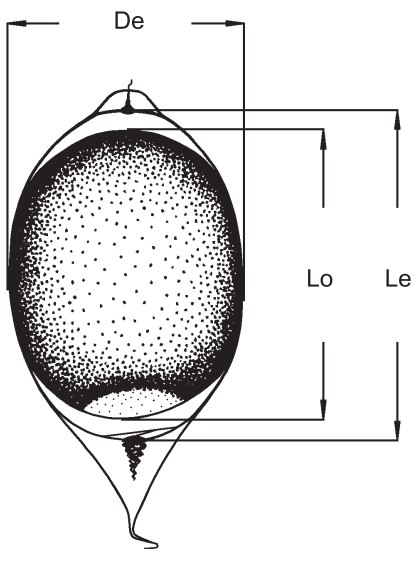

2

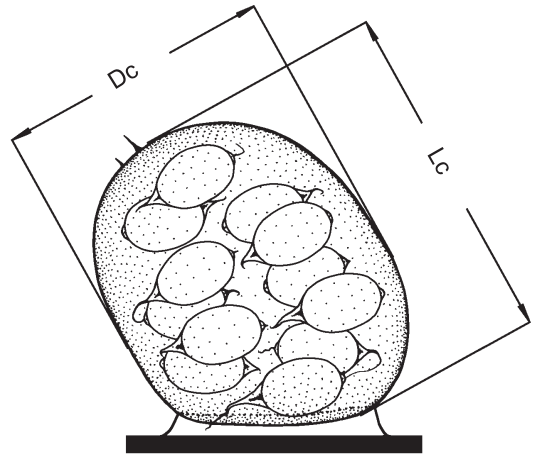

3

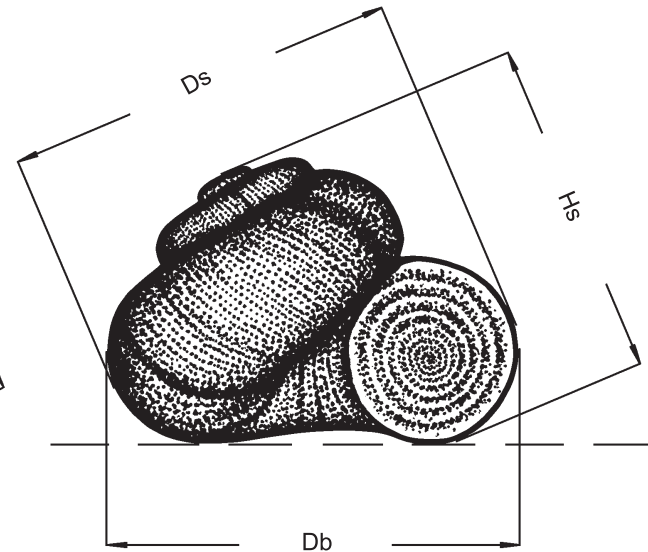

4

Figs 2-4. Measurements: 2 - egg: De - egg chamber diameter, Le - egg chamber length, Lo - egg cell length; 3 - Cocoon: Dc - maximum cocoon diameter in the plane of sutures, Lc - cocoon length measured parallel to the capsule striae; 4 Shell: Db - body whorl diameter, Ds - shell diameter, Hs - shell height 
eggs per cocoon etc.). In order to compare the shell variation a sample was also collected from a fish pond built in a Brda oxbow.

Measurements are shown in Figs 2-4. Cocoons were measured in a large drop of water, after removing the mucus layer. Cocoon length was measured parallel to the striae on the capsule, the diameter - in the widest place in the plane of sutures. Length measurements omitted threads of capsule-forming substance found sometimes on the top of the capsule, and the layer of cementing substance (Fig. 3). During shell measurements small snails were kept in a large drop of water, larger snails (diameter exceeding $1.7 \mathrm{~mm}$ ) were measured dry. Since measurements of shell diameter (Ds) in live snails were rather difficult (often resulting in damage to fresh increments) in order to determine size the body whorl diameter was measured (Fig. 4 - Db) like in V. macrostoma (MYZYK 2004). Precise measurements of adult shells were taken after the snails died. Comparison of the results of the measurements showed that the body whorl diameter was larger than the shell diameter on average by $6.2 \%$ (maximum 12.1\%) (Fig. 5). Only for small shells with a very low spire the difference was slightly smaller than the measurement error. Most measurements were taken with calibrated eyepiece to the nearest $0.01 \mathrm{~mm}$ (range $0.1-1 \mathrm{~mm}$ ) or $0.05 \mathrm{~mm}$ (above $2.3 \mathrm{~mm}$ ). Diameter and height of adult shells were

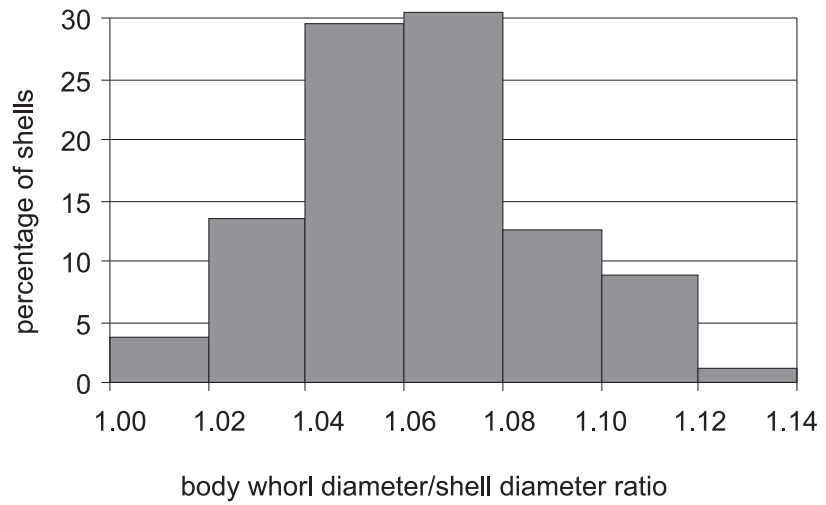

Fig. 5. Variation in the body whorl diameter/shell diameter ratio

measured on millimetre paper at $6 \times$ magnification (accuracy ca. $0.1 \mathrm{~mm}$ ). The number of whorls in live shells was estimated roughly, to the nearest $1 / 8$ $(=0.125)$ whorl, during shell measurements on dead snails - to the nearest 0.05 whorl.

To facilitate description of embryonic development the whole development period was divided in three stages: "egg" - from cocoon deposition to breaking of external egg envelope, "larva" - intermediate stage, "snail" - from formation of shell covering the whole body to hatching (MYZYK 2002: Figs 43-51).

All figures in the text are original.

\section{RESULTS AND DISCUSSION}

\section{COPULATION}

The course of copulation in $V$. piscinalis was similar to that in V. cristata and V. macrostoma (MYZYK 2002, 2004). During the initial phase the "female" was usually feeding while the male approached her and took a proper position on her shell near the aperture. Very often the "female" burdened with the "male" detached from the substratum and both snails dropped to the bottom (almost always apex first) where the copulation continued. Both PIECHOCKI (1979) and FALNIOWSKI (1989a) report that during copulation the "female" is positioned with her apex pointing downwards and turns her head strongly to the left which makes the gonopore accessible. According to my observations the head twisting by the "female" resting on the bottom was more of an attempt at regaining the normal position and attaching to the substratum (sometimes successful). During copulation the "male" turned his head strongly to the left, his ctenidium protruded, cephalic tentacles were rather flabby and the pallial tentacle was usually in its normal position. Head tilting to the left with its simultaneous twist made it easier to extrude the penis from the mantle cavity and direct it to the "female's" mantle cavity. Sometimes the "male" insterted all his head into the "female's" mantle cavity. At the end of the initial phase the "female" stopped feeding and also slightly contracted her body (head, cephalic tentacles, ctenidum) but the pallial tentacle remained usually erect. After finishing the copulation (first) the roles often became reversed and another (second) copulation took place. Sometimes already during the first copulation the "female" protruded her penis and tried to place it in the "male's" mantle cavity, but no reciprocal copulation was observed. During the second copulation, after reversing the roles, no such behaviour was observed. The total time of one copulation was in most cases 35-60 minutes, but sometimes became prolonged to ca. 2 hours.

Some young snails copulated before reaching female maturity, both as males and females. Just after reaching maturity and in the early spring copulations were repeated many times (sometimes even every 2-3 days). In the winter increasing the temperature for several hours to $15-16^{\circ} \mathrm{C}$ resulted in most snails starting to copulate. The lowest temperature at which copulation took place in the winter was ca. $11^{\circ} \mathrm{C}$ (both snails with many vitellogenic oocytes). In the summer and early autumn copulations were less frequent, and 
decrease in temperature below $19^{\circ} \mathrm{C}$ usually stopped them completely. At the end of life (including spring) the snails rarely copulated as males.

\section{COCOON DEPOSITION}

Cocoon deposition started usually 1-2 days after copulation. Prior to deposition the snail usually stayed in one place rasping the substratum with its radula. This behaviour lasted from about a dozen minutes to over 2 hours; the more numerous the eggs in the cocoon were, the longer the time spent in one place (generally 2-4 minutes multiplied by the number of eggs in the cocoon). At that time the eggs accumulating in the nidamental gland could be seen. Just before deposition the snail tilted its shell strongly to the right, so that the aperture margin became parallel to the substratum. It remained in this position during cocoon deposition and glueing the cocoon to the substratum. The head was then somewhat contracted but the proboscis and the flabby cephalic tentacles partly protruded beyond the aperture margin. The ctenidium in some snails was much contracted, in others it protruded. The pallial tentacle usualy retained its normal position. The cocoon emerging from the reproductive ducts was provided with a drop of cementing substance and usually covered by a mucus layer. Usually after 5-15 minutes from the start of cocoon deposition the snail slowly tilted the shell to the left, to its normal position and crawled away after another few minutes.

Cocoons were deposited during daytime and in the night. In the winter single cocoons were deposited even at the temperature of ca. $10^{\circ} \mathrm{C}$ (beginning of February) and with increasing temperature reproduction became more intense. In the summer and early autumn a decrease in temperature below $19^{\circ} \mathrm{C}$ often resulted in cessation of cocoon deposition. In the laboratory most cocoons were deposited in the upper part of the containers, on walls and leaves close to the surface and under the surface film. Sporadically cocoons were found above the water table or unattached to the substratum. Some snails from time to time deposited small lumps of mucus (sometimes with short sections of egg cord).

In natural conditions (lake Sosnowe) cocoons were deposited on leaves and shoots of live, growing aquatic plants (mainly Potamogeton perfoliatus and Ceratophyllum demersum) and on submerged objects on the bottom (e.g. dead leaves). On growing plants the cocoons were rather often placed $0.7-1.0 \mathrm{~m}$ above the bottom.

\section{REPRODUCTION TIMING AND DURATION}

In the laboratory conditions the beginning and end of reproduction of snails kept in pairs depended mainly on food conditions (Figs 6-9). They influenced both the time of maturation and the life span.
Increased temperature in the laboratory, compared to natural conditions in the autumn-winter period, resulted in the reproductive period being considerably extended. However, in most containers in that period there was a long break in cocoon deposition (more than 3 weeks), but its beginning and duration varied. In some containers during the break single cocoons were deposited. Short breaks in cocoon deposition (a few to ca. dozen days) occurred also in other periods, e.g. during cool summer nights.

Most snails fed with periphyton (11 pairs hatched in 1996-1998) attained female maturity in late autumn (end of October - beginning of December). The first cocoons in individual containers were deposited 25-75 days from attainment of maturity (between half of December and end of January next year). Only two pairs hatched in 1997 reached maturity much earlier (August - beginning of September) and already after 8-14 days started reproducing (end of August - half of September). The mean time from hatching to deposition of the first cocoon was 170 days $(\mathrm{SD}=38, \mathrm{n}=13$, range $102-235)$. The course of reproduction varied between the years and containers (Figs 6-7). In two containers cocoon deposition was uninterrupted till the death of snails (218 and 293 days). In 11 containers after 1-63 days (mean 27) from the start of reproduction, in the autumn-winter period there was a longer break in cocoon deposition; it lasted 24-123 days (mean 62 days). Two pairs of 1997 which started reproducing already at the end of summer, interrupted cocoon deposition at the end of October and resumed it as late as in February. The remaining snails started their winter break between the end of December and end of February, to resume reproduction usually in February or March (2 pairs as late as beginning of May). In 10 containers the second reproductive period lasted 97-204 days (mean 139) and ended in some snails at the end of May, in others in mid-October, depending on the life span. In one container with a snail of a much longer life span compared to the other snails (hatched on July 20th 1998) the reproduction had a slightly different course. After death of its partner (June 21st 1999) the snail was kept singly but kept depositing cocoons till the 20th of August. Copulations on the 25th of August and then on the 6th of October resulted in continued reproduction which lasted till the 9 th of November. Later a longer winter break occurred (53 days), and cocoon deposition was resumed on the 2 nd and lasted till the 28th of January 2000 (died February 3rd 2000).

All snails fed mainly with filamentous diatoms (13 pairs hatched in 1999-2001) very soon reached female maturity. The first cocoons in individual containers were deposited 2-17 days after attainment of maturity (June-August). The mean time from hatching till the first cocoon was 66 days $(S D=9, n=13$, range 51-87). The course of reproduction varied depend- 
ing on feeding intensity (Figs 8-9). Five pairs of snails, hatched in 1999 (rather little filamentous diatoms in the food), after starting reproduction deposited cocoons during 60-97 days (mean 83) and then at the end of October/beginning of November a break started and lasted 101-131 days (mean 112). Reproduction was resumed in February or at the beginning of March and lasted 64-87 days (mean 78), almost till the death of the snails (April-May). Snails hatched in 2000 and 2001 (large quantities of filiamentous dia-
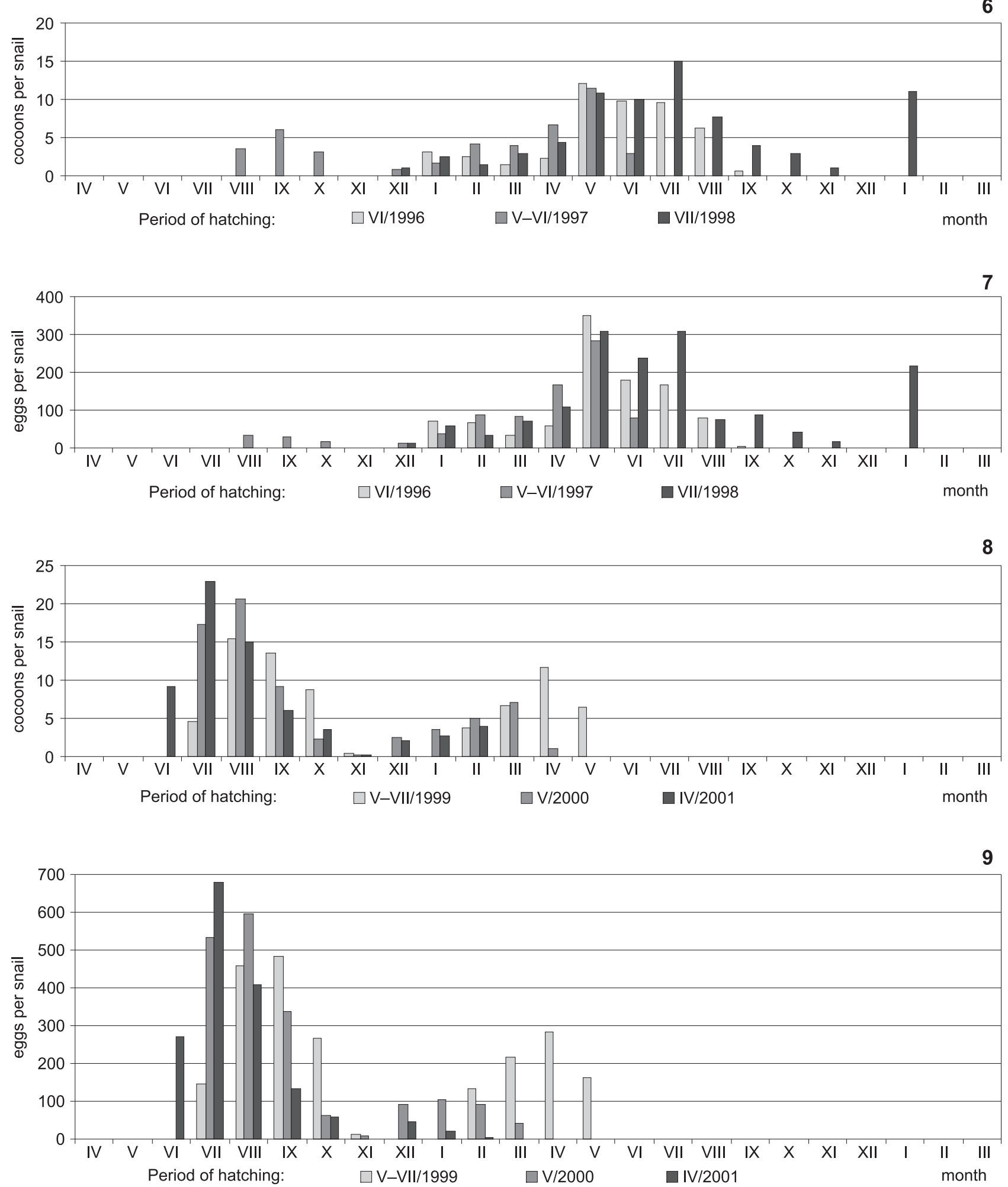

Figs 6-9. Cocoons laid in consecutive months and years by snails kept in pairs; mean number of cocoons and eggs converted to one snail living in a given month: 6-7 - mainly periphyton as food; 8-9-mainly filamentous diatoms as food 
toms in the food) after starting reproduction deposited cocoons for 61-149 days (mean 101). In the autumn most snails died, and those that survived interrupted their reproduction for 30-76 days (mean 62). The reproduction was often resumed already in December and lasted 1-100 days (mean 36). Depending on the life span cocoons were deposited from the beginning of April (hatched in 2000) or half of February (hatched in 2001).

The mean period between the first and the last cocoon in a container for snails hatched in 1996-1998 was 247 days $(\mathrm{SD}=58, \mathrm{n}=13$, range $159-386)$, and for those hatched in 1999-2001 - 206 days $(\mathrm{SD}=75, \mathrm{n}=13$, range $85-286$ ). The time between the last cocoon in the container and the death of the longest-lived snail did not depend on food conditions and was on average 22 days $(\mathrm{SD}=27, \mathrm{n}=26$, range $1-97)$. For snails dying in the spring and summer that time was rather short (1-16 days), and in some of them the nidamental gland even after death contained partly formed cocoons. For snails dying in the late autumn and winter the time between the last cocoon and death was usually much longer; the maximum such time was 97 days.

Among 29 snails kept singly (no possibility to copulate) only 15 deposited cocoons (including 1 individual depositing cocoons in 2 seasons). The cocoons were deposited from May till the end of September (sporadically still at the beginning of November). Deposition of the first cocoon was as a rule later than in snails kept in pairs. Snails hatched in 1997-1998 started depositing cocoons on average 258 days after hatching ( $\mathrm{SD}=87, \mathrm{n}=6$, range $140-358$ ), and those hatched in 1999-2001 on average 127 days after hatching ( $\mathrm{SD}=34$, $\mathrm{n}=9$, range 53-178). Also the mean time between the attainment of female maturity and the first cocoon was longer (147 and 72 days, respectively). The time between the last cocoon and death did not depend on food conditions and for snails kept singly was on average 70 days $(\mathrm{SD}=80, \mathrm{n}=15$, range $0-230)$.

In natural conditions (lake Sosnowe) reproduction started in the second half of April and lasted at least till mid-July (no cocoons were found later but snails with vitellogenic oocytes were still present). In June the number of cocoons found was maximum. According to PIECHOCKI (1979) and FALNIOWSKI (1989a) the reproduction lasts from April till August.

Adult snails collected in the field (irrespective from the season) started reproducing within a few days spent in the laboratory if adequate conditions were provided (temperature ca. $20^{\circ} \mathrm{C}$, food and partner).

\section{FECUNDITY}

At the moment of deposition of the first cocoon the shells of snails kept in pairs had the body whorl diameter of 2.25-5.0 mm (usually 4.0-4.5 mm) and
2.87-4.0 whorls (usually 3.62-3.75). The first cocoon contained 1-46 eggs, the number of eggs per cocoon was weakly positively correlated with the shell size (body whorl diameter): $r=0.49, n=29$. Cocoons of snails fed only with periphyton contained 1-28 eggs (mean 16), and of those fed with periphyton with addition of filamentous diatoms 4-46 eggs (mean 25).

During 24 hours a pair of snails deposited a maximum of two cocoons (rarely 3 or 4 , often preceded or followed by a day without or with only a single cocoon). The number of eggs produced within 24 hours depended, among other factors, on the number of deposited cocoons and with two cocoons it usually did not exceed 50-80 (sporadically up to 130); with three or four cocoons it was maximally 154 eggs. At the peak of reproduction period in the best food conditions a pair of snails deposited within month a maximum of 54 cocoons with 1,525 eggs, whereas $V$. macrostoma produced 53 cocoons with 471 eggs (MYZYK 2004).

Snails kept singly after their partner's death deposited another 15-33 cocoons containing a total of 196-797 eggs and then stopped reproducing. Following copulation (one or more during 24 hours) another 7-30 cocoons were produced containing 181-897 eggs. Cocoons deposited soon before cessation of reproduction contained increasingly fewer eggs, and the formed vitellogenic oocytes were accumulated in the gonads.

In 11 containers with snails fed with periphyton (hatched in 1996-1998) before the winter break 1-28 cocoons (mean 11) with 26-374 eggs (mean 158) were produced. During the winter break in four containers cocoons appeared (one in each), with 2-22 eggs, and in one container three cocoons with 63 eggs. When reproduction was resumed the number of deposited cocoons and eggs was always much greater and amounted to 37-108 cocoons (mean 77) with 609-2,448 eggs (mean 1,713). The peak of reproduction usually occurred in May next year after hatching (sometimes in June or even in July) (Figs 6-7). In May individual pairs of snails deposited 16-29 cocoons containing 418-837 eggs; the mean number of eggs per cocoon ranged from 18.2 to 30.6. In June and July in most containers reproduction was still rather intense and a pair of snails deposited within a month a maximum of 32 cocoons/773 eggs (except those hatched in 1997 and dead before the end of June 1998). Later, the number of deposited cocoons and eggs decreased rapidly (in August maximum of 16 cocoons/225 eggs), but some snails deposited single cocoons even till mid-October. The reproduction of the longest-lived snail, hatched in 1998 (life span 563 days), was somewhat different. From the start of reproduction till the partner's death (21st June 1999) a total of 62 cocoons with 1,704 eggs were deposited in the container. The remaining live snail was kept singly and intially during 30 days continued depositing co- 
coons (24 cocoons with 710 eggs). Later cocoons were produced irregularly and contained increasingly fewer eggs (the last one with one egg deposited on the 20th of August). Following copulation (25th of August) it resumed reproduction which till the end of September was rather intense (cocoons containing even up to 50 eggs). From the partner's death till the winter break (22 June-9 November) the snail produced 71 cocoons with 1,792 eggs, and in January 2000 another 11 cocoons with 218 eggs. In two containers where reproduction was not interrupted the number of cocoons deposited was 88 and 100, with 1,943 and 2,123 eggs, respectively.

Snails fed with filamentous diatoms (hatched in 1999-2001) reproduced most intensely usually between 11 th and 20th day since the beginning of reproduction. During the reproductive peak (July-September depending on when they reached maturity) within a month a pair of snails deposited 38-54 cocoons containing 1,249-1,525 eggs, the mean number of eggs per cocoon ranging from 26.0 to 42.7 . Later the number of deposited cocoons and eggs decreased rapidly (Figs 8-9). Five pairs of snails hatched in 1999 (rather small quantities of filamentous diatoms in the food) before the winter break produced 52-99 cocoons (mean 80) containing 1,839-3,179 eggs (mean 2,553). After the winter break they deposited 22-67 cocoons (mean 38) containing 682-2,375 eggs (mean 1,077). Only in one container in 1999 the number of cocoons and eggs in the first reproductive period was smaller than in the second (52 cocoons/1,839 eggs and 67 cocoons/2,375 eggs, respec- tively). Eight pairs of snails, hatched in 2000-2001 (much filamentous diatoms in the food), after starting to reproduce deposited 75-135 cocoons (mean 103) containing 1,938-4,049 eggs (mean 2,951), and then most of them died. Longer-lived individuals after the winter break produced 1-24 cocoons (mean 9) with 3-506 eggs (mean 146).

The mean numbers of cocoons and eggs produced in consecutive months by snails kept in pairs in different food conditions are presented in Figs 6-9 (converted to one adult alive in a given month); Figs 10-11 show the mean number of eggs per cocoon.

In very unfavourable conditions one pair of snails hatched in 1994 deposited during their lifetime only 10 cocoons with a total of 56 eggs ( 5 cocoons/28 eggs per snail).

The remaining snails kept in pairs deposited 18-113 cocoons with 387-2,862 eggs (converted to one snail) during their lifetime. Snails fed mainly with periphyton (hatched in 1996-1998) produced 23-113 cocoons (mean $47, \mathrm{SD}=18, \mathrm{n}=26$ ) contatining a total of 387-2,862 eggs (mean 1,021, SD=450, $\mathrm{n}=26$ ); the mean number of eggs per cocoon ranged from 11.8 to 28.6 (mean 21.7, $\mathrm{SD}=4.0$ ). The greatest number of cocoons (113) and eggs $(2,862)$ was produced by the longest-lived snail (life span 563 days). The remaining snails fed with periphyton deposited much fewer cocoons (maximum 71) and eggs (maximum 1,445). Snails fed mainly with filamentous diatoms (hatched in 1999-2001) produced 18-80 cocoons (mean 56, $\mathrm{SD}=14, \mathrm{n}=26$ ) with a total of 673-2,143 eggs (mean 1,637, $\mathrm{SD}=384, \mathrm{n}=26$ ); the

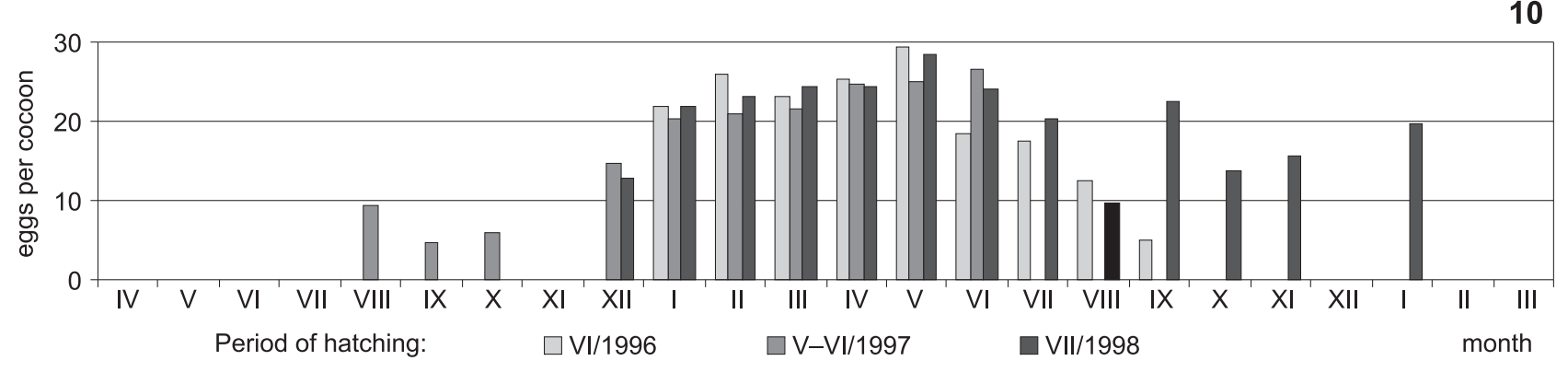

11

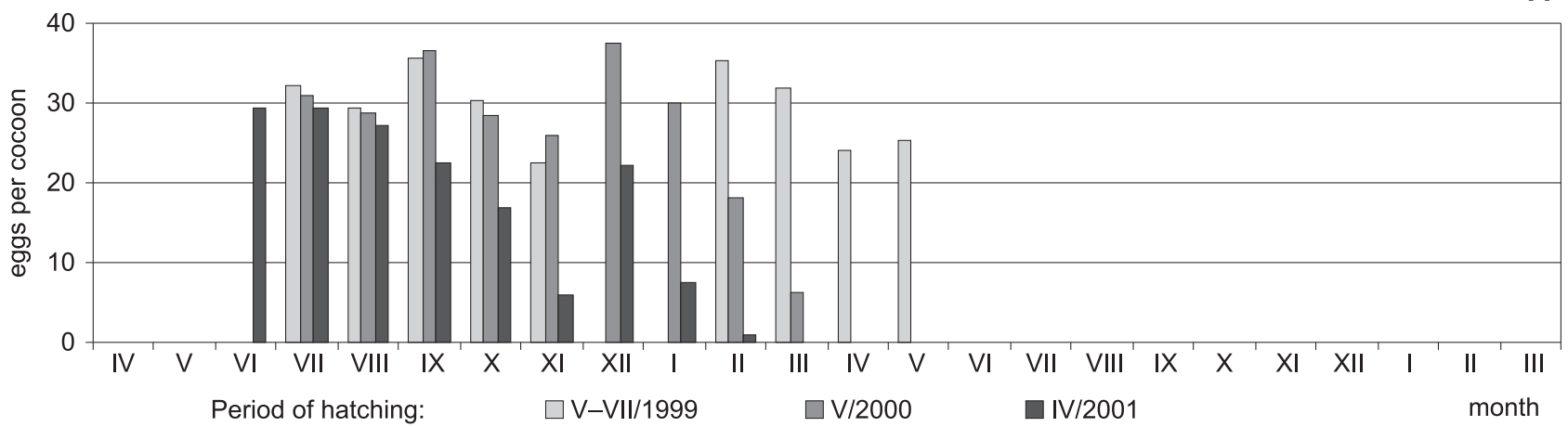

Figs 10-11. Cocoons laid in consecutive months and years by snails kept in pairs; mean number of eggs per cocoon: 10 mainly periphyton as food; 11 - mainly filamentous diatoms as food 
12

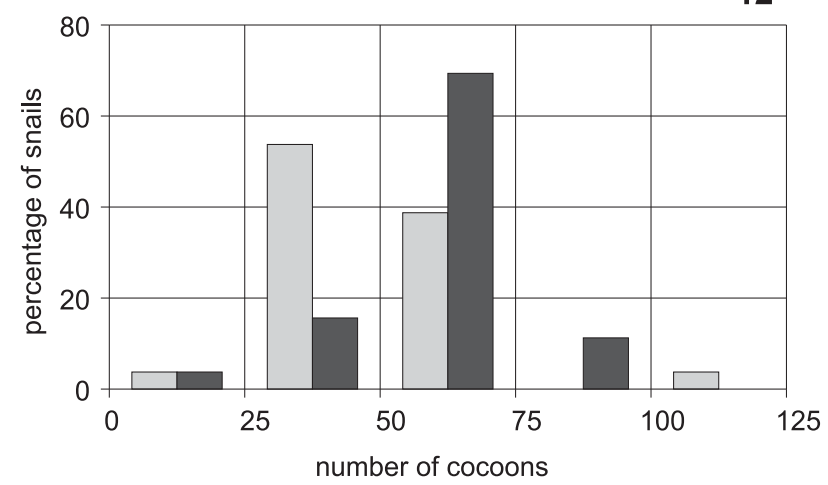

13

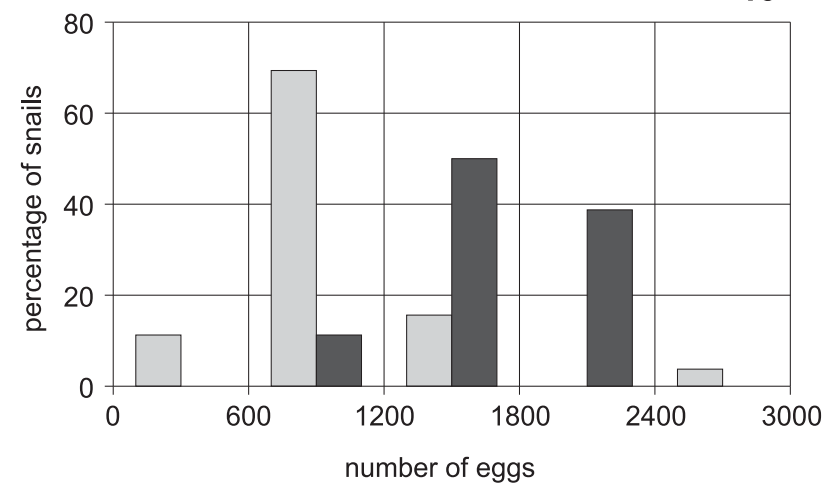

14

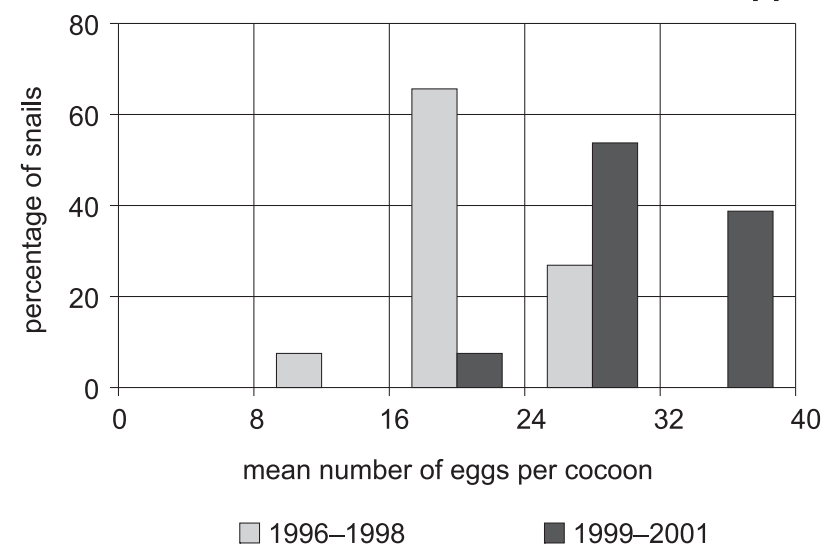

Figs 12-14. Variation in the number of cocoons and eggs deposited during lifetime by snails kept in pairs, and in the mean number of eggs per cocoon mean number of eggs per cocoon ranged from 21.9 to 37.4 (mean 29.1, $\mathrm{SD}=4.0$ ). The most efficient reproduction (maximum 80 cocoons/2,143 eggs) was observed in snails not very intensely fed with filamentous diatoms (hatched in 1999). More intense feeding resulted in so great a shortening of life span that the total number of produced cocoons and eggs was somewhat smaller. Variation in the number of cocoons and eggs deposited during lifetime by snails kept in pairs and the mean number of eggs per cocoon are presented in Figs 12-14.

Among 29 snails kept singly without the posibility to copulate 14 produced no cocoons, 15 deposited a total of 37 cocoons with a total of 32 eggs. During lifetime six snails deposited only one cocoon each (0-1 eggs), and four snails - two cocoons each (1-5 eggs). The remaining five snails deposited from three to seven cocoons containing a total of three to six eggs. Only one snail deposited cocoons during two seasons: I - 3 cocoons/ 4 eggs, II -2 cocoons/ 2 eggs. A comparison of the mean numbers of eggs and cocoons deposited by snails kept in pairs and singly in different food conditions (hatched in different years) is presented in Table 1.

FRETTER \& GRAHAM (1962) and FALNIOWSKI (1989a) state, after FRÖMMING (1956), that a single individual can deposit ca. 10 cocoons containing a total of ca. 150 eggs. According to my observations snails which had a possibility to copulate produced so few cocoons and eggs only in unfavourable food conditions or after only one copulation. Snails kept singly with no possibility to copulate produced much fewer eggs (not more than six during lifetime).

Gonads of dead snails nearly always contained vitellogenic oocytes. In most snails kept in pairs their number did not exceed 50. Only in six the whole gonads, except the embryonic whorl, were filled with vitellogenic oocytes (220-550) which could result from the lack of copulation at the end of life. On average $5.3 \%$ vitellogenic oocytes produced by snails kept in pairs remained in the gonads. Snails kept singly in most cases $(65.2 \%)$ had their whole gonads, except

Table 1. Mean number of cocoons and eggs deposited per lifetime - variable food conditions: 1996-1998 mainly periphyton as food, 1999-2001 mainly filamentous diatoms as food

\begin{tabular}{ccccccccc}
\hline \multirow{2}{*}{ Year of hatching } & \multicolumn{4}{c}{ Kept in pairs } & \multicolumn{4}{c}{ Kept singly } \\
\cline { 2 - 9 } & $\begin{array}{c}\text { Number } \\
\text { of snails }\end{array}$ & cocoons & eggs & $\begin{array}{c}\text { eggs per } \\
\text { cocoon }\end{array}$ & $\begin{array}{c}\text { Number } \\
\text { of snails }\end{array}$ & cocoons & eggs & $\begin{array}{c}\text { eggs per } \\
\text { cocoon }\end{array}$ \\
\hline 1996 & 4 & 47.5 & $1,006.0$ & 21.2 & - & - & - & - \\
1997 & 8 & 36.6 & 747.0 & 20.4 & 6 & 0.3 & 0.3 & 1.0 \\
1998 & 14 & 52.7 & $1,182.4$ & 22.4 & 9 & 1.4 & 0.9 & 0.6 \\
Total 1996-1998 & 26 & 47.0 & $1,021.3$ & 21.7 & 15 & 1.0 & 0.7 & 0.7 \\
\hline 1999 & 10 & 59.2 & $1,819.3$ & 30.7 & 4 & 1.5 & 1.7 & 1.2 \\
2000 & 4 & 56.0 & $1,672.5$ & 29.9 & 4 & 0.7 & 0.5 & 0.7 \\
2001 & 12 & 53.9 & $1,472.7$ & 27.3 & 6 & 2.2 & 2.2 & 1.0 \\
Total 1999-2001 & 26 & 56.3 & $1,636.7$ & 29.1 & 14 & 1.6 & 1.6 & 1.0 \\
\hline
\end{tabular}




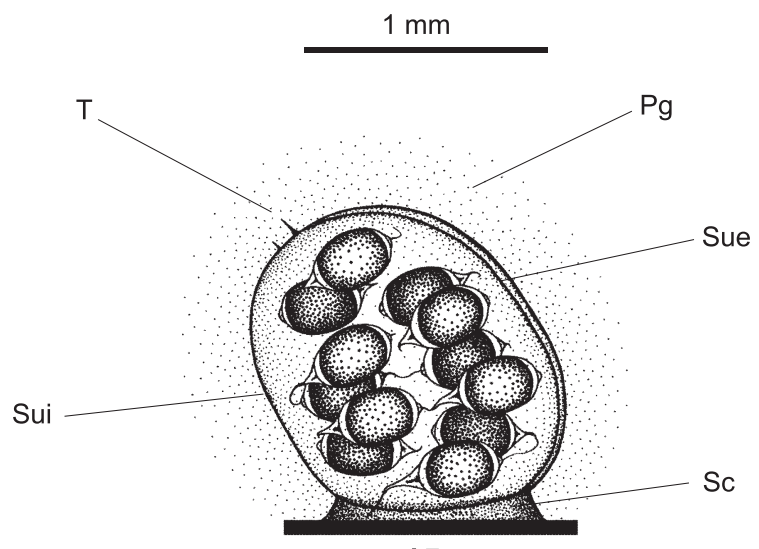

15

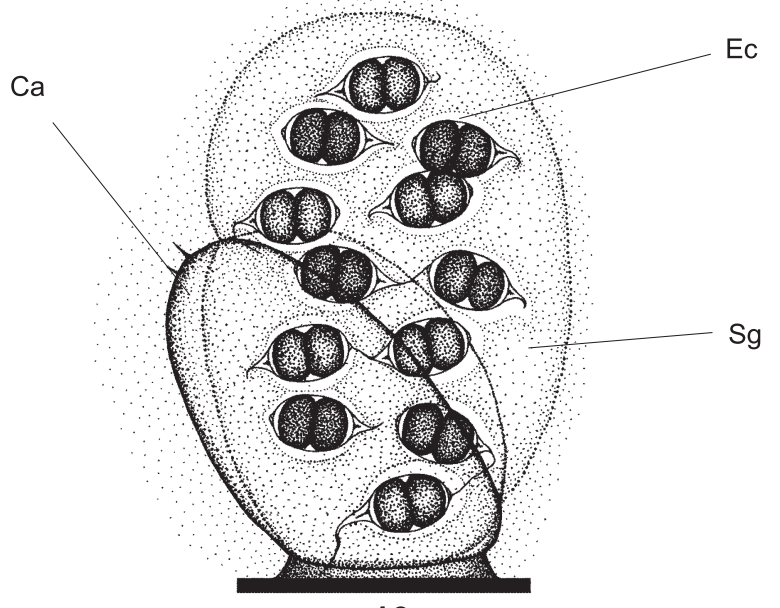

16

Figs 15-16. Cocoon structure: 15 - Newly deposited cocoon: Pg - mucus layer covering cocoon (palium gelatinosum), Sc cementing substance, Sue - suture located on the external (more convex) margin of the cocoon, Sui - suture located on the margin opposite to Sue (rarely visible), T - filament extending from the capsule; 16 - Cocoon disrupted shortly after deposition: $\mathrm{Ca}$ - cocoon capsule, Ec - cavities around eggs, formed in the gelatinous substance, $\mathrm{Sg}$ - gelatinous substance filling the space between the eggs and the capsule

the embryonic whorl, filled with vitellogenic oocytes (200-450). Snails which died shortly after attaining maturity (2-30) and four snails with disturbed gonad functioning (70-120) had partly filled gonads.

The intensity of production of vitellogenic oocytes (number of oocytes deposited during lifetime and remaining in the gonad divided by the number of days of adult life) in snails kept in pairs was: those fed mainly with periphyton - mean 3.9 per day (range 1.3-6.2), fed with filamentous diatoms - mean 10.1 per day (range 6.3-21.5). Snails kept singly stopped producing vitellogenic oocytes when the gonad was filled.

Inbreeding in generation I (joining in pairs snails from the same cocoon) had no significant effect on the reproduction. However, one pair resulting from inbreeding in generation II produced the smallest number of eggs among all the snails (the parents and other snails hatched in the same year produced about twice as many eggs). Also the intensity of production of vitellogenic oocytes was the smallest among all the snails (1.3 oocyte per day).

\section{COCOON STRUCTURE}

Cocoons were most often ovate-shaped, of varied proportions (Figs 15-16, 17). Rather frequently they were of a different shape, e.g. pear-shaped, conical, with constrictions $(1.2 \%)$ or composed of 2-4 connected capsules $(4.8 \%)$ (Figs 18-19). Sporadically $(0.2 \%)$ one mucus tunicle could contain two unconnected capsules which were regarded as separate cocoons. The extra capsules were not provided with cementing substance and contained one or two eggs. Cocoons composed of a few connected capsules were in most cases arcuate. Variation in the cocoon shape was similar to that observed in $V$. macrostoma (MYZYK 2004: Figs 21-35), but as a rule they contained more eggs and were larger. In cross-section cocoons were usually slightly flattened (major diameter of the ellipsoid in the plane of sutures) or circular, less often somewhat distended (minor dimeter of the ellipsoid in the plane of sutures).

In cocoons in the form of a single capsule the length/diameter ratio (Fig. 2 - Lc/Dc) ranged from 0.71 to 2.71. Only much distorted cocoons or those with constrictions were more elongate. Cocoons with

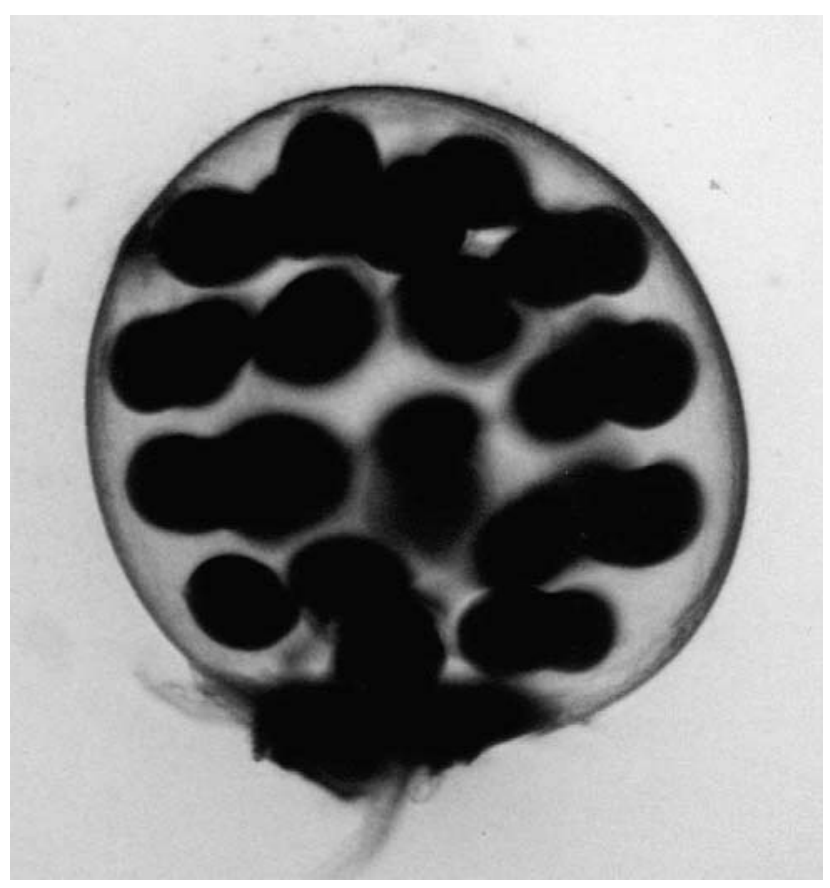

Fig. 17. Light microscope, a typical cocoon with eggs arranged spirally, $40 \times$ 


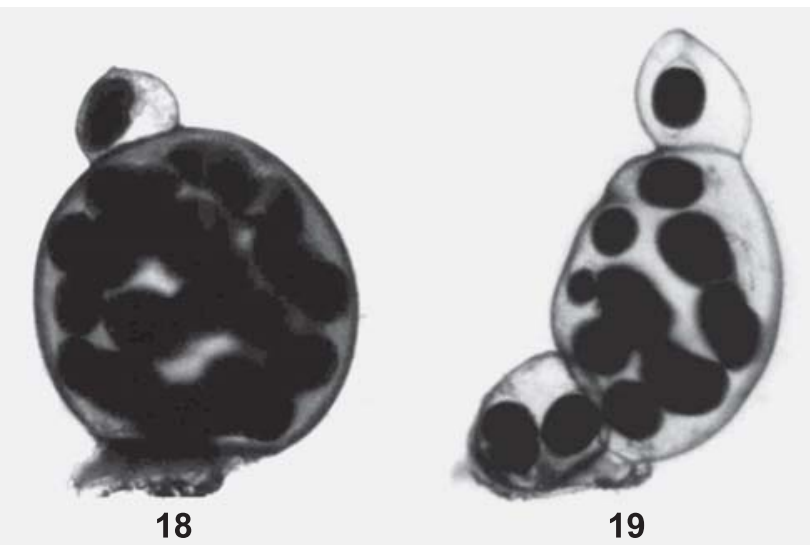

Figs 18-19. Light microscope, examples of constricted cocoons, $20 \times$

rather few eggs (1-20) were mostly somewhat flattened (Lc/Dc ratio smaller than 1) or roughly spherical $(\mathrm{Lc} / \mathrm{Dc}=1)$. With increasing number of eggs in the cocoon the percentage of elongated cocoons increased (Fig. 20). Cocoons containing no eggs but only an egg cord were usually elongate; the mean value of $\mathrm{Lc} / \mathrm{Dc}$ ratio was 1.75 (range $0.76-4.67)$.

The scheme of the cocoon structure is presented in Figs 15-16. The capsule was as a rule surrounded by a mucus layer (palium gelatinosum - Pg) of variable thickness and density. In some small cocoons the thickness of the mucus layer was larger than the capsule diameter. Droplets or rows of droplets of the capsule-forming substance found sometimes in the mucus layer indicate that formation of this layer takes place already in the nidamental gland (like in $\mathrm{u} V$. macrostoma - MYZYK 2004).

Distinct striae running from the base to the apex were nearly always visible on the surface of the capsule. A few cocoons deposited by different snails had capsules of uneven surface (wrinkled or with protruding fine spines, and rows of fine droplets radiating from them in the mucus layer). The apex of ca. $2 \%$ cocoons bore a short thread or strand (sometimes several) running from the capsule. Its length as a rule did not exceed $0.6 \mathrm{~mm}$, but sporadically was ca. $2 \mathrm{~mm}$. The capsule thickness was 0.001-0.026 mm (usually $0.010-0.015 \mathrm{~mm}$ ), and some capsules had varied thickness in different places (e.g. from 0.009 to 0.017 $\mathrm{mm}$ ). Immediately after deposition the capsule was colourless or grey (when the striae were strongly marked) but in a few hours it usually assumed a yellow or brown colour (very rarely light green or remained colourless). The base of the cocoon was usually not parallel to the apex and one side was more convex. The capsule was composed of two parts connected by sutures; the suture situated on the more convex side (Sue) was nearly always clearly marked. Sometimes a narrow wavy ridge ran along the Sue suture. The Sui suture located on the opposite side of the capsule was clearly visible on its whole length only in few cocoons (ca. $5 \%$ ). As a rule it was only a line along which striae on the capsule converged near the base and apex; in some cocoons it was completely invisible.

The interior of the cocoon between the eggs and the capsule was tightly filled with gelatinous substance $(\mathrm{Sg})$, which after breaking of the cocoon increased its volume by ca. $50 \%$. The eggs were arranged irregularly or their row formed a dextral spiral (both in the case of eggs connected and unconnected by the cord - Fig. 16). The cord running from the first egg was as a rule connected with the cocoon base and sporadically protruded outside. Also the remainng eggs in the cocoon (all or some of them) were sometimes connected by the egg cord. Distorted eggs were nearly always connected by a cord, like in $V$. cristata in $V$. macrostoma (MYZYK 2002, 2004).

The cocoon was glued to the substratum with a layer of cementing substance. Usually it was placed more or less centrally on the basis or slightly shifted toward the Sui suture. Only in some flattened co-

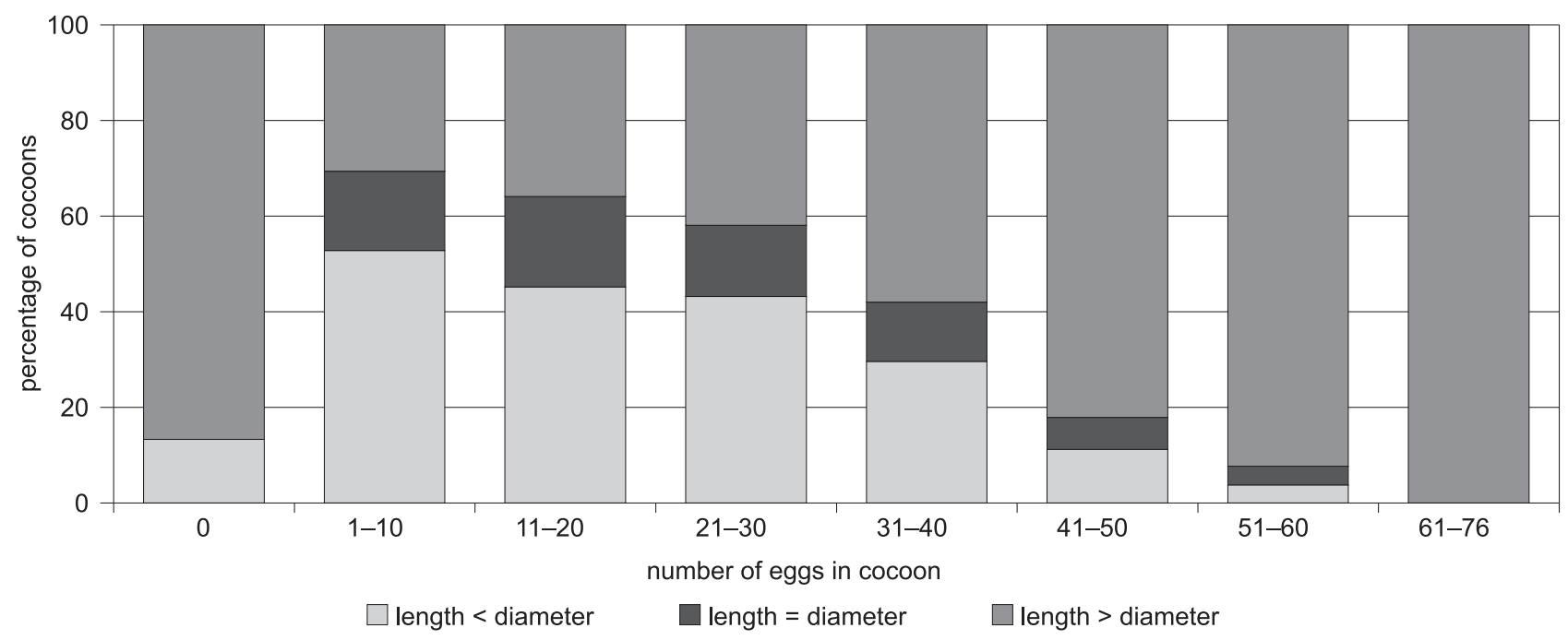

Fig. 20. Percentage of flattened and elongated cocoons depending on the number of eggs in cocoon 


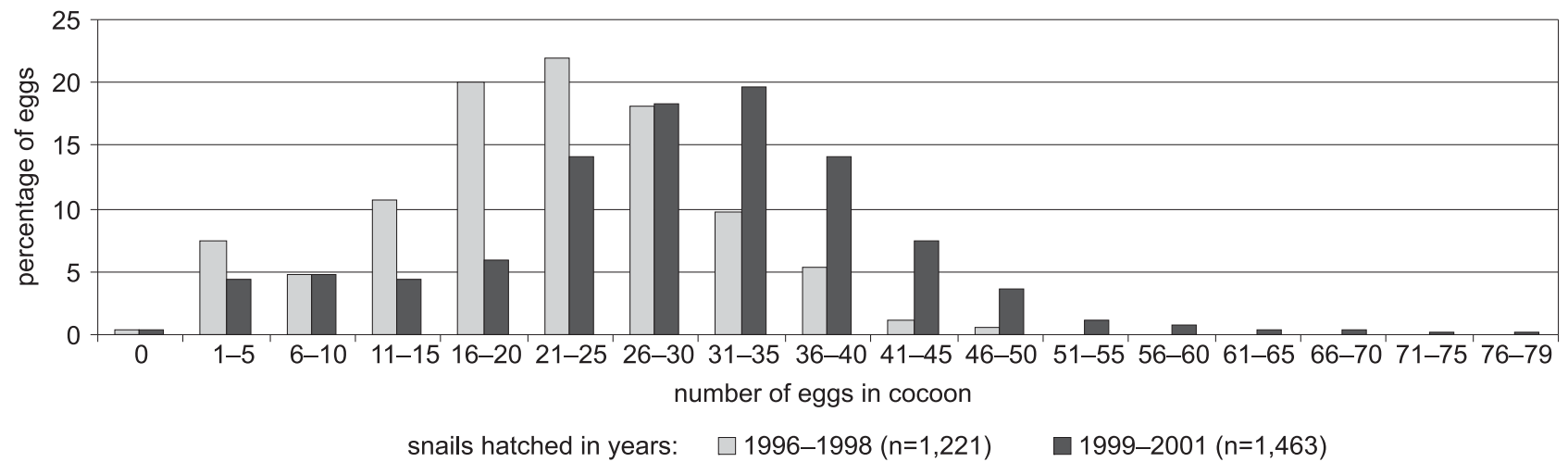

Fig. 21. Variation in the number of eggs in cocoons laid by snails kept in pairs; number of cocoons given in parentheses

coons it was situated on the side of the cocoon where the Sui suture was.

The number of eggs in the cocoon was very variable and depended, among other things, on the size of the snail, season and food conditions (Figs 10-11, 21). Cocoons of snails kept in pairs and fed mainly with periphyton (1996-1998) contained usually 15-30 eggs (mean 21.7, $\mathrm{SD}=9.4, \mathrm{n}=1,221$, range $0-50)$. Cocoons of snails fed mainly with filamentous diatoms (1999-2001) contained as a rule 22-40 eggs (mean 29.1, $\mathrm{SD}=12.1, \mathrm{n}=1,463$, range $0-76$ ). In the worst food conditions (snails hatched in 1994) cocoons contained only 3-9 eggs (mean 5.6, $\mathrm{SD}=1.5$, $\mathrm{n}=10$ ). Among cocoons produced by snails kept in pairs ca. $0.3 \%$ contained no eggs but only a twisted egg cord. Cocoons of snails kept singly contained a maximum of three eggs (mean 0.9, $\mathrm{SD}=0.9, \mathrm{n}=37$ ) and $40.5 \%$ cocoons contained no eggs.

The size of the cocoons showed a close positive correlation with the number of eggs contained in them (cocoons containing no eggs, distorted or composed of several capsules excluded from the analysis). Pearson's correlation coefficients were: cocoon length - number of eggs $r=0.83$, cocoon diameter - number of eggs $r=0.76$, cocoon length - cocoon diameter $\mathrm{r}=0.75, \mathrm{n}=2,612$. The length and diameter of typical cocoons (single capsules) are shown in Table 2. The smallest cocoons with one egg were: I - length 0.40

Table 2. Length and diameter of cocoons (containing no eggs - all measured, remaining - only single-capsule cocoons)

\begin{tabular}{|c|c|c|c|c|c|c|c|c|c|}
\hline \multirow{2}{*}{$\begin{array}{l}\text { Number } \\
\text { of eggs } \\
\text { in cocoon }\end{array}$} & \multirow{2}{*}{$\begin{array}{c}\text { Number } \\
\text { of measured } \\
\text { cocoons }\end{array}$} & \multicolumn{4}{|c|}{ Length of cocoons in $\mathrm{mm}$} & \multicolumn{4}{|c|}{ Diameter of cocoons in $\mathrm{mm}$} \\
\hline & & mean & $\mathrm{SD}$ & $\begin{array}{l}\text { mini- } \\
\text { mum }\end{array}$ & $\begin{array}{l}\operatorname{maxi}- \\
\text { mum }\end{array}$ & mean & SD & $\begin{array}{l}\text { mini- } \\
\text { mum }\end{array}$ & $\begin{array}{l}\text { maxi- } \\
\text { mum }\end{array}$ \\
\hline 0 & 15 & 1.19 & 0.43 & 0.60 & 2.10 & 0.75 & 0.24 & 0.30 & 1.10 \\
\hline 1 & 33 & 0.67 & 0.15 & 0.40 & 0.95 & 0.67 & 0.12 & 0.40 & 0.90 \\
\hline 2 & 27 & 0.76 & 0.17 & 0.45 & 1.20 & 0.79 & 0.20 & 0.40 & 1.40 \\
\hline 3 & 33 & 0.80 & 0.18 & 0.55 & 1.30 & 0.80 & 0.16 & 0.50 & 1.10 \\
\hline 4 & 32 & 0.83 & 0.18 & 0.55 & 1.35 & 0.85 & 0.17 & 0.60 & 1.15 \\
\hline 5 & 31 & 0.86 & 0.21 & 0.60 & 1.35 & 0.84 & 0.15 & 0.60 & 1.15 \\
\hline 6 & 32 & 0.88 & 0.16 & 0.65 & 1.40 & 0.86 & 0.17 & 0.60 & 1.10 \\
\hline 7 & 29 & 0.90 & 0.16 & 0.65 & 1.30 & 0.94 & 0.17 & 0.70 & 1.20 \\
\hline 8 & 28 & 0.94 & 0.13 & 0.75 & 1.25 & 0.97 & 0.17 & 0.75 & 1.25 \\
\hline 9 & 25 & 0.98 & 0.12 & 0.80 & 1.20 & 0.99 & 0.19 & 0.60 & 1.40 \\
\hline 10 & 31 & 1.02 & 0.13 & 0.85 & 1.35 & 1.09 & 0.15 & 0.90 & 1.45 \\
\hline $11-15$ & 187 & 1.11 & 0.16 & 0.80 & 1.85 & 1.11 & 0.15 & 0.75 & 1.55 \\
\hline $16-20$ & 331 & 1.23 & 0.15 & 0.85 & 1.80 & 1.22 & 0.12 & 0.90 & 1.70 \\
\hline 21-25 & 467 & 1.33 & 0.16 & 0.90 & 2.00 & 1.31 & 0.13 & 0.90 & 1.80 \\
\hline $26-30$ & 463 & 1.42 & 0.17 & 1.00 & 2.25 & 1.39 & 0.14 & 0.90 & 1.80 \\
\hline $31-35$ & 389 & 1.51 & 0.18 & 1.15 & 2.20 & 1.44 & 0.15 & 0.95 & 1.95 \\
\hline $36-40$ & 257 & 1.62 & 0.20 & 1.30 & 2.15 & 1.49 & 0.16 & 1.00 & 1.95 \\
\hline $41-45$ & 123 & 1.71 & 0.22 & 1.35 & 2.40 & 1.51 & 0.14 & 1.15 & 2.05 \\
\hline $46-50$ & 56 & 1.89 & 0.30 & 1.50 & 3.25 & 1.55 & 0.14 & 1.20 & 1.95 \\
\hline $51-55$ & 14 & 1.95 & 0.26 & 1.65 & 2.55 & 1.60 & 0.14 & 1.40 & 1.95 \\
\hline $56-60$ & 12 & 2.05 & 0.24 & 1.60 & 2.55 & 1.49 & 0.09 & 1.40 & 1.75 \\
\hline $61-76$ & 12 & 2.37 & 0.32 & 1.90 & 2.90 & 1.64 & 0.17 & 1.35 & 2.00 \\
\hline
\end{tabular}


$\mathrm{mm}$, diameter $0.45 \mathrm{~mm}$; II - length $0.45 \mathrm{~mm}$, diameter $0.40 \mathrm{~mm}$. Only cocoons with no eggs had a smaller diameter $(0.30 \mathrm{~mm}$; single capsule). The largest cocoons of typical structure (single capsule) were: I with 50 eggs (nearly conical), length $3.25 \mathrm{~mm}$, diameter $1.20 \mathrm{~mm}$; II - with 69 eggs, length $2.90 \mathrm{~mm}$, diameter $1.80 \mathrm{~mm}$; III - with 45 eggs, length $2.40 \mathrm{~mm}$, diameter $2.05 \mathrm{~mm}$. Only distorted, constricted or severalcapsule cocoons were longer. Examples: I - much elongate cocoon with 21 eggs, inside, close to the base a very thin twisted egg cord, eggs grouped at the apex, capsule with holes, length $3.50 \mathrm{~mm}$, diameter 1.10 $\mathrm{mm}$, from the apex ran a strand of envelope $1.40 \mathrm{~mm}$ long and $0.10 \mathrm{~mm}$ wide; II - cocoon composed of four connected capsules containing a total of 47 eggs $(39+1+3+4)$, length $4.20 \mathrm{~mm}$, diameter of the largest capsule $1.45 \mathrm{~mm}$.

Cocoons deposited in natural conditions (lake Sosnowe) contained 10-37 eggs (mean 24.7, $\mathrm{SD}=7.3$, $\mathrm{n}=17$ ). Most cocoons $(58.8 \%)$ contained 20-30 eggs wich agrees with PIECHOCKI's (1979) data. The mean number of eggs per cocoon was the greatest at the beginning of reproduction (in April 30.0), then it decreased gradually (in May 26.0, in June 24.4, in July $17.5)$.

\section{EGG STRUCTURE}

The egg was surrounded by two colourless, translucent envelopes (Figs 22-23, 24). The rather stiff external envelope was the thinnest near the equator of the egg, and became increasingly thicker towards the

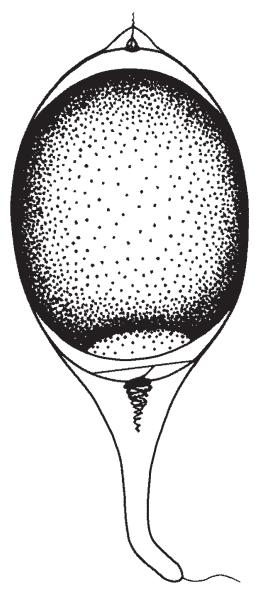

22

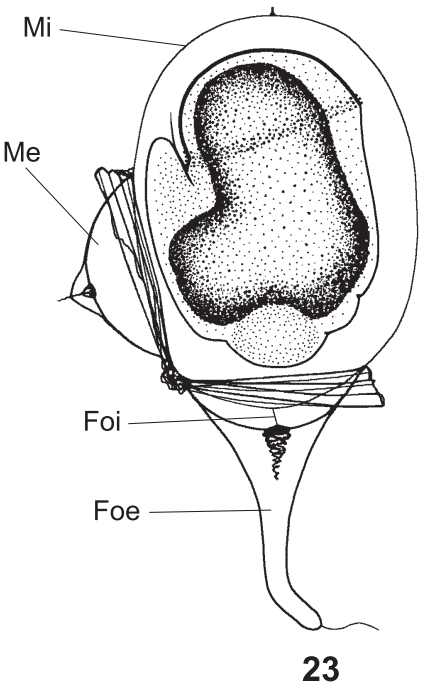

23
Figs 22-23. Egg structure: 22 - newly laid egg; 23 - egg after disruption of external membrane (first day of "larva" stage): Foe - egg cord extending from external membrane, Foi - egg cord extending from internal membrane, Me - egg external membrane, Mi - egg internal membrane poles. The thin and elastic internal envelope was often visible only after the external envelope was broken. The yolk-rich egg cell was surrounded by a very thin vitelline membrane. Like in $V$. cristata and $V$. macrostoma (MYZYK 2002, 2004) the yolk was basically yellow but admixture of "green" blue-green algae in the food (e.g. Oscillatoria) made the colour yellow-greenish or green. In cocoons deposited in lake Sosnowe the egg cells were usually yellow-green (less often yellow or green). The egg cell was usually located centrally and touched the egg envelopes near the equator. Its length was 73.5-93.5\% egg chamber length (mean $84.9 \%, \mathrm{SD}=4.0 \%, \mathrm{n}=682$ ). Variation in the egg shape was similar to that observed in $V$. cristata (MYZYK 2002: Figs 52-67), but because of the greater diameter of the egg cord also differently shaped eggs were observed (Figs 25-28). At the anterior pole the external envelope was cone-like thickened and as a rule passed into the egg cord, though in some eggs only a tubercular swelling was visible, not much larger than that at the posterior pole. The posterior pole usually bore a small tubercule from which sometimes a short section of a very thin egg cord extended. The egg cord extending from the anterior pole showed a considerable variation. In some eggs it was twisted (dextral), and its diameter decreased gradually with increasing distance from the egg chamber, like in $V$. macrostoma (MYZYK 2004: Fig. 36); in other eggs it was relatively thick and only slightly bent, while behind the bend it became narrower to get very thin, almost thread-like (Figs 22-23). Sometimes the cord contained chambers of different size and contents

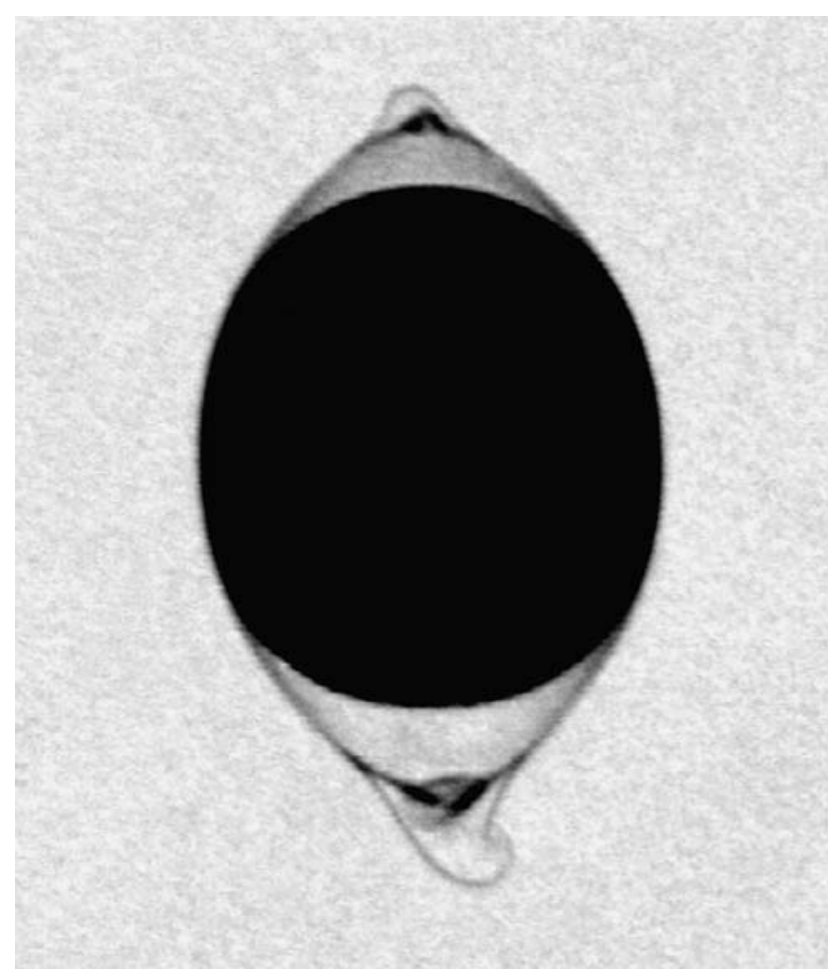

Fig. 24. Light microscope, newly deposited egg, 200× 


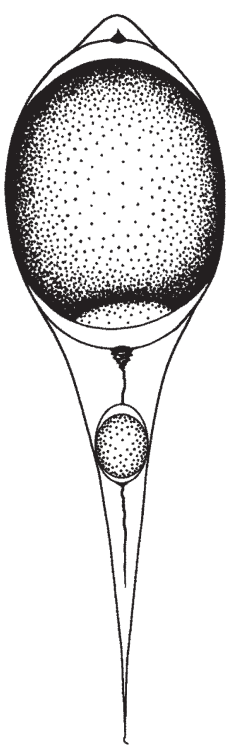

25

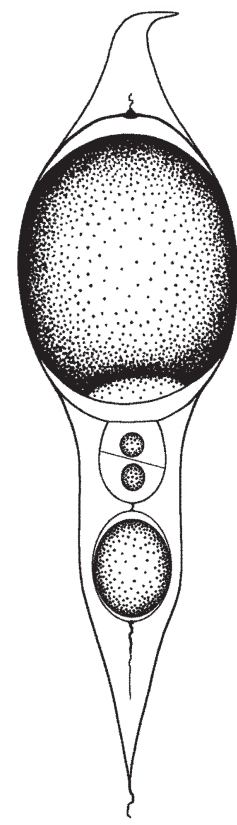

26

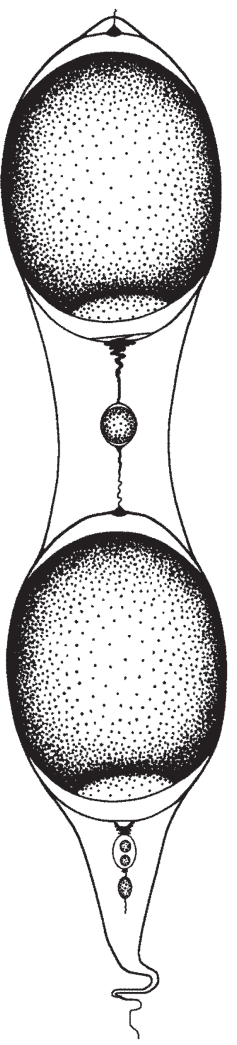

27

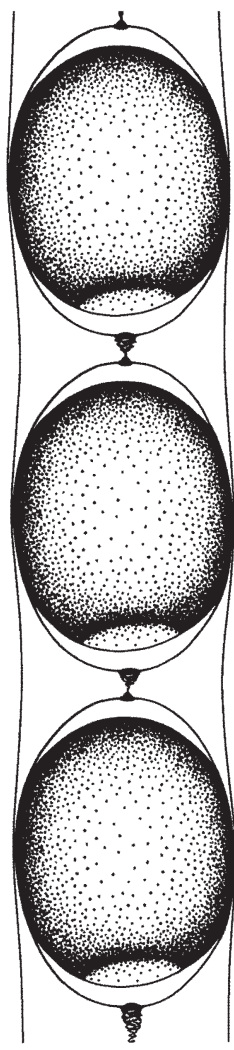

28

Figs 25-28. Examples of egg variation: 25-26 - eggs with egg-like accumulations of yolk in a thickened cord; 27-28 - connected eggs

(empty, with single granules or lumps of yolk) (Figs 25-27). Sporadically, the cord diameter was so great that all the eggs were contained within it (Fig. 28). In some eggs, near the anterior pole, the internal envelope did not adhere closely to the external envelope and a cord extending from the internal envelope was visible between the two envelopes (Fig. 23 - Foi).

Because of the absence of the lower limit of the range of egg size variation, eggs with egg cells of at least $0.12 \mathrm{~mm}$ diameter (sporadically observed cleavage) were adopted as the smallest. Smaller lumps of yolk were regarded as variations of the egg cord. The largest eggs contained two egg cells and reached the following size: chamber length $0.55 \mathrm{~mm}$ (with constriction even up to $0.78 \mathrm{~mm}$ ), chamber diameter 0.31 $\mathrm{mm}$. The largest egg with one egg cell was $0.45 \mathrm{~mm}$ long and $0.30 \mathrm{~mm}$ in diameter. Young hatched only from eggs with one egg cell and size within 0.24-0.36 $\mathrm{mm}$ length and $0.20-0.27 \mathrm{~mm}$ diameter. The remaining eggs (e.g. smaller or larger, containing two egg cells, with broken envelopes) were regarded as abnormal and omitted from calculations of mean dimensions. Among eggs produced by snails kept in pairs ca. $0.5 \%$ were abnormal (the percentage varied between containers from 0 to $4.3 \%$ ). Among eggs laid by snails kept singly $34.4 \%$ were abnormal.
The mean size of eggs with single egg cells was $(\mathrm{n}=682)$ : egg chamber length $0.353 \mathrm{~mm}(\mathrm{SD}=0.023$ $\mathrm{mm})$, egg cell length $0.299 \mathrm{~mm}(\mathrm{SD}=0.018 \mathrm{~mm})$, egg chamber diameter $0.239 \mathrm{~mm}(\mathrm{SD}=0.016 \mathrm{~mm}$ ) (Figs 29-31). Pearson's correlation coefficients were $(n=682)$ : egg chamber length - diameter $r=0.24$, egg cell length - egg diameter $r=0.19$, egg chamber length - egg cell length $\mathrm{r}=0.71$.

\section{EMBRYONIC DEVELOPMENT}

Immediately after cocoon deposition the egg cells were usually at the stage of oocyte I. In cocoons composed of a few capsules, eggs in individual capsules were sometimes at different development stages (sporadically the differences were of several divisions). Like in V. cristata and V. macrostoma (MYZYK 2002, 2004) the egg falling out of the gelatinous substance did not affect the development. However, the absence or too early breaking of any envelope resulted in embryo's death.

The total number of incubated eggs obtained from snails kept in pairs was 4,754. At the temperature of $11^{\circ} \mathrm{C}$ the first division of the zygote took place 24-26 hours from cocoon deposition, and at $19^{\circ} \mathrm{C}$ after 9-9.5 hours (subsequent divisions took place 

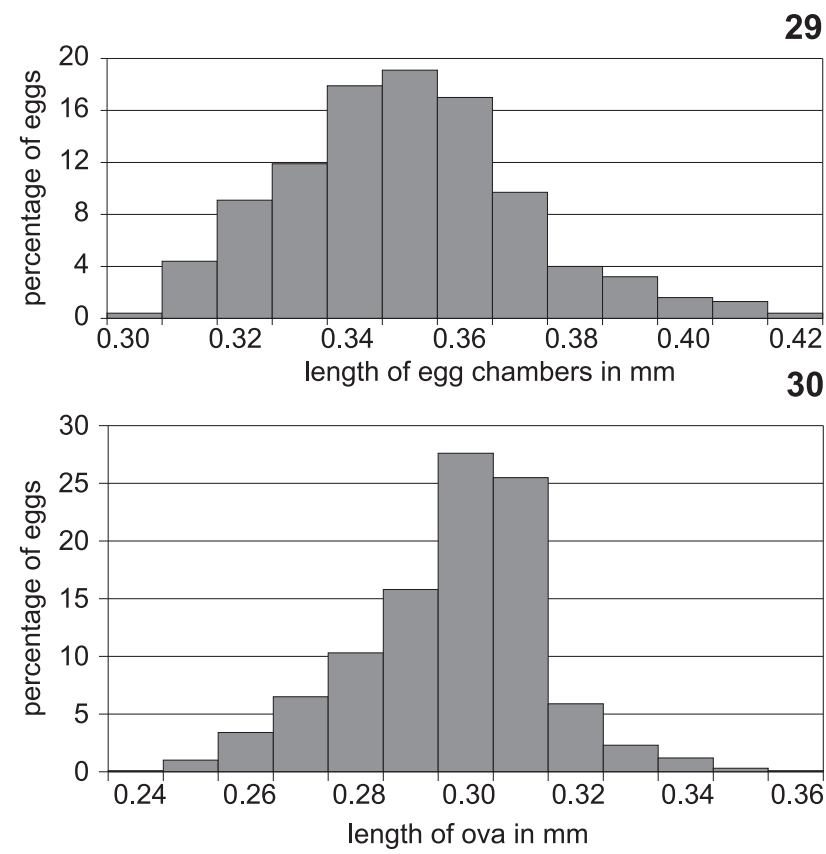

31

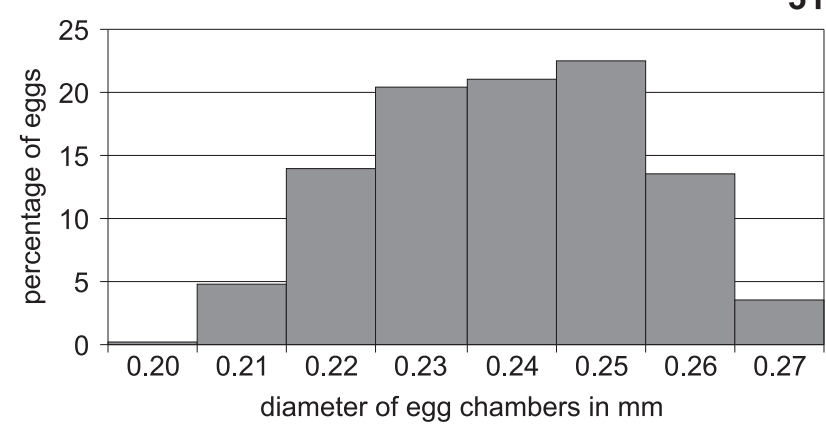

Figs 29-31. Size variation of eggs containing one oocyte $(n=682)$

about three times faster). At ca. $1^{\circ} \mathrm{C}$ the development was not arrested though it was very slow, and polocyte I appeared as late as 10-12 days after cocoon deposition. The duration of embryonic development showed a strong negative correlation with the mean ambient temperature, and Pearson's correlation coefficient was $r=-0.87, n=3,011$. At the temperature of

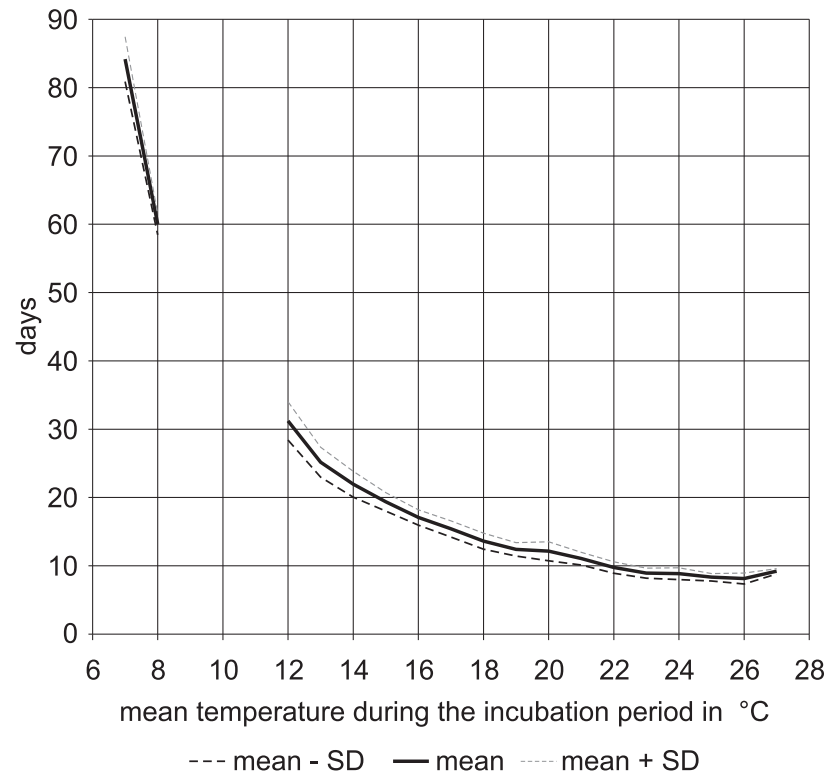

Fig. 32. Dependence between the mean temperature and the mean duration of embryonic development

$7^{\circ} \mathrm{C}$ hatching took place between the 80th and 90th day of incubation, and at $24-26^{\circ} \mathrm{C}$ between the 6th and 12th day of incubation (usually on the 8th or 9th day). The dependence between the mean duration of embryonic development and the mean incubation temperature is shown in Fig. 32. Individual variation in the duration of embryonic development at temperatures of 12,18 and $24^{\circ} \mathrm{C}$ is also shown (Fig. 33).

Literature data on the duration of embryonic development vary but there is no reference to incubation temperature (FRETTER \& GRAHAM 1962: 15-30 days, PIECHOCKI 1979: ca. 2 weeks, GIROD et al. 1980: 12-16 days, RATH 1988: 15-17 days, FALNIOWSKI 1989: $15-30$ days).

The course of embryonic development was similar to that of V. cristata (MYZYK 2002: Figs 43-51), but the time it took to reach each stage was somewhat longer. At the egg stage the development took place within the egg chamber. At the end of this stage a small, cap-like shell and operculum were usually vis-

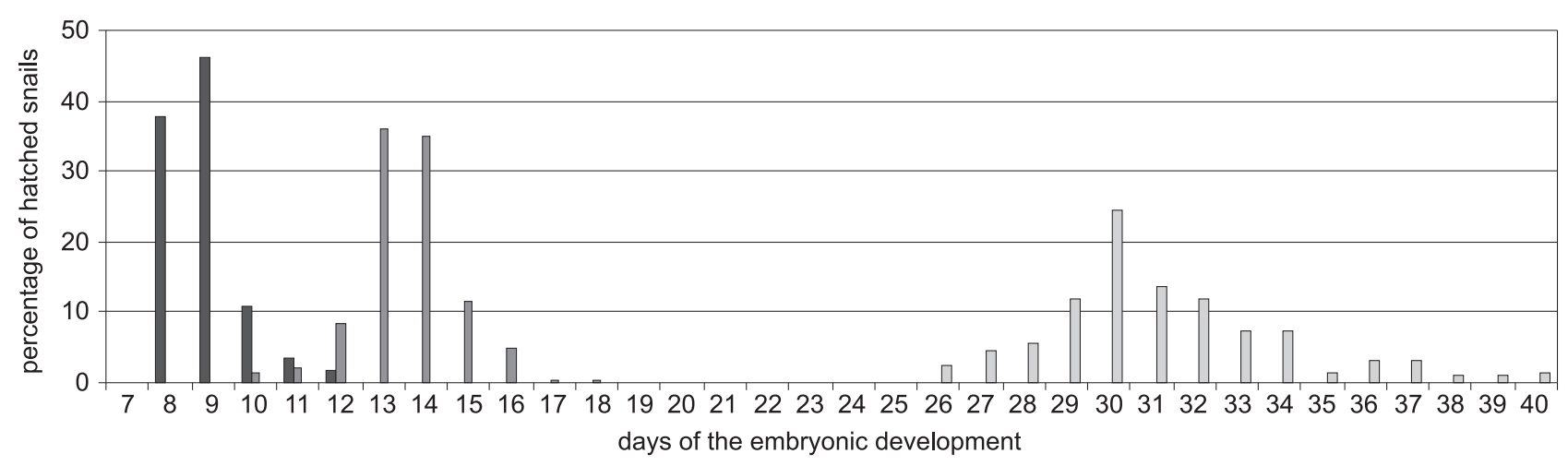

$\square 24^{\circ} \mathrm{C}(\mathrm{n}=232) \quad \square 18^{\circ} \mathrm{C}(\mathrm{n}=582) \quad \square 12^{\circ} \mathrm{C}(\mathrm{n}=218)$

Fig. 33. Variation in incubation time at constant temperature $\left(12^{\circ} \mathrm{C}, 18^{\circ} \mathrm{C}\right.$ and $\left.24^{\circ} \mathrm{C}\right)-$ percentage of snails hatched on consecutive days 


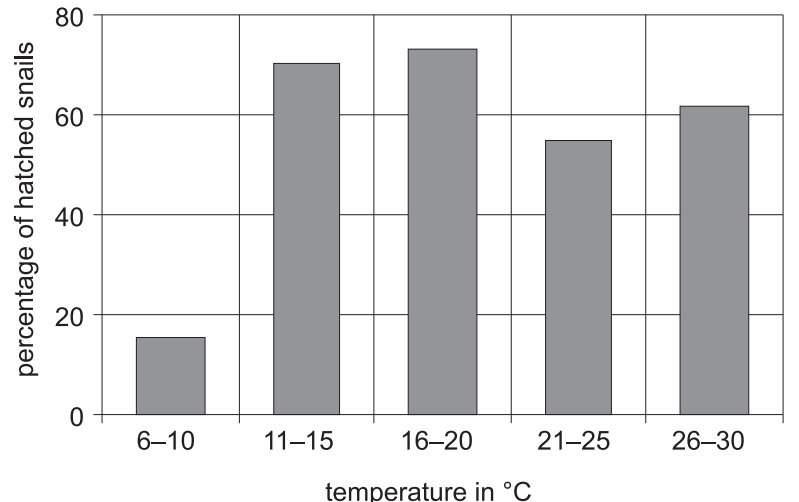

Fig. 34. Variation in the percentage of hatched snails (with normal shell) depending on the mean incubation temperature

ible, and the embryo was rotating clockwise. Breaking of the external egg envelope marked the beginning of the larva stage (Fig. 23). The internal envelope gradually increased its volume and before hatching it reached a diameter of $0.45-0.68 \mathrm{~mm}$ (sometimes up to $0.78 \mathrm{~mm}$ ). At the end of the larva stage eyes, dorsum pulsation, heartbeat and a small mantle cavity were visible but the body of the embryo remained relaxed. At the beginning of the snail stage the shell had usually $0.3-0.4$ whorl and could accommodate the contracted embryo. As a rule it was only in that stage that the capsule broke, though in small cocoons (below 10 eggs) it often remained unbroken even after hatching. On the day preceding hatching stomach, rectum, radula, pallial part of kidney, short pallial tentacle and usually primordial ctenidium (though in some snails it appeared only after hatching) were visible. Information on the appearance of primordial ctenidium only one day before hatching has been also given by RATH (1988). The foot and head of juvenile snails rather often bore scattered gran- ules of brown pigment, like in V. macrostoma (MYZYK 2004). Before hatching the snail made a small hole in the internal egg envelope with its radula, then it retracted into its shell. After shrinking of the envelope it crawled about inside it which resulted in the envelope breaking. Within a few minutes the hatchling got out of the gelatinous substance and usually crawled away from the cocoon. The relative duration of consecutive stages did not depend on the incubation temperature; the mean values were $(\mathrm{n}=3,011)$ : egg $-53.6 \% \quad(\mathrm{SD}=6.7 \%)$, larva $-18.1 \% \quad(\mathrm{SD}=5.7 \%)$, snail $-28.3 \% \quad(\mathrm{SD}=7.1 \%)$. The duration of embryonic development at each temperature was usually somewhat longer than in V. cristata and V. macrostoma (on average by ca. $10 \%$, but at higher temperatures even up to $18 \%$ ). However, hatchlings of $V$. piscinalis were usually less advanced in their development (e.g. shorter cephalic and pallial tentacles, less developed primordial ctenidium).

The percentage of hatchlings with normally developed shells and without osmotic disturbances varied with incubation temperature (Fig. 34). It was the highest $(70.3-72.9 \%)$ at temperatures of $11-20^{\circ} \mathrm{C}$. At rather low $\left(7-8^{\circ} \mathrm{C}\right)$ and high temperatures $\left(26-27^{\circ} \mathrm{C}\right)$ the percentage of hatchlings with osmotic disturbances or too small shells increased $(23.2 \%$ and $10.1 \%$, respectively), while at $11-20^{\circ} \mathrm{C}$ it was only 2.3-2.4\%. The percentage of dead embryos (combined for egg and larva stages) was the lowest at $16-20^{\circ} \mathrm{C}(24.8 \%)$, and the highest at $7-8^{\circ} \mathrm{C}(61.6 \%$, usually at egg stage).

The embryonic shell was composed of $0.37-1.0$ whorl (usually $0.62-0.87$ whorl) (Figs $35-37$ ). The initial ca. 0.5 whorl was as a rule covered by distinct spiral striae, and further also with radial striae. The spiral striae were formed of rather regular rows of granular tubercules separated by narrow strips of nearly smooth

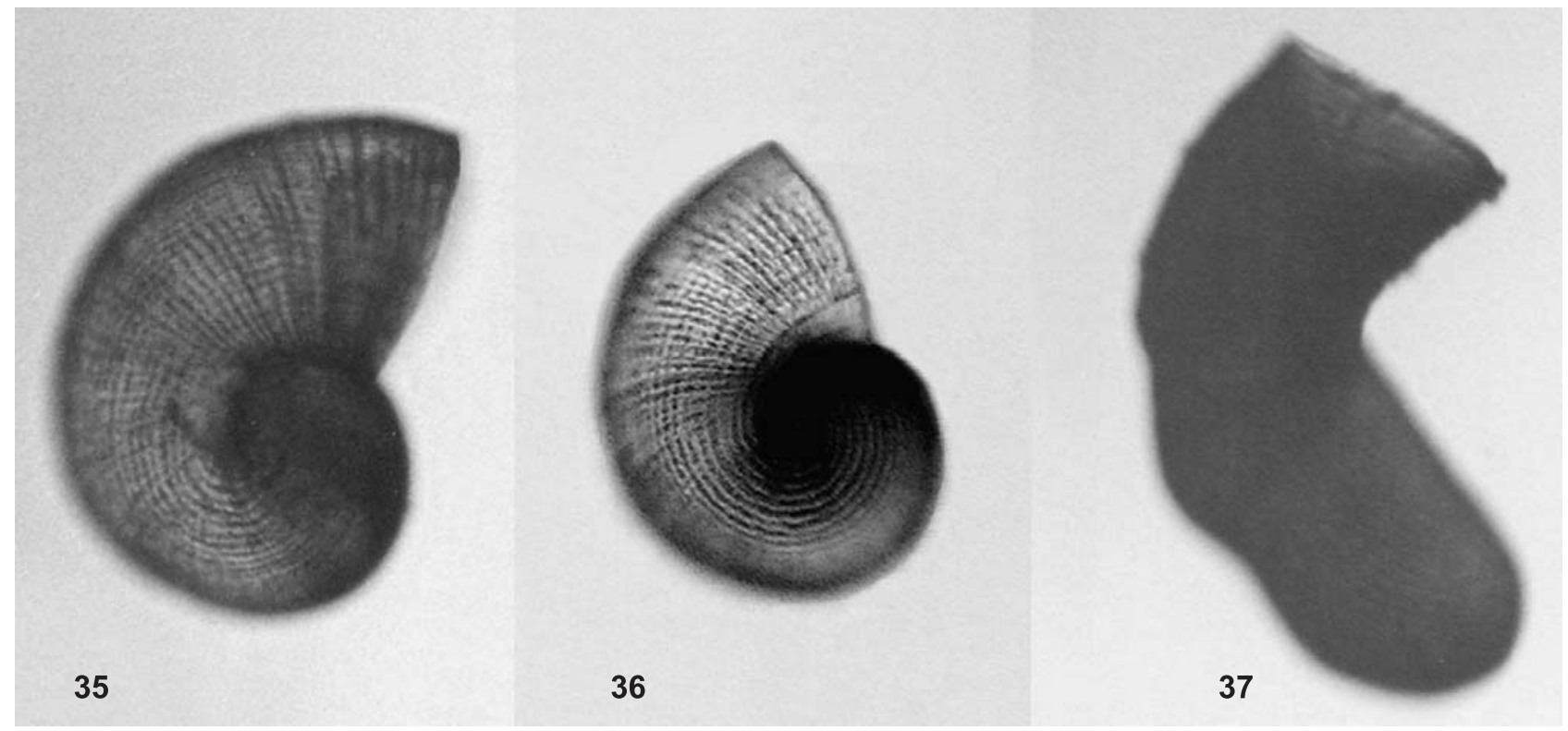

Figs 35-37. Light microscope, embryonic shells, 100×: 35-36 - normally developed shells; 37 - uncoiled, tubular shell 
surface. At ca. 0.25 whorl, on the external side of the whorl, the width of spiral striae was $0.006-0.011 \mathrm{~mm}$, and towards the internal side their width increased gradually to $0.010-0.015 \mathrm{~mm}$, which is in agreement with BINDER's (1967) observations. On scalariform shells the whorl surface near the columellar margin was devoid of spiral striae. The apex ca. $0.15 \mathrm{~mm}$ in diameter (later hidden by growing whorls) was covered by irregular granularities which on the margins passed into spiral striae. On some shells the spiral striae disappeared already at ca. 0.3 whorl (further the surface was nearly smooth), on other shells they were distinct till the aperture and criss-crossed with the radial striae. Regular radial striae appeared most often starting with ca. 0.5-0.6 whorl but poorly marked and irregular striae - sometimes starting with 0.3 whorl. On some shells they were intially poorly marked and gradually became more pronounced; on other shells already from 0.62 whorl they were marked as delicate ribs. On some shells between 0.3 and 0.5 whorl a concavity was visible, resulting from the pressure from other shells within the unbroken capsule. The moment of capsule breaking was often marked as a single, more or less distinct radial stria. Besides typical shells of adhering whorls, rarely there occurred shells which were to various extent scalariform (detached whorls) or, sporadically, not coiled, tubular shells (Figs 37). Initial 0.5-0.6 whorl, because of its dense spiral striae, was usually visible as white-greyish, and further increments were light yellow or light yellow-green.

Descriptions of embryonic shells have been given by BINDER (1967) and FALNIOWSKI (1989a, 1990). According to both authors the embryonic shell is the initial part of the shell, covered by spiral striae $(0.5$ whorl acording to BINDER and 1.5 whorl according to FALNIOWSKI), while radial striae appear only on postembryonic increments. In my experience small shells covered only by spiral striae (up to ca. 0.5 whorl) were observed only in $15.6 \%$ hatchlings. As a rule the shells were larger (maximum 1 complete whorl) and bearing more or less distinct radial striae near the aperture.

Measurements of normal embryonic shells were $(\mathrm{n}=607)$ : diameter $0.30-0.58 \mathrm{~mm}$ (mean 0.465 , $\mathrm{SD}=0.054$ ), height $0.20-0.33 \mathrm{~mm}$ (mean 0.267, $\mathrm{SD}=0.029$ ), number of whorls 0.37-1.00 (mean 0.70, $\mathrm{SD}=0.13$ ). Shells smaller than $0.35 \mathrm{~mm}$ diamter and below 0.5 whorl were usually too small to accommodate the contracted snail body and this was possible only when the aperture was somewhat dilated (the smaller the shell diameter, the higher its height). The shell height was measured as the maximum height of the embryonic whorl (usually just next to the aperture, sometimes farther up, at ca. 0.3-0.5 whorl). Variation in the size of embryonic shells (diameter and number of whorls) and the shell diameter/height dependence are presented in Figs
38-40. Pearson's correlation coefficients were $(\mathrm{n}=607)$ : shell diameter - height $\mathrm{r}=0.87$, shell diameter - number of whorls $r=0.87$, shell height - number of whorls $\mathrm{r}=0.76$.

The embryonic operculum was as a rule composed of 1.5-2.6 whorls (maximum ca. 3 whorls) that is about three times the number of whorls of the shell. The embryonic whorls were $0.035-0.05 \mathrm{~mm}$ wide (rarely somewhat less or more). The operculum major diameter was $0.20-0.33 \mathrm{~mm}$ and was usually equal to aperture height.

All eggs obtained from snails kept singly were incubated at $19-22^{\circ} \mathrm{C}$. Among the 32 deposited eggs only five underwent initial divisions (maximum three) and then the development ceased.

38

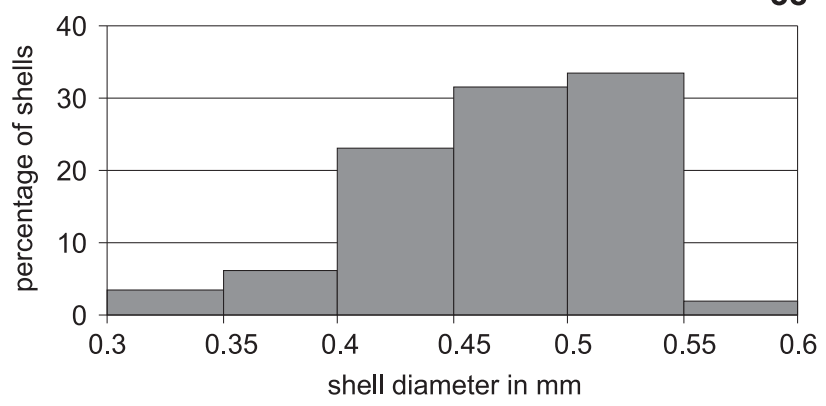

39

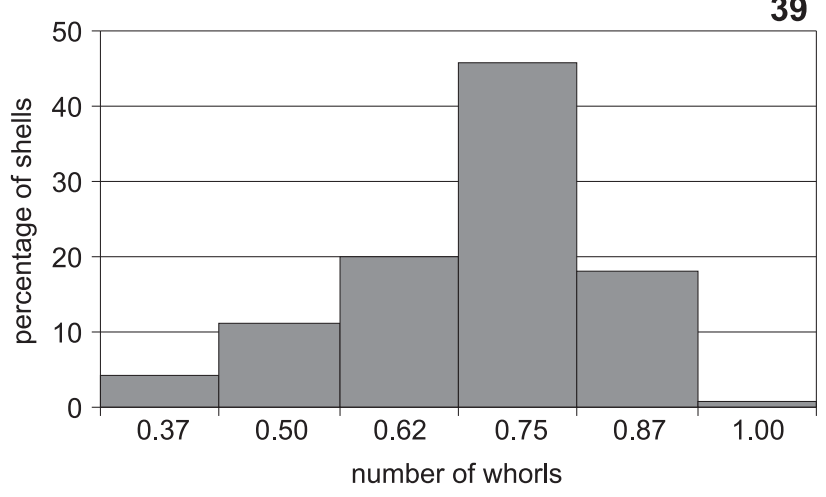

40

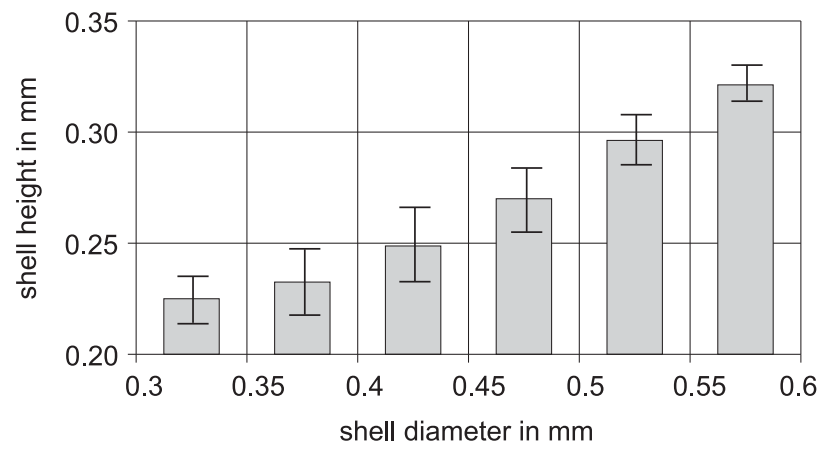

Figs 38-40. Size variation of embryonic shells $(n=607): 38-$ shell diameter; 39 - number of whorls; 40 - dependence between the mean shell height and shell diameter, standard deviation marked with bars 


\section{POST-EMBRYONIC DEVELOPMENT AND MATURATION}

Soon after hatching most snails left the gelatinous substance and usually crawled rather far away from the cocoon. Nearly always the hatchlings had a small store of yolk inside their bodies; in most cases the yolk disappeared in 3-7 days. However in those juveniles that were not very active still after 20 days single yolk granules could be seen (like in $V$. cristata and $V$. macrostoma; MYZYK 2002, 2004). When the cocoon capsule remained unbroken after hatching, the trapped hatchlings died soon after their yolk reserves became exhausted.

The surface sculpture of postembryonic increments usually did not differ from that found on the embryonic shell next to the aperture (radial riblets or striae, sometimes criss-crossing with spiral lines). The border between the embryonic and definitive whorls was rather rarely distinct, e.g. when the aperture margin became damaged or the whorl diameter changed rapidly. As a rule it was hidden among the radial striae (Fig. 41).

The growth rate varied individually even in similar food conditions. These conditions, however, affected the mean growth curves (Figs 42-43). The greatest variation in shell size attained (diameter, number of whorls) was observed about the 50th-60th day after hatching. For example, on the 60th day of life the shell size was: in very unfavourable conditions (small quantity of periphyton) $(\mathrm{n}=16)$ - body whorl diameter $0.99-1.60 \mathrm{~mm}$ (mean $1.20, \mathrm{SD}=0.15)$, number of whorls $1.50-2.12$ (mean $1.69, \mathrm{SD}=0.16$ ); in the group fed only with periphyton $(\mathrm{n}=41)$ - body whorl diameter $1.01-3.05 \mathrm{~mm}$ (mean $2.10, \mathrm{SD}=0.61$ ), number of whorls 1.50-3.12 (mean 2.44, $\mathrm{SD}=0.43$ ); in the group fed with periphyton and filamentous diatoms $(n=40)$

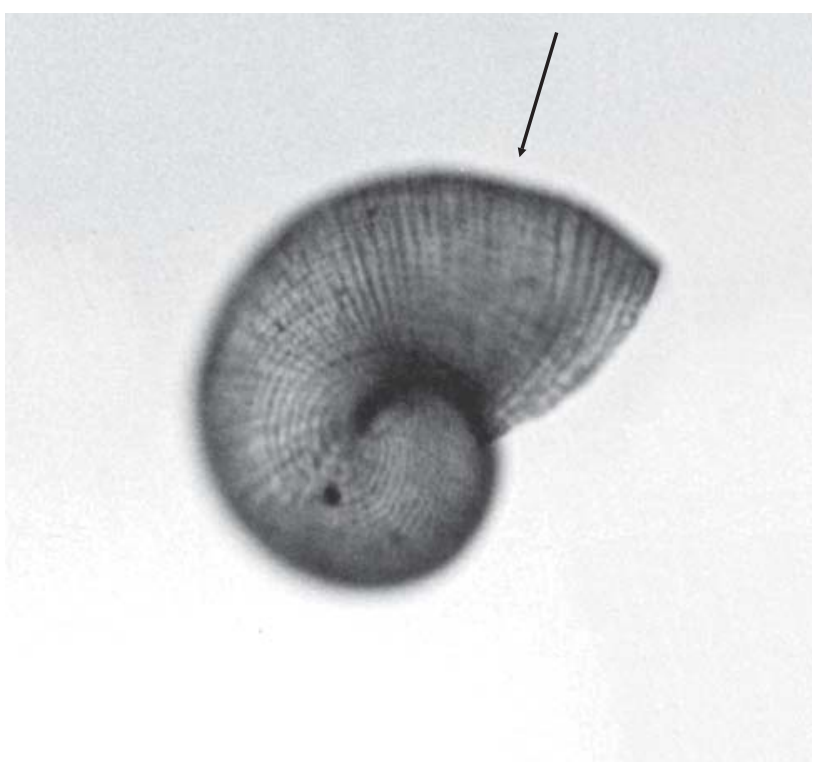

Fig. 41. Light microscope, shell of a young snail, 100×. The border of embryonic shell indicated with arrow
- body whorl diameter 1.61-5.05 mm (mean 3.86, $\mathrm{SD}=0.88$ ), number of whorls 2.12-4.12 (mean 3.40, $\mathrm{SD}=0.47)$.

Among snails hatched in 1996-2001 and placed in the laboratory culture $37.8 \%$ died within 30 days from hatching. The overall proportion of snails dead as juveniles was $43.2 \%$, and the longest surviving of them (114 days) formed a shell $3.0 \mathrm{~mm}$ in diameter and of 3.12 whorls. In very unfavourable food conditions (snails hatched in 1994) $83.4 \%$ died as juveniles, and the mortality fell mainly in two periods: between days 40th and 120th and between days 410th and 500th since hatching. The last survivor (500 days) produced a shell of $3.15 \mathrm{~mm}$ diameter and 2.9 whorls.

When the shell diameter reached ca. $0.60 \mathrm{~mm}$ single granules of black piment appared on the heads of juveniles and with increasing size the number of grains increased quickly. The penis, as a small colourless swelling at the base of the right tentacle, appeared 20-120 days after hatching. At that time the
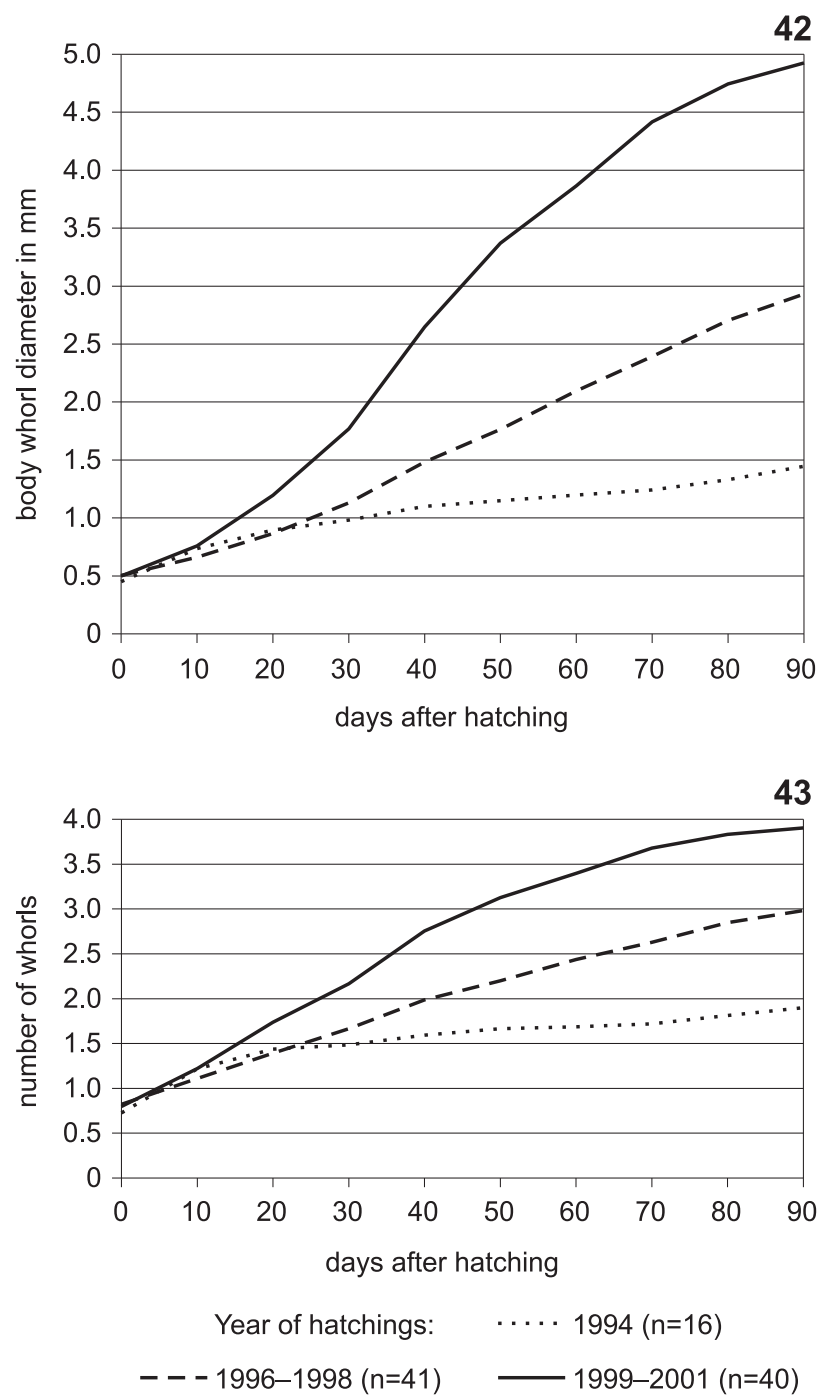

Figs 42-43. Mean growth curves of young snails kept in different food conditions: 42 - body whorl diameter; $43-$ number of whorls 
gonad was visible as a small lighter spot near the apex (usually 0.1-0.25 whorl, sometimes slightly more). The shell size at the moment of penis appearance was $(\mathrm{n}=49)$ : body whorl diameter 1.15-1.66 mm (mean 1.40, $\mathrm{SD}=0.13$ ), number of whorls $1.75-2.25$ (mean 1.91, SD=0.12). Snails hatched in 1994 (the worst food conditions) grew very slowly and the penis appeared only 50-120 days from hatching (man 96) at the mean shell size of: body horl diameter $1.51 \mathrm{~mm}$ 1.92 whorl. In snails hatched in 1996-1998 the penis appeared 20-80 days after hatching (mean 44) at the mean shell size: body whorl diameter $1.40 \mathrm{~mm}, 1.94$ whorl. In nearly all snails hatched in 2001 the penis appeared already 20 days after hatching at the shell size: body whorl diameter $1.31 \mathrm{~mm}, 1.83$ whorl. Variation in the shell size at the moment of penis appearance and the time elapsed since hatching among snails hatched in different years (different food condition) are shown in Figs 44-46.

Growth of reproductive organs (gonad, pallial organs, penis) was slightly faster than the overall growth in body size. Example: at the moment of penis appear-

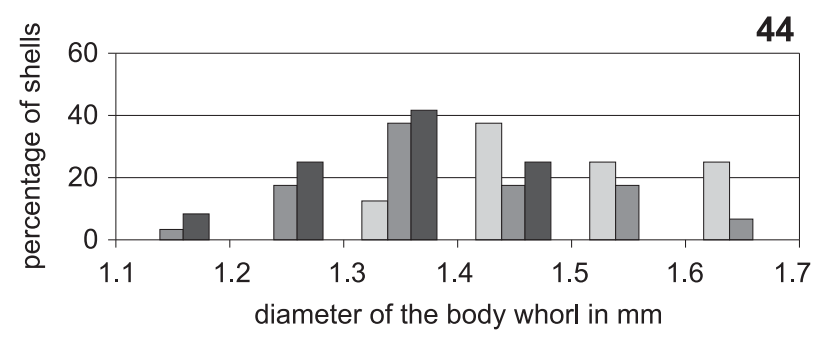

45

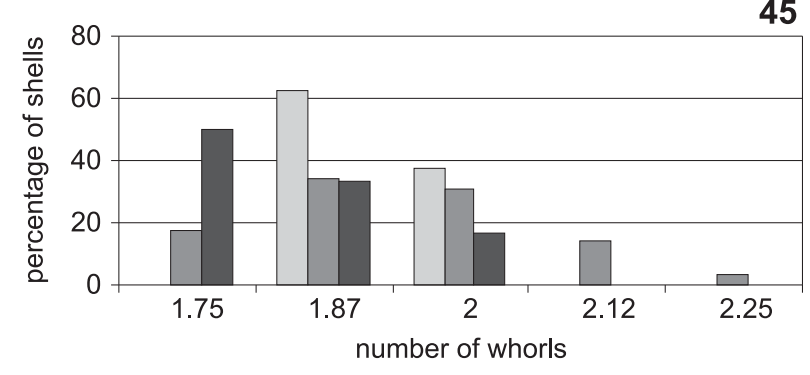

46

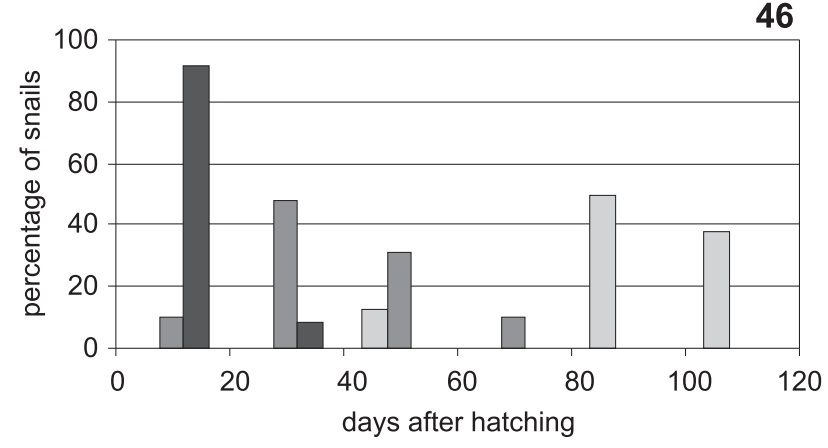

$\square 1994(\mathrm{n}=8) \quad \square 1996-1998(\mathrm{n}=29) \quad \square 2001(\mathrm{n}=12)$

Figs 44-46. Variation in the shell size and the time of appearance of penis depending on food conditions, from the worst to gradually improving ance the shell was $1.36 \mathrm{~mm}$ in diameter and had 1.75 whorl, the gonad occupied 0.12 whorl; at the diameter of $3.00 \mathrm{~mm}$ and 2.75 whorls the penis was $0.7 \mathrm{~mm}$ long, the gonad occupied 1.37 whorl; at shell of 3.75 $\mathrm{mm}$ and 3.12 whorls the first vitellogenic oocytes appeared and the gonad occupied two whorls. In adults the gonad occupied all the initial whorls except the body and a part of penultimate whorls (0.12-0.25 whorl, rarely somewhat more or less). The male maturity somewhat preceded the female maturity since some snails started copulating as males ca. 1-2 weeks before vitellogenic oocytes appeared in their gonads.

The shell size of individuals in whose gonad vitellogenic oocytes appeared (female maturity) varied very much. Some snails had their first vitellogenic oocytes in the gonad when the body whorl was 2.15 $\mathrm{mm}$ in diameter, and the shell had 2.75 whorls; in other individuals the female maturity was attained at $4.70 \mathrm{~mm}$ diameter and 3.87 whorls. In the worst food conditions (4 snails hatched in 1994) the female maturity was attained at 3.00-3.45 mm body whorl diameter (mean 3.24) and 3.12-3.25 whorls (mean 3.16). Snails hatched in 1996-1998 $(\mathrm{n}=41)$ fed only with periphyton became mature at $2.15-4.70 \mathrm{~mm}$ body whorl diameter (mean 3.60, $\mathrm{SD}=0.49$ ) and 2.75-3.87 whorls (mean 3.36, SD=0.25). Those hatched in 1999-2001 $(n=40)$ fed with periphyton and filamentous diatoms attained the female maturity at 3.45-4.65 mm body whorl diameter (mean 4.10, $\mathrm{SD}=0.29$ ) and 3.25-3.75 whorls (mean 3.53, $\mathrm{SD}=0.17)$. The longest time needed to attain the female maturity was observed in the worst food conditions (1994) and amounted to 300-720 days (mean 435). Snails hatched in 1996-1998 took 70-304 days from hatching to become mature (mean $132, \mathrm{SD}=44$ ), and those of 1999-2001 - 42-85 days (mean 59, $\mathrm{SD}=11)$. Variation in the shell size at the moment of attainment of female maturity and the time from hatching till maturity are presented in Figs 47-49. The relative duration of juvenile period (ratio of time before maturity to lifetime) varied and depended partly on food conditions. In very unfavourable conditions (1994) it was on average $83.4 \%(73.4-87.8 \%)$ lifetime. In snails fed with periphyton it was $39.4 \%$ $(17.8-82.2 \%)$, and in those fed with diatoms $-29.7 \%$ (13.4-72.7\%) lifetime.

The growth rate of juvenile snails in the lake varied much, and wintering juveniles were found even till mid-June (e.g.: I. sample of April 20th 1996, shells of 2.3-4.0 mm diameter and 2.62-3.62 whorls; II. sample of June 13th 1999, shells of 3.35-4.20 mm diameter and 3.75-4.25 whorls; III. sample of May 10th 2002, the smallest snail of $1.6 \mathrm{~mm}$ shell diameter and 2.25 whorls. The largest juvenile (with no vitellogenic oocytes) had a shell of $4.25 \mathrm{~mm}$ diameter and 4.37 whorls, and the smallest adult - of $3.3 \mathrm{~mm}$ diameter and 3 whorls. The percentage of adults, depending on the shell diameter, was: $8.3 \%$ for shells of $3.0-3.45$ 
$\mathrm{mm}, 16.7 \%$ for $3.5-3.95 \mathrm{~mm}, 68.4 \%$ for $4.0-4.45 \mathrm{~mm}$, $100 \%$ above $4.5 \mathrm{~mm}$. The same percentage in relation to the number of whorls was: $16.7 \%$ for $3.0-3.4$ whorls, $35.3 \%$ for $3.5-3.9$ whorls, $62.1 \%$ for $4.0-4.4$ whorls, $100 \%$ above 4.5 whorls.
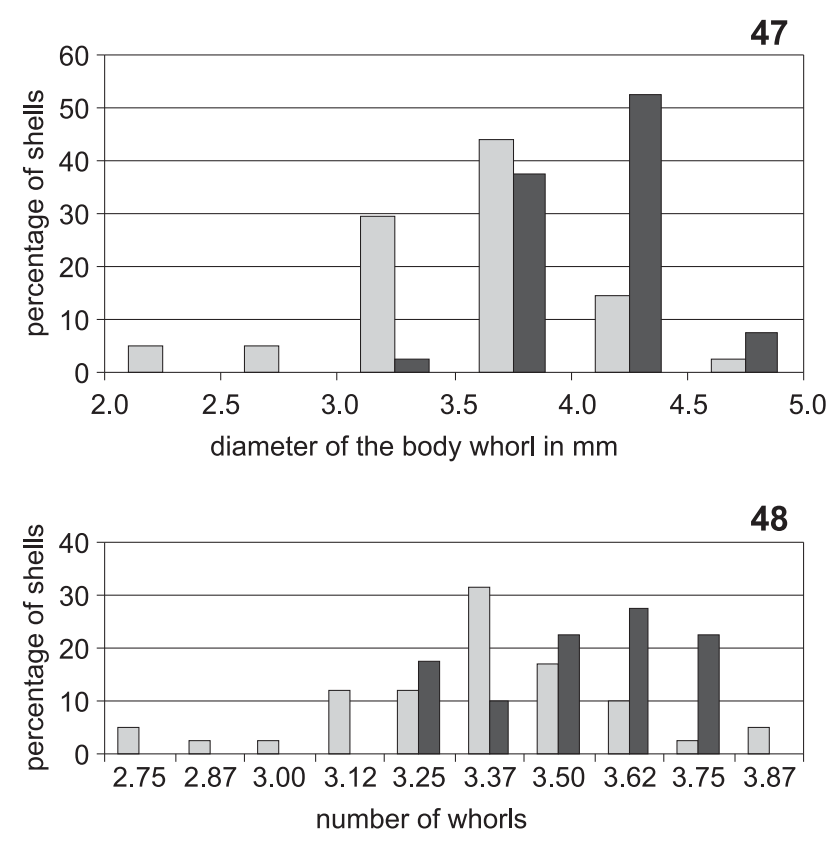

49

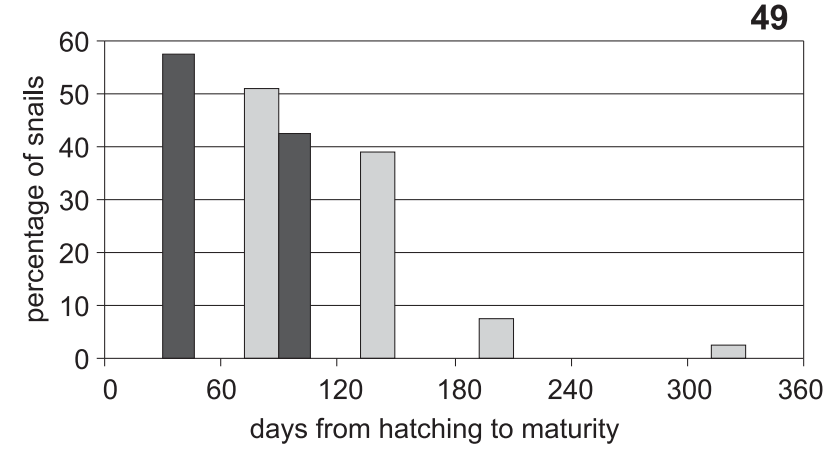

$\square$ 1996-1998 (n=41) $\square$ 1999-2001 (n=40)

Figs 47-49. Variation in the shell size and the time of female maturation in different food conditions: snails hatched in 1996-1998 mainly periphyton as food, and those hatched in 1999-2001 mainly filamentous diatoms as food

\section{ADULT GROWTH AND MORTALITY}

From the moment of attaining maturity and beginning of reproduction the shell growth became increasingly slower. Some individuals stopped growing just before death (1-10 days), other snails ceased to grow much earlier (even 6 months before death). After growth cessation the snails usually remained active (feeding, cocoon deposition). Individual growth curves were rather varied and depended, among other factors, on food conditions (Fig. 50). The mean growth of three groups of snails hatched in June and July (hatching period in natural conditions) is presented in Fig. 51. Figs 52-53 show mean growth curves for the number of whorls for the whole laboratory population. Growth of snails fed mainly with periphyton (Fig. 52) terminated in most cases in 10-12 months though sometimes it continued for 17 months. Later the mean growth visible in the figure was only apparent and resulted from gradual dying out of snails of smaller size (the longest-lived snail had the largest shell). At not very intense feeding on diatoms (Fig. 53) the growth lasted usually for 6-10 months, and only rarely up to 350 days. Intense feeding on filamentous diatoms resulted in attaining the maximum shell size usually already within 4-6 months (range 80-310 days), and then the snails died within a rather short period (usually 6-36 days).

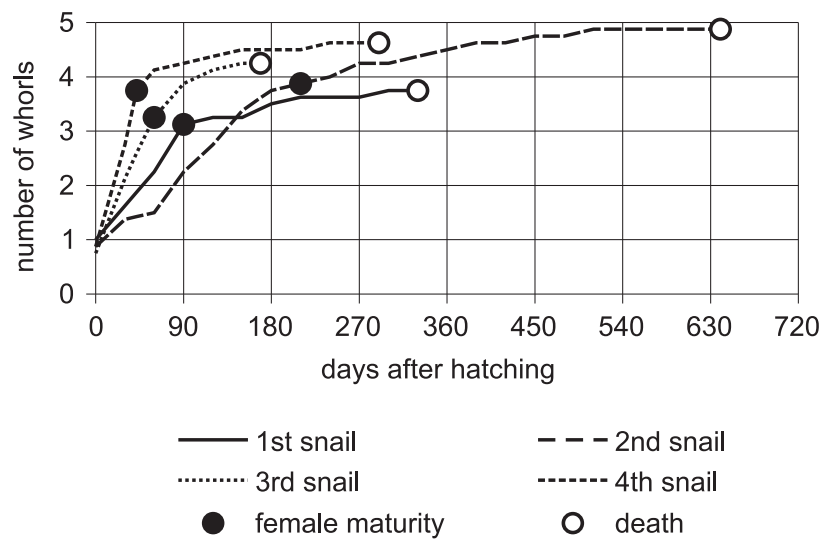

Fig. 50. Examples of individual growth curves for the number of shell whorls: snails 1 and 2 mainly periphyton as food, snails 3 and 4 mainly filamentous diatoms as food

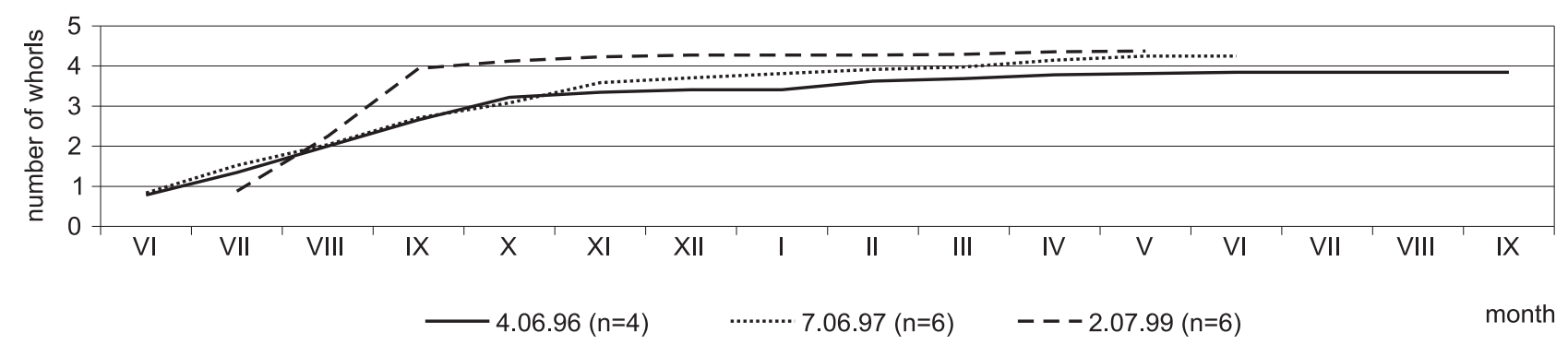

Fig. 51. Examples of mean growth curves of three groups snails kept in different food conditions: 1996-1997 - mainly periphyton as food, 1999 - mainly filamentous diatoms as food 
52

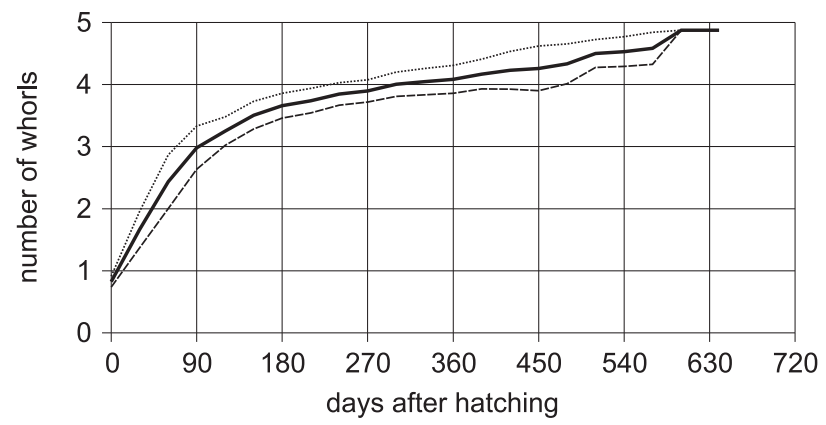

53

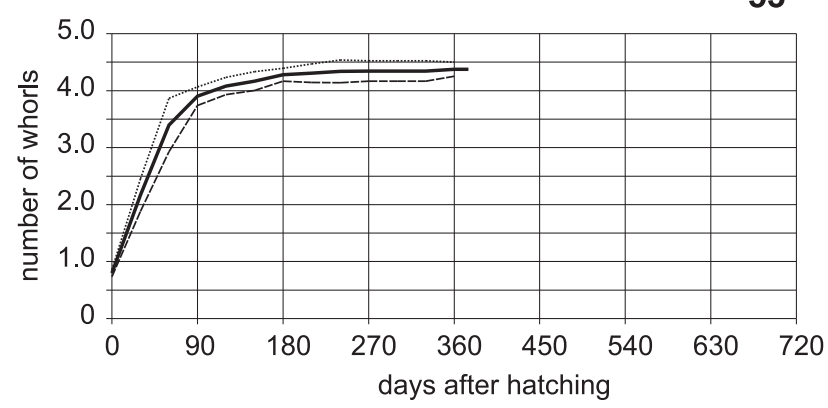

--- mean -........... mean +SD

Figs 52-53. Mean growth curves for the number of shell whorls in different food conditions: 52 - mainly periphyton as food; 53 - mainly filamentous diatoms as food

In very unfavourable food conditions (hatched in 1994) adult shells reached a maximum diameter of 3.0-4.0 mm and 3.1-3.6 whorls (Fig. 54). Their shells bore numerous striae testifying to growth inhibition (light striae resulting from thickening of the walls, or dark, ridge-like striae). In better food conditions (hatched in 1996-2001) the size attained was usually much larger. The shell shape varied considerably: from spherical-conical to turret-like. The apex was usually somewhat flattened and only rarely distinctly tapered. The whorls were as a rule strongly convex,

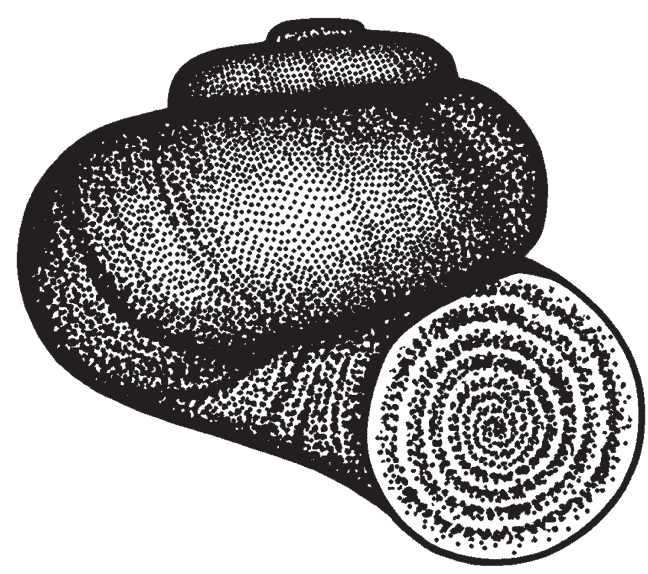

Fig. 54. Shell of the snail kept in very bad food conditions, life span 830 days and in some large shells $(14.8 \%)$ the body whorl did not adhere to the penultimate. The relative spire height was $36.8-58.7 \%$ shell height and in the group fed with with periphyton was on average somewhat greater than in that fed with diatoms $(48.6 \%$ and $46.8 \%$, respectively). The umbilicus constituted $10-16 \%$ shell diameter and was sometimes slightly covered by the body whorl. The sculpture of definitive whorls was much variable. Initial two (sometimes three) whorls were usually covered by regular, densely arranged radial riblets or striae. They often criss-crossed with delicate spiral lines which extended from the embryonic whorls. On further whorls the radial striae were usually irregular and more sparsely arranged, while the spiral lines occurred only sporadically. On several shells with strongly marked spiral lines, on the surface of the second and third whorls, the ridge-like ribs bore short, dense spines. In the group fed intensely with filamentous diatoms the growing whorl had a nearly smooth surface (sometimes with very weak spiral lines). Each short period of growth inhibition (e.g. food deficit) was usually marked as a dark ridge-like riblet (or a few such riblets close together), sometimes preceded by a lighter stria. Long periods of food deficit resulted in a distinct narrowing of the diameter of the whorl increment following such a period. Some of the snails, which terminated their growth $(12.3 \%)$, formed inside the aperture a thickening, especially strongly marked on the contact with the penultimate whorl (callus) and on the basal wall of the aperture. Less often the aperture margin became slightly reflexed. The aperture was usually oval with a weak angle on the contact with the penultimate whorl (rarely almost circular). Most shells of laboratory snails were light brown and the region of umbilicus was sometimes of different colour (e.g. greyish-white). When the food contained large quantities of "green" blue-green algae the shell colour changed to grey-white or grey-green (sometimes wide, coloured radial stripes arose, especially well visible on the umbilical side).

Shell from lake Sosnowe varied in shape from spherical-conical to turret-like (form antiqua). The apex was usually flattened and rarely distinctly tapered. Some shells had poorly convex whorls (aperture elongated vertically with a distinct angle, sometimes slightly incised by the preceding whorl), others had very convex whorls (aperture nearly circular) (Figs 55-56). Initial whorls were covered by striae or delicate radial riblets often criss-crossing with spiral lines (sometimes the riblets were ridge-like with fine spines on the edge). The relative spire height was $35.9-60.9 \%$ shell height (mean $50.0 \%$ ). The umbilicus in some shells was narrow, partly covered by the body whorl, in others relatively wide (up to $17.4 \%$ shell diameter). Striae testifying to growth disturbance were observed rather rarely (a single stria on the body whorl, only on large shells sometimes two or 


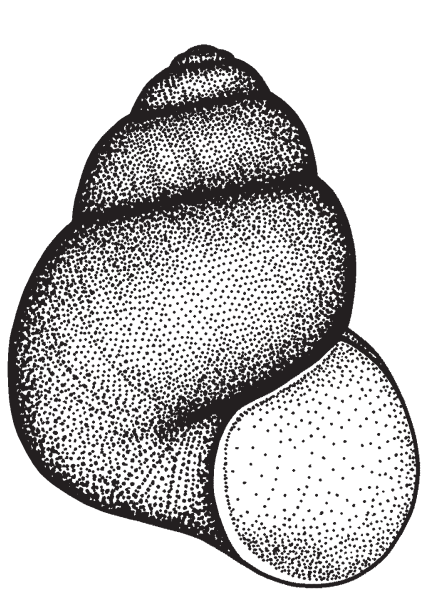

55

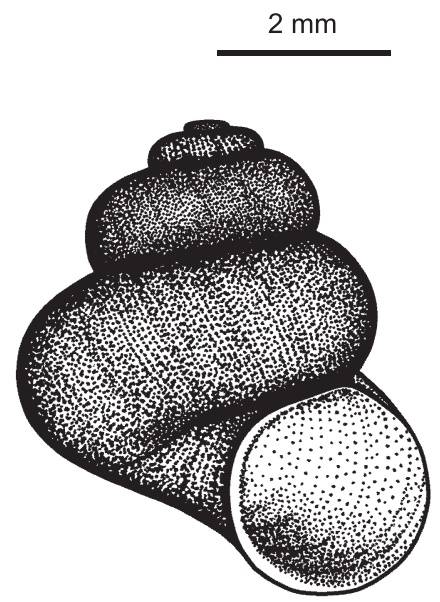

56

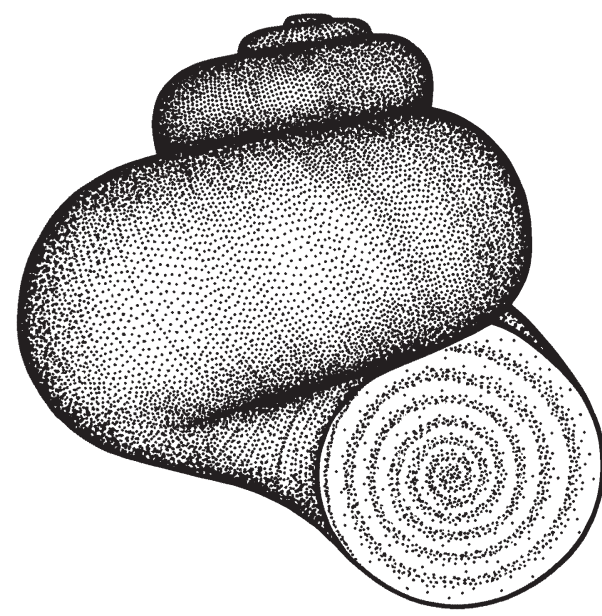

57

Figs 55-57. Examples of shell variation: 55-56 - lake Sosnowe near Sapolno, 57 - fish-pond

three such striae, one of them always near the aperture). Also the shell colour was very variable (from whitish or light brown to green-brown or bluishgreen) and depended on both the location of the site and the year.

The pond shells were as a rule conical with tapered apex (Fig. 57) and usually had strongly convex whorls (aperture slightly elongated on the contact with the penultimate whorl or less often nearly circular). The relative spire height was $38.3-56.5 \%$ shell height (mean $49.0 \%$ ). The umbilicus constituted usually 6-9\% shell diameter (sporadically to $20 \%$ ). Regular radial striae often covered the whole shell surface. Some shells bore striae testifying to growth disturbance (usually one at a different distance from the apex and aperture, rarely a second one near the aperture). The shell colour was as a rule light brown, less often grey-white or grey-green.

In the laboratory shells of snails fed mainly with periphyton (1996-1998) reached maximum dimensions $(\mathrm{n}=41)$ : diameter 2.65-7.1 $\mathrm{mm}$ (mean 4.78, $\mathrm{SD}=0.80$ ), height 2.3-7.9 mm (mean 4.81, $\mathrm{SD}=1.04$ ), number of whorls 3.05-4.9 (mean 4.07, $\mathrm{SD}=0.40$ ) (Figs 58-60). The largest shell in the laboratory was $7.1 \mathrm{~mm}$ in diameter, $7.9 \mathrm{~mm}$ high and had 4.9 whorls. Shells of snails fed mainly with filamentous diatoms (1999-2001) reached the maximum size $(n=40)$ : diameter 4.4-6.3 mm (mean 5.15, SD=0.53), height $4.2-7.0 \mathrm{~mm}$ (mean 5.48, $\mathrm{SD}=0.63$ ), number of whorls 3.8-4.7 (mean 4.23, $\mathrm{SD}=0.23$ ). The dependence between the maximum shell dimensions and life span in various food conditions is presented in Figs 61-63.

Shells of snails from lake Sosnowe reached the following dimensions $(\mathrm{n}=143)$ : diameter up to $5.0 \mathrm{~mm}$ (mean 4.13, $\mathrm{SD}=0.35$ ), height up to $6.4 \mathrm{~mm}$ (mean $4.58, \mathrm{SD}=0.57$ ), number of whorls up to 4.8 (mean $4.14, \mathrm{SD}=0.25)$. The correlation coefficients were: diameter - height $r=0.81$, diameter - number of whorls $r=0.65$, height - number of whorls $r=0.90$. The largest
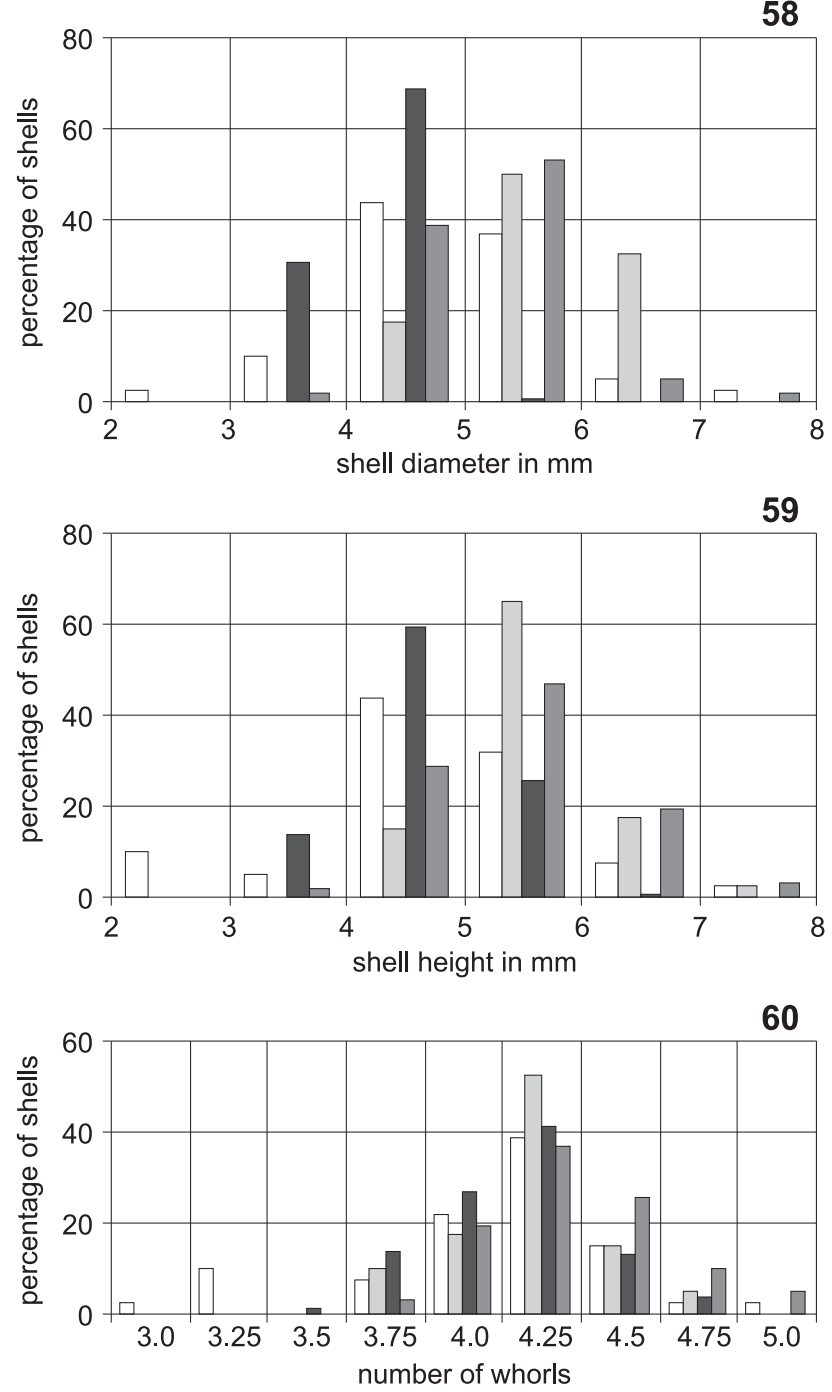

$\begin{array}{ll}\square \text { lab culture 96-98 } & \square \text { lab culture 99-01 } \\ \square \text { lake Sosnowe } & \square \text { fish-pond }\end{array}$

Figs 58-60. Variation in shell size reached in the laboratory, lake Sosnowe and fish-pond 
shells from the lake had the following dimensions: I. diameter $5.0 \mathrm{~mm}$, height $4.9 \mathrm{~mm}, 4.15$ whorls; II. diameter $4.7 \mathrm{~mm}$, height $6.4 \mathrm{~mm}, 4.7$ whorls.

Shells of snails from the fish pond had the following dimensions $(\mathrm{n}=62)$ : diameter up to $7.1 \mathrm{~mm}$ (mean 5.12, $\mathrm{SD}=0.59$ ), height up to $7.8 \mathrm{~mm}$ (mean $5.35, \mathrm{SD}=0.82$ ), number of whorls up to 5.0 (mean

61

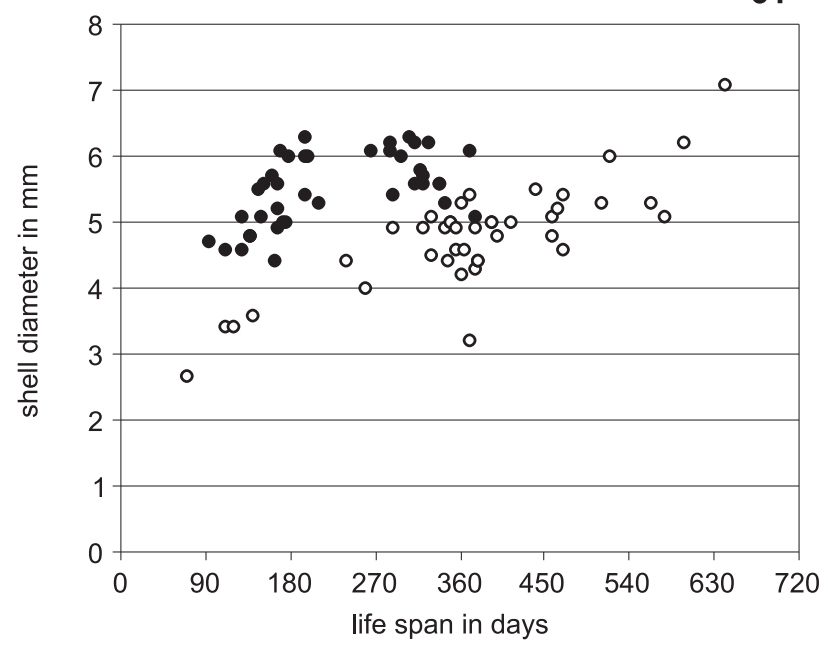

62

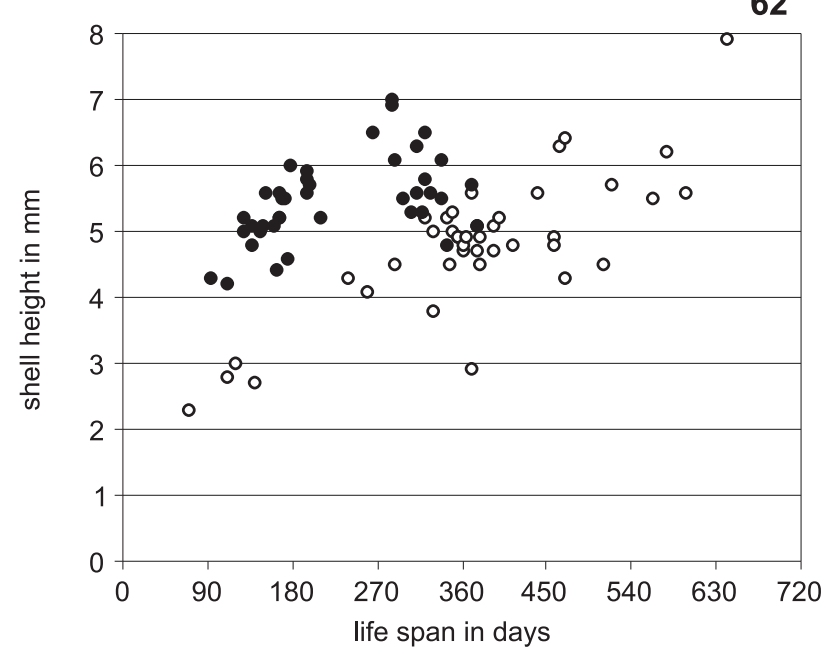

63

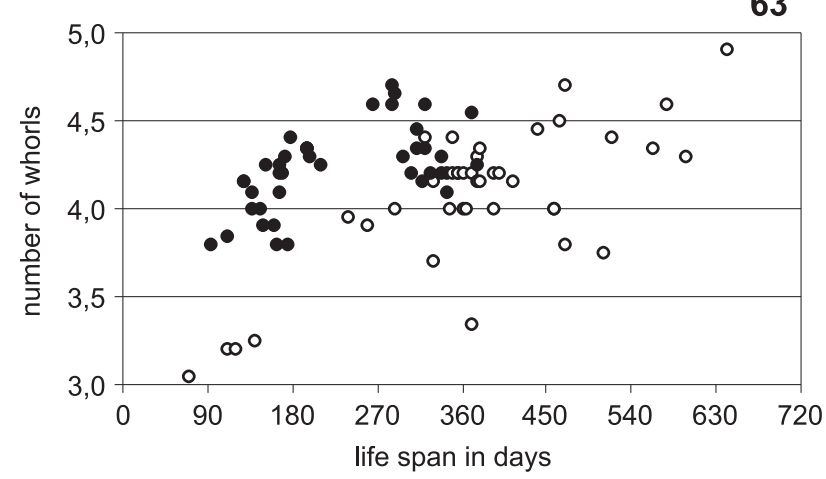

○ periphyton - filamentous diatoms

Figs 61-63. Shell of adult snails from the laboratory culture: relationship between maximum shell size and life span
4.32, $\mathrm{SD}=0.27)$. The correlation coefficients were: diameter - height $r=0.84$, diameter - number of whorls $r=0.71$, height - number of whorls $r=0.93$. The largest shell from the pond was $7.1 \mathrm{~mm}$ in diameter, $7.8 \mathrm{~mm}$ in height and had 4.95 whorls.

The height/diameter ratio (Hs/Ds) is one of the diagnostic characters of conchological forms (e.g. antiqua). For adult snails from different populations its values were: laboratory $0.75-1.22$ (mean 1.00 , $\mathrm{SD}=0.09, \mathrm{n}=81$ ), lake Sosnowe 0.89-1.36 (mean 1.11, $\mathrm{SD}=0.08, \mathrm{n}=143$ ), fish pond 0.85-1.28 (mean 1.04, $\mathrm{SD}=0.09, \mathrm{n}=62$ ) (Figs 64-65). The Hs/Ds ratio showed a positive correlation with the number of whorls (Figs 66-69), and Pearson's correlation coefficients were: laboratory $r=0.69(n=81)$, lake Sosnowe $r=0.77(n=143)$, fish pond $r=0.70(n=62)$. Shells corresponding to form antiqua (Hs/Ds exceeding 1.2) in the lake sample constituted $11.9 \%$ while in the laboratory population they were rather rare $(2.5 \%)$. The mean value of the parameter in the progeny born in laboratory was always smaller than in the parents born in the wild. Production of form antiqua in the lake could result from rather unfavourable conditions (scarce food of low value), causing a slow increase in whorl diameter (shell diameter) and increase in life span and shell growth period (number of whorls and height).
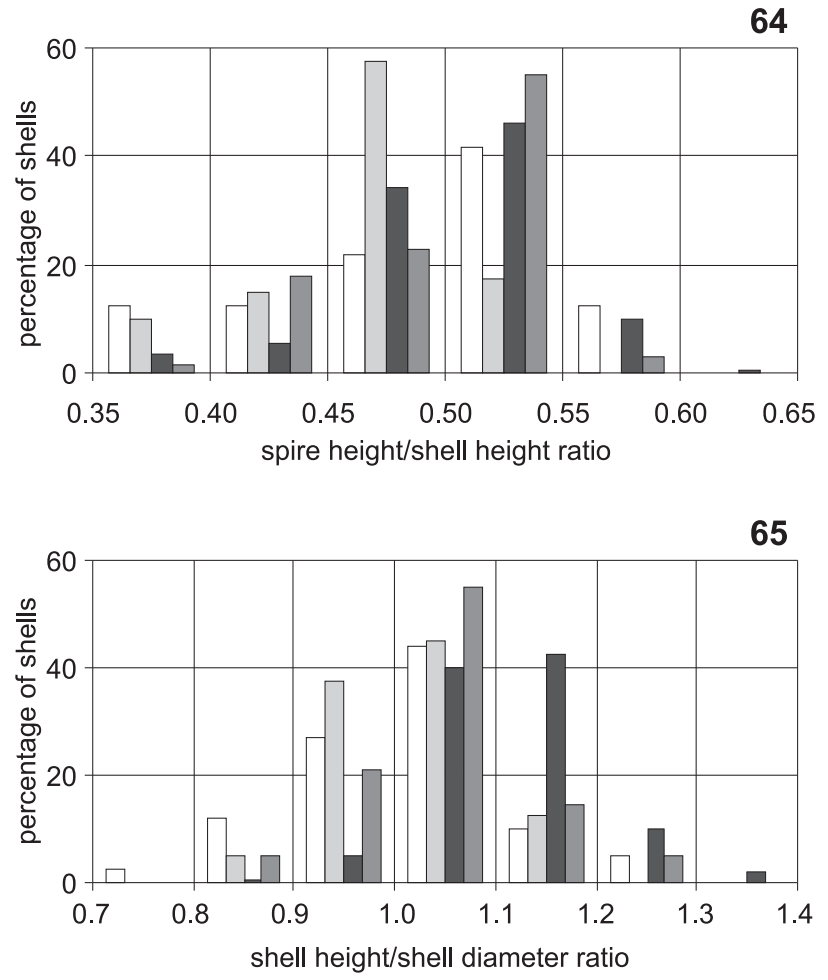

$\square$ lab culture 96-98 $\square$ lab culture 99-01

$\square$ lake Sosnowe $\quad \square$ fish-pond

Figs 64-65. Variation in shell parameters: 64 - relative spire height; 65 - shell height/diameter ratio 
66

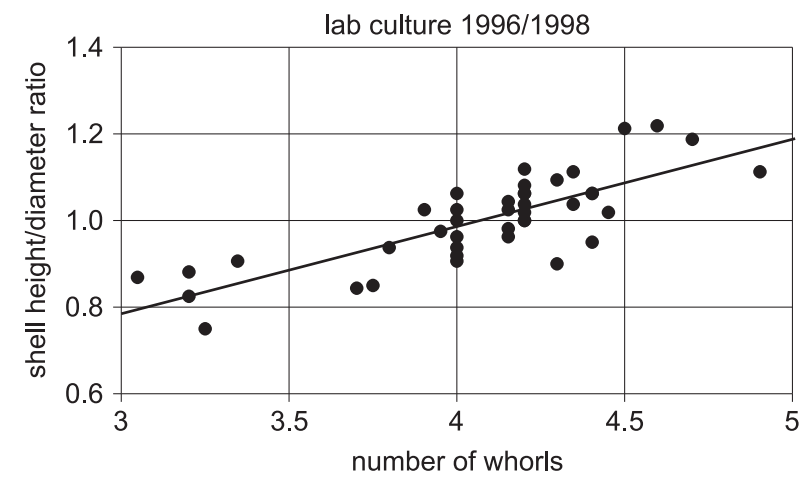

68

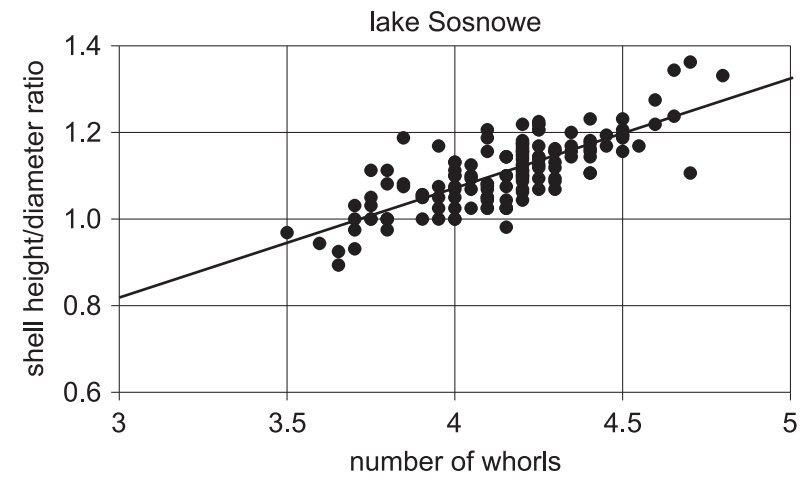

67

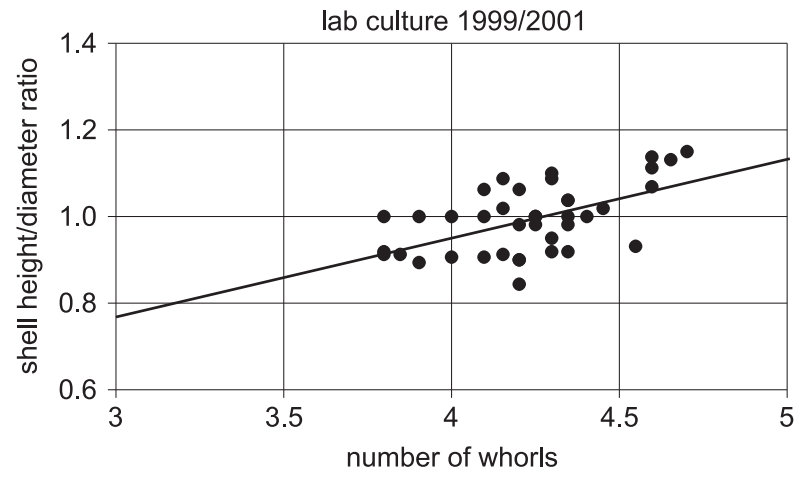

69

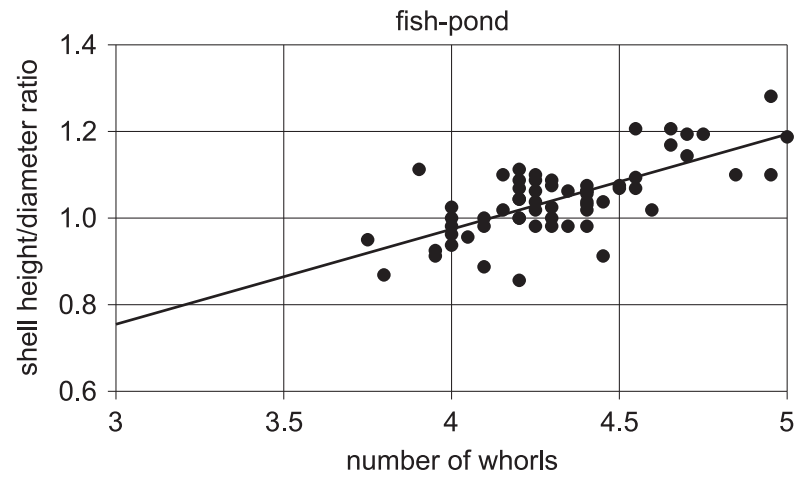

Figs 66-69. Relation between shell height/diameter ratio and number of whorls in the laboratory culture (66 - mainly periphyton as food, 67 - mainly filamentous diatoms as food), lake Sosnowe (68) and fish-pond (69); linear regression marked

Shell characters observed in parents (e.g. whorl convexity, relative diameter of umbilicus) were rarely repeated among the offspring, and shells varied much among snails hatched from the same cocoon. Example: shells of parents (from the lake) had poorly convex whorls and slit-like umbilicus (like the shell in Fig. 55 ), while their offspring had shells with strongly convex whorls and the umbilicus constituted 10.1-14.6\% shell diameter. The height/diameter ratio was: parents 1.14; offspring from one cocoon 0.92-1.22 (mean 1.08); from another cocoon 0.90-1.08 (mean $0.99)$. The maximum shell size and life span also varied in spite of similar conditions (e.g.: I. diameter 3.2 $\mathrm{mm}$, height $2.9 \mathrm{~mm}, 3.35$ whorls, life span 370 days; II. diameter $6.2 \mathrm{~mm}$, height $5.6 \mathrm{~mm}, 4.3$ whorls, life span 599 days).

The above data are compatible with the information given by PIECHOCKI (1979) and FALNIOWSKI (1989a) on the wide shell variation in $V$. piscinalis.

The opercula were very thin, usually oval with a poorly marked angle (rarely nearly circular) and had sinistral whorls (Figs 70-71). The central part of the operculum was slightly concave, and the apical angle was on average $141^{\circ}\left(\mathrm{SD}=4.7^{\circ}, \mathrm{n}=73\right)$. Initially the whorl width increased slowly, but the last increments were large. In some opercula the last whorl was twice wider than the penultimate and reached a width of $0.65 \mathrm{~mm}$. The increasing whorl usually partly over- lapped the preceding one (15-25\% width, sporadically up to $40 \%$ ), and the border between the two was often double. In some opercula the external edge of the whorls did not adjoin the preceding whorl but formed a spiral ridge. Periodical growth inhibitions were marked as oblique lines across the whorl. The surface sculpture of the whorls was rather varied. Initial whorls were mostly covered by more or less distinct spiral striae (sometimes over 30 striae per whorl); rarely their surface was smooth or had a different sculpture. The sculpture of the last whorl (sporadically also a part of the penultimate) usually differed distinctly from the earlier ones: the spiral striae disappeared and numerous oblique growth lines appeared instead, as well as irregular wrinkles (Fig. 72). The total number of opercular whorls (including embryonic whorls) in adult snails was nearly twice higher than that of the shell whorls (mean 1.95, $\mathrm{SD}=0.14$, $\mathrm{n}=42$, range $1.64-2.25$ ). Adult opercula were usually composed of 7.5-8.5 whorls (maximum 10). The operculum growth was independent from the shell growth and only during strong contraction of the body its shape and size became adjusted to fit the aperture. Very rarely operculum was larger than the aperture (observed both in the laboratory culture and in the field). The largest operculum in the culture was $3.82 \times 3.45 \mathrm{~mm}$ and had 10 whorls (shell: diameter $7.1 \mathrm{~mm}, 4.9$ whorls). 
The adult life span clearly depended on food conditions, and in snails kept singly was usually somewhat shorter than in those kept in pairs in similar conditions (Table 3). Only three snails kept singly (1998),

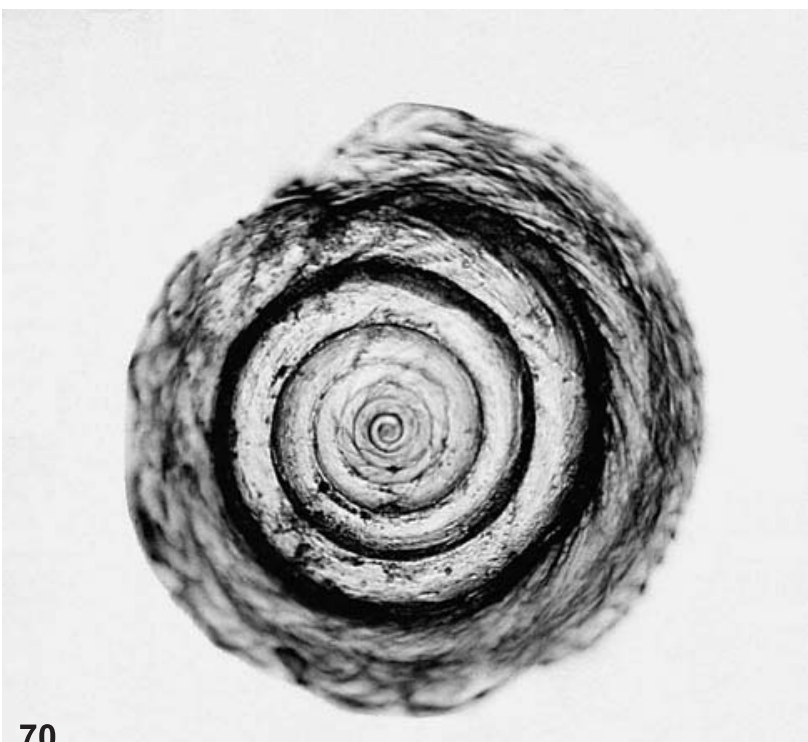

70

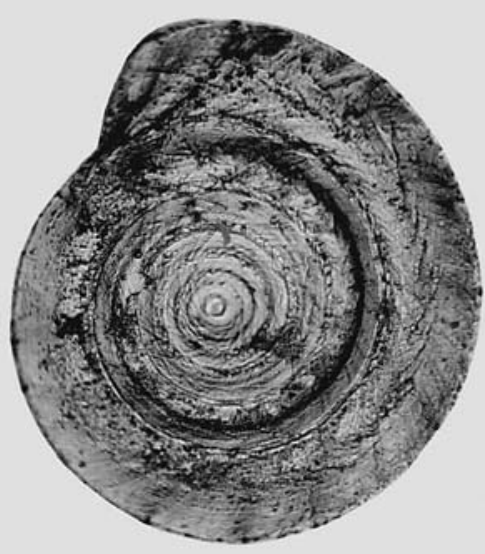

71

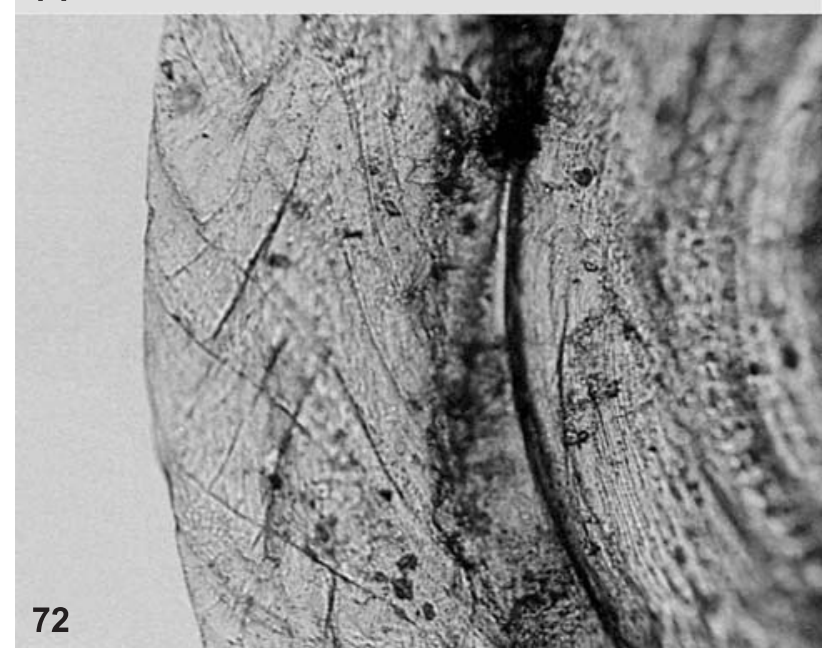

Figs 70-72. Light microscope: 70-71 - opercula of adult snails, $20 \times ; 72-$ a fragment of operculum ultimate and penultimate whorls, $60 \times$ with clear disturbance of gonad activity, lived longer (578, 600 and 641 days) than those kept in pairs (maximum 563 days). In very unfavourable conditions (1994) the mean life span was 517 days $(\mathrm{SD}=181$, $\mathrm{n}=4$, range 409-830) and the snails died within a rather short period (50-110 days) after attaining maturity. The average life span of snails fed mainly with periphyton (1996-1998) was 376 days $(\mathrm{SD}=123, \mathrm{n}=41$, range 70-641) and they mostly died in two periods: May-July (51.2\%) and September-October (19.5\%) next year after hatching. The longest-lived individuals hibernated for the second time and died in February-April. Snails fed mainly with filamentous diatoms (1999-2001) had the mean life span of 227 days ( $\mathrm{SD}=83, \mathrm{n}=40$, range 94-375). Those fed with diatoms but not very intensely (1999) in most cases died next spring (March-May). Intense feeding with diatoms (2000-2001) resulted in the mean life span of 187 days (maximum 337) and most such snails (73.1\%) died at the end of summer and in autumn (August-October) in the year of their hatching; the longest-lived individual died at the beginning of April. Mortality of snails in the laboratory culture is presented in Figs 73-74 and in Table 4.

My observations in natural conditions (lake Sosnowe) confirmed the literature information (ClEland 1954, FretTER \& Graham 1962, PIECHOCKI 1979, FALNIOWSKI 1989a) on dying of the adults after reproduction, though the process started usually much earlier (in some years already at the end of June). However, snails with rather large shells (diameter 4.8-5.0 mm, 4.1-4.5 whorls) found throughout the year indicate that the life span could be much longer than one year and that such snails could hibernate twice (in the spring on some shells two striae of growth inhibition).

\section{DEVELOPMENTAL ANOMALIES}

Some development anomalies became apparent already during embryonic development, for example osmotic disturbances (swelling of whole body or only mantle, head, foot) and underdevelopment of shell or operculum (often combined with osmotic disturbances). Most snails with such anomalies died within egg envelopes but some hatched and lived for a short time (maximum two weeks). Sporadically the shell or operculum fell off inside the egg envelopes or soon after hatching. Examples of hatched abnormal snails: I. anterior part of body swollen, near aperture shell funnel-like dilated, diameter $0.40 \mathrm{~mm}$, height $0.36 \mathrm{~mm}$, 0.37 whorl, no operculum; II. whole body swollen, shell horn-shaped, diameter $0.33 \mathrm{~mm}$, height $0.40 \mathrm{~mm}$, 0.5 whorl, aperture kidney-shaped of $0.19 \times 0.40 \mathrm{~mm}$, operculum diameter $0.19 \mathrm{~mm}$; III. whole body swollen, shell horn-shaped (ca. 0.25 whorl, aperture size $0.27 \times$ $0.35 \mathrm{~mm}$ ) fell off within the egg envelopes, operculum diameter $0.12 \mathrm{~mm}$; IV. body normally developed (not 
Table 3. Mean life span in days; variable food conditions - initially the worst and then gradually improving: 1996-1998 mainly periphyton as food, 1999-2001 mainly filamentous diatoms as food

\begin{tabular}{crccccccccc}
\hline \multirow{2}{*}{ Year of hatching } & \multicolumn{3}{c}{ Kept in pairs } & \multicolumn{3}{c}{ Kept singly } & \multicolumn{3}{c}{ Total } \\
\cline { 2 - 10 } & $\mathrm{n}$ & mean & SD & $\mathrm{n}$ & mean & SD & $\mathrm{n}$ & mean & SD \\
\hline 1996 & 4 & 473 & 21 & - & - & - & 4 & 473 & 21 \\
1997 & 8 & 371 & 16 & 6 & 233 & 101 & 14 & 312 & 96 \\
1998 & 14 & 412 & 68 & 9 & 377 & 185 & 23 & 398 & 129 \\
Total 1996-1998 & 26 & 409 & 61 & 15 & 319 & 172 & 41 & 376 & 123 \\
\hline 1999 & 10 & 319 & 44 & 4 & 260 & 88 & 14 & 302 & 65 \\
2000 & 4 & 241 & 66 & 3 & 163 & 2 & 7 & 208 & 63 \\
Total 1999-2001 & 12 & 192 & 68 & 7 & 159 & 20 & 19 & 179 & 58 \\
\hline
\end{tabular}

Table 4. Mortality of adult snails in laboratory: 0 - year of hatching; 1, 2 - consecutive years

\begin{tabular}{|c|c|c|c|c|c|c|c|c|c|c|c|c|c|}
\hline \multirow{2}{*}{ Years } & \multicolumn{12}{|c|}{ Month of death } & \multirow{2}{*}{ Total } \\
\hline & I & II & III & IV & $\mathrm{V}$ & VI & VII & VIII & IX & $\mathrm{X}$ & $\mathrm{XI}$ & XII & \\
\hline 0 & - & - & - & - & - & 2 & 1 & 6 & 7 & 9 & 1 & - & 26 \\
\hline 1 & 4 & 1 & 3 & 5 & 11 & 10 & 6 & 1 & 5 & 3 & 1 & 1 & 51 \\
\hline 2 & - & 2 & 1 & 1 & - & - & - & - & - & - & - & - & 4 \\
\hline$\Sigma$ & 4 & 3 & 4 & 6 & 11 & 12 & 7 & 7 & 12 & 12 & 2 & 1 & 81 \\
\hline
\end{tabular}
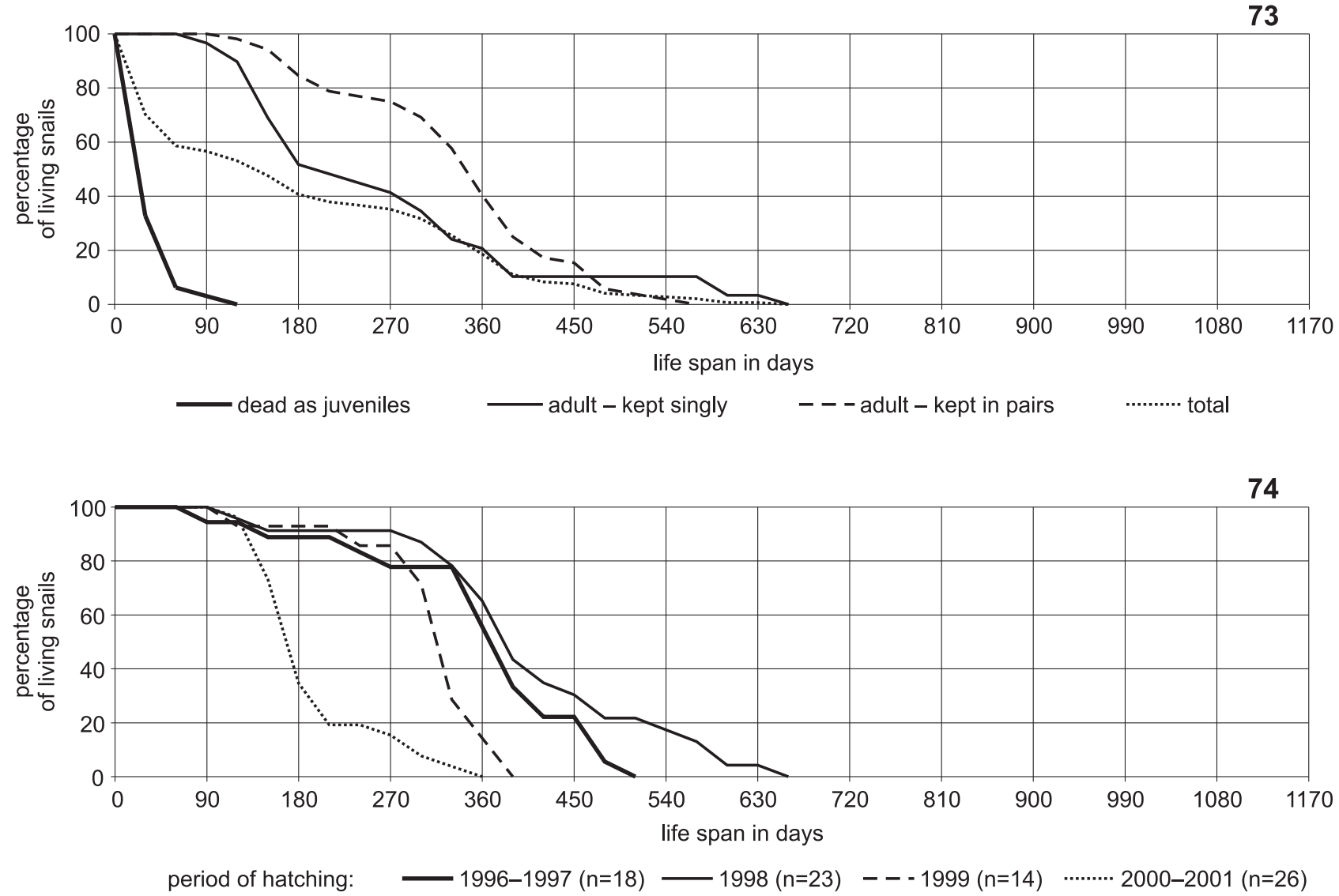

Figs 73-74. Mortality of snails in the laboratory: 73 - all snails hatched in the laboratory; 74 - only adult snails, variation in the mortality curves depending on food conditions (initially the worst, then gradually improving) 
swollen) but mantle pulled backwards and instead of shell an irregular lump, operculum diameter $0.22 \mathrm{~mm}$. Slight osmotic disturbances (swellings) sometimes receded and the shells bore a trace of first dilation and then narrowing of the whorl. At the end of embryonic development also other anomalies became apparent (e.g. absence of eye or cephalic tentacle), which however did not affect further life after hatching.

At the end of life bodies of two adult snails started to gradually slide out of their shells. One of them shed the shell completely (diameter $5.0 \mathrm{~mm}$, height $5.5 \mathrm{~mm}, 4.3$ whorl). During the next four days the snail moved and fed, then died.

Three snails originating from different parents showed a gonad growth much slower compared to the remaining individuals. They did not attain female maturity till death, in spite of the large shell size and normally developed penis and pallial reproductive organs (exclusively male).

Disturbances in gonad functioning were observed both in the laboratory and in the field. Examples: I. snail from the lake, shell diameter $3.5 \mathrm{~mm}$, height 4.0 $\mathrm{mm}, 4$ whorls - when placed in the culture deposited 3 cocoons with a total of 43 eggs, and after death its gonad contained 15 vitellogenic oocytes and numerous scattered yolk granules; II. snail with shell diameter $4.5 \mathrm{~mm}$, height $5.7 \mathrm{~mm}, 4.5$ whorls (after two months in the culture the shell reached the diameter of $5.8 \mathrm{~mm}$, height $7.3 \mathrm{~mm}, 5.15$ whorls) - did not deposit any cocoons but after death its gonad contained about a dozen vitellogenic oocytes of $0.10-0.15 \mathrm{~mm}$ diameter and large quantities of yolk. Most offspring of the first snail showed no similar disturbances. Only in four of them the number of vitellogenic oocytes produced during lifetime was rather small (70-120 oocytes) though their life span was long and they reached a big size.

\section{PREDATORS AND PARASITES}

Contrary to $V$. cristata and $V$. macrostoma no digenean larvae were found in the gonads of $V$. piscinalis, either in the laboratory culture or in specimens collected in the field. Parasitic fungi infected some incubating eggs (especially those produced by snails kept singly). Also about $10 \%$ adults already before death were overgrown with fungal hyphae. Dipteran larvae which were present in the containers (brought sometimes with food) damaged cocoon capsules and consumed egg cells. Some shells from lake Sosnowe bore distinct traces of damage of aperture margin (or even fragments of the whorl broken off), which were later regenerated.

\section{FOOD AND FEEDING}

During feeding the snails constantly crawled and scraped the substratum (leaves, container walls, under- side of surface film) with their radulae. No filter-feeding was observed, and the mantle cavity was almost always clean (sporadically it contained fragments of faeces or live ciliates). Juveniles usually foraged on the thin layer of periphyton covering leaves of trees and aquatic plants. With increasing body size their food requirements increased and they foraged on increasingly thicker layers of periphyton. Leaves of trees provided as food (mainly black alder Alnus glutinosa, oak Quercus sp., poplar Populus sp.) were collected in the lake, near the shore, leaves of aquatic plants (manna grass Glyceria maxima, sweet rush Acorus calamus) - in the river. Food was generally consumed indiscriminately and included for example fine algae, blue-green algae, bacteria, sedentary protozoans, detritus. A similar food composition has been reported in the literature (WESSENBERG-Lund 1939, CLELAND 1954, FRETTER \& GRAHAM 1962, PIECHOCKI 1979, FALNIOWSKI 1989a). When the food was inadequate (e.g. only Oscillatoria) or scarce (e.g. very thin periphyton layer) the snails moved rather fast and only from time to time made scraping movements with their radulae. During longer periods of food deficit they usually lay on the bottom shut in their shells. In the laboratory the most valuable food included colonies of filamentous diatoms of the genus Melosira (Chrysophyta: Bacillariophyceae: Centrales). The diatom in Fig. 1 was identified as Melosira moniliformis. In natural conditions the diatoms sometimes occurred in masses on aquatic plants near the Brda River shore. Their cells usully contain large quantities of lipids and are easy to squash during eating. Even a small addition of diatoms to the food resulted in a distinct increase in the number of deposited cocoons and eggs and a much faster growth.

Faeces of $V$. piscinalis had the shape of short cylinders with a clear longitudinal groove (C-shaped in cross-section) like in V. macrostoma (MYZYK 2004) (in $V$. cristata the longitudinal groove was only sporadically observed). In adult snails the cylinder diameter was usually $0.20-0.35 \mathrm{~mm}$, the length $0.40-0.75 \mathrm{~mm}$. Sometimes the faeces were not divided into sections but formed spirals of considerable length (over 10 $\mathrm{mm}$ ). Like in V. cristata and V. macrostoma the faeces often contained live organisms (e.g. diatoms).

\section{OTHER INFORMATION}

The velocity of movement depended on the size of the snail and for large snails (shell diameter ca. 5 $\mathrm{mm}$ ) was ca. $0.5 \mathrm{~mm} / \mathrm{s}(1.8 \mathrm{~m} / \mathrm{h})$. In the laboratory the snails often crawled below the surface film where they foraged and sometimes deposited cocoons.

\section{COMPARISON BETWEEN V. PISCINALIS, V. MACROSTOMA AND V. CRISTATA}

Cocoon formation in $V$. cristata proceeds according to the following pattern: oocytes covered in 
Table 5. Comparison of egg size

\begin{tabular}{lccc}
\hline & V. cristata $(\mathrm{n}=662)$ & V. macrostoma $(\mathrm{n}=573)$ & V. piscinalis $(\mathrm{n}=682)$ \\
\cline { 2 - 3 } & mean $\pm \mathrm{SD}$ & mean $\pm \mathrm{SD}$ & mean $\pm \mathrm{SD}$ \\
\hline chamber length in mm & $0.307 \pm 0.020$ & $0.337 \pm 0.023$ & $0.353 \pm 0.023$ \\
cell length in mm & $0.251 \pm 0.026$ & $0.290 \pm 0.018$ & $0.299 \pm 0.018$ \\
diameter in mm & $0.205 \pm 0.011$ & $0.235 \pm 0.014$ & $0.239 \pm 0.016$ \\
\hline
\end{tabular}

vitelline membrane move along the oviduct to the albumen gland where the egg envelopes (external and internal) are produced. Then in the nidamental gland they are covered with the gelatinous substance and capsule. In $V$. macrostoma and $V$. piscinalis in the nidamental gland the capsules are surrounded with an additional mucus layer. The eggs of $V$. cristata are generally smaller than in the remaining two species (Table 5). Also the egg cord extending from the anterior pole of the egg has usually a smaller diameter. The mean volume of egg cells in $V$. cristata is smaller than in $V$. macrostoma by $34 \%$, and in $V$. piscinalis by $38 \%$. The size and structure of most eggs of $V$. piscinalis and $V$. macrostoma are similar. Only some eggs of $V$. piscinalis have a characteristic structure of egg envelopes or the cord extending from the anterior pole (Figs 22-23).

Cylindrical, usually arcuately bent cocoons of $V$. cristata with a single row of eggs differ clearly from the ovate cocoons of $V$. macrostoma and $V$. piscinalis, with their eggs arranged irregularly or in a dextral spiral row. Besides, cocoons of $V$. macrostoma and $V$. piscinalis are usually covered by a mucus layer never observed in $V$. cristata. The differences between cocoons of $V$. macrostoma and $V$. piscinalis are small and pertain mainly to the capsule thickness, maximum size and proportions. In all species the number of eggs per cocoon depends, among other factors, on the snail size, food conditions and season. The maximum numbers of eggs per cocoon are: $V$. cristata - 16, V. macrostoma$34, V$. piscinalis -76 . The variation of the number of eggs in cocoons deposited by $V$. cristata kept in pairs or groups (MYZYK 2002: Figs 30-33) is distinctly different from that in V. macrostoma (MYZYK 2004: Fig. 13) and V. piscinalis (Fig. 21). The variation in the number of eggs per cocoon deposited by snails kept singly is similar in all three species (close to Poisson distribution).

During cocoon deposition the egg cells are usually at the stage of oocyte I (polocytes I and II appear only in deposited cocoons). Thus, inside the parent's body the eggs are only supplied with spermatozoa while the actual fertilisation takes place after cocoon deposition. In cocoons with numerous eggs, with a long constriction or composed of several capsules, the advancement of embryonic development sometimes differs between the eggs in extreme positions and in $V$. piscinalis the differences amount at most to a few divisions. Also anomalies in capsule formation observed sometimes (perforation, absence of apex or one side) often delay cocoon deposition and the development starts already within the parent's body. It may constitute an intermediate stage between the oviparity of Valvata and ovoviviparity Borysthenia naticina.

The relative duration of individual stages of embryonic development of $V$. cristata and $V$. macrostoma shows no greater differences, while in $V$. piscinalis the snail stage is distinctly shorter (Table 6). The duration of one division of egg cell (measured between the first and second division) at the same temperature in $V$. piscinalis is by 25-30\% longer than in the remaining two species. The ratio of the mean duration of incubation to the duration of single egg cell division (approximate number of egg cell divisions during embryonic development including two mitotic divisions) is 108-117 (mean 113) for V. cristata and V. macrostoma and 94-99 (mean 96) for $V$. piscinalis. The calculations confirm the slightly less advanced development of hatchlings of $V$. piscinalis compared to the other two species.

Table 6. Comparison of the relative duration of particular stages of embryonic development

\begin{tabular}{lccc}
\hline \multirow{2}{*}{ Stage } & $\begin{array}{c}\text { V. cristata } \\
(\mathrm{n}=1.037)\end{array}$ & $\begin{array}{c}\text { V. macrostoma } \\
(\mathrm{n}=3.044)\end{array}$ & $\begin{array}{c}\text { V. piscinalis } \\
(\mathrm{n}=3.011)\end{array}$ \\
\cline { 2 - 4 } & mean $\pm \mathrm{SD}$ & mean $\pm \mathrm{SD}$ & mean $\pm \mathrm{SD}$ \\
\hline "egg" & $51.2 \% \pm 7.9 \%$ & $50.7 \% \pm 5.5 \%$ & $53.6 \% \pm 6.7 \%$ \\
"larva" & $14.9 \% \pm 5.7 \%$ & $16.0 \% \pm 5.5 \%$ & $18.1 \% \pm 5.7 \%$ \\
"snail" & $33.9 \% \pm 9.8 \%$ & $33.3 \% \pm 6.2 \%$ & $28.3 \% \pm 7.1 \%$ \\
\hline
\end{tabular}

The duration of embryonic development depends mainly on the temperature, and the Pearson correlaion coefficients are: for $V$. cristata and $V$. piscinalis $\mathrm{r}=-0.87$, for $V$. macrostoma $\mathrm{r}=-0.83$. Differences in the resistance to breaking of the internal egg envelope or in the activity of the embryos just before hatching have a small effect on it. Deviations from the mean duration are usually smaller than $10 \%$ and only sporadically they reach minus $26-27 \%$, or plus $38-57 \%$. When embryonic development is considered as a sequence of chemical reactions, the dependence between its mean duration and temperature should result from a transformation of the Arrhenius equation: $\ln \mathrm{t}=\mathrm{A} / \mathrm{T}-\mathrm{B}(\ln \mathrm{t}-$ natural logarithm of duration of incubation in days, $\mathrm{T}$ - temperature in Kelvin degrees, A and B - coefficients). Calculations for $V$. macrostoma and $V$. piscinalis show, however, that 
irrespective from the adopted coefficient values the dependence between the mean incubation time and temperature differs clearly from that resulting from the above equation (Figs 75-76). A more exact description of the regression curve is rendered by logarithmic equations of another type:

V. macrostoma:

$\ln \mathrm{t}=28,306,000 / \mathrm{T}_{c}-185,100 / \mathrm{T}+304.39$

$\ln \mathrm{t}=106,803 / \mathrm{T}-698.82+1.149 \times \mathrm{T}$

$\ln \mathrm{t}=0.0043403 \times \mathrm{T}_{\mathrm{c}}-2.6394 \times \mathrm{T}+403.09$

V. piscinalis:

$\ln \mathrm{t}=31,319,000 / \mathrm{T}_{c}-206,480 / \mathrm{T}+342.36$

$\ln \mathrm{t}=115,430 / \mathrm{T}-760.4+1.259 \times \mathrm{T}$

$\ln \mathrm{t}=0.0046683 \times \mathrm{T}_{\mathrm{c}}-2.8216 \times \mathrm{T}+428.40$

Regretfully, no theoretical justification for any of the above equations could be found. Empirical equations describe the dependence between the incubation time (days) and temperature (centigrade Tc) fairly precisely: for $V$. macrostoma $\mathrm{t}=824 / \mathrm{Tc}-52+$ $1.046 \times \mathrm{Tc}$, and for $V$. piscinalis $\mathrm{t}=838 / \mathrm{Tc}-53+1.118$

75

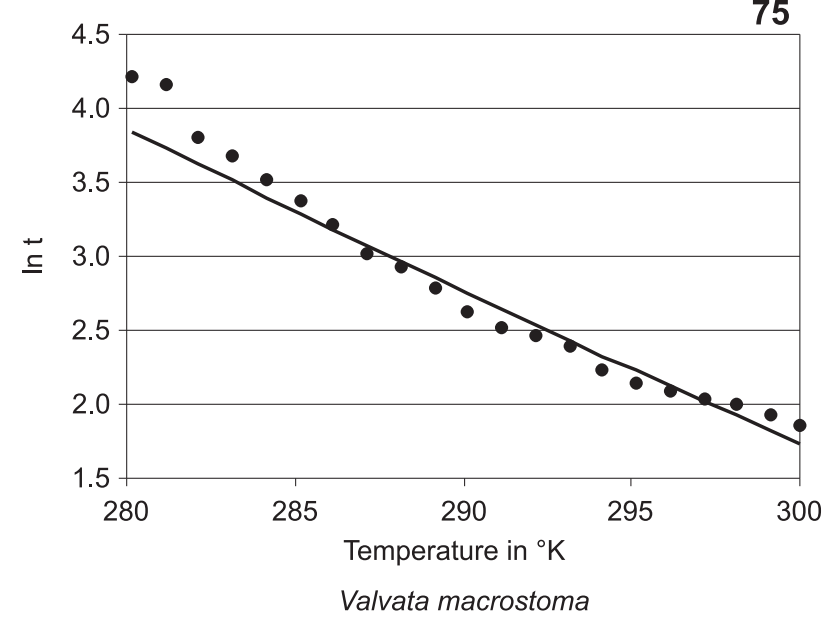

77

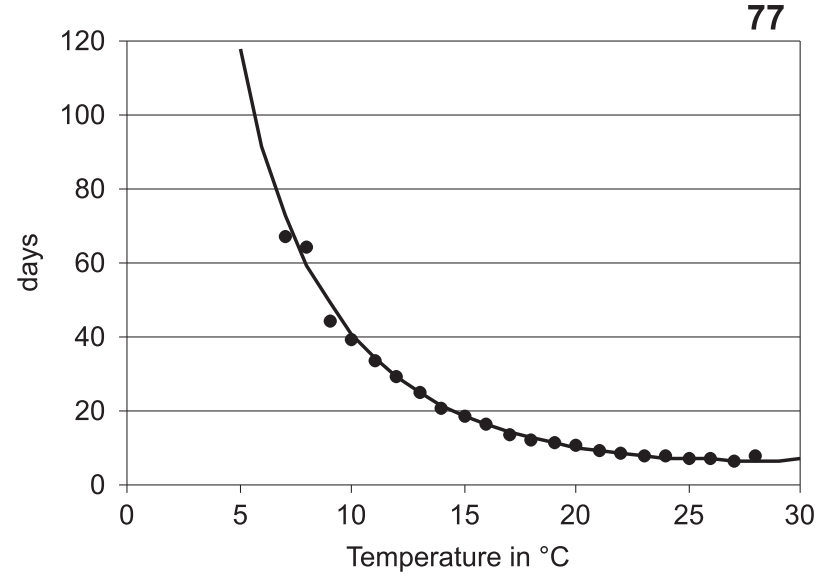

Valvata macrostoma $\times$ Tc (Figs 77-78). The observations suggest that with increasing temperature the mean duration of embryonic development intially becomes faster but after exceeding a certain threshold temperature (ca. $27^{\circ} \mathrm{C}$ for $V$. macrostoma and ca. $26^{\circ} \mathrm{C}$ for $V$. piscinalis) it slows down again. Similar dependences result from the above equations, but the optimum temperature calculated on their basis is somewhat higher.

The initial 0.5 whorl of the embryonic shell is usually covered by spiral striae which are the least marked in $V$. macrostoma. The partly overlapping ranges of variation of this character usually do not permit identification of single shells. Differences in microsculpture of the shell surface have been studied and described by FALNIOWSKI (1989a, 1990). Embryonic shells of $V$. cristata are as a rule smaller (most often 0.5-0.62 whorl) than in the remaining two species (most often 0.75 whorl) (Table 7 ). At the same number of whorls also the mean diameter and height of embryonic shells of $V$. cristata is distinctly smaller than

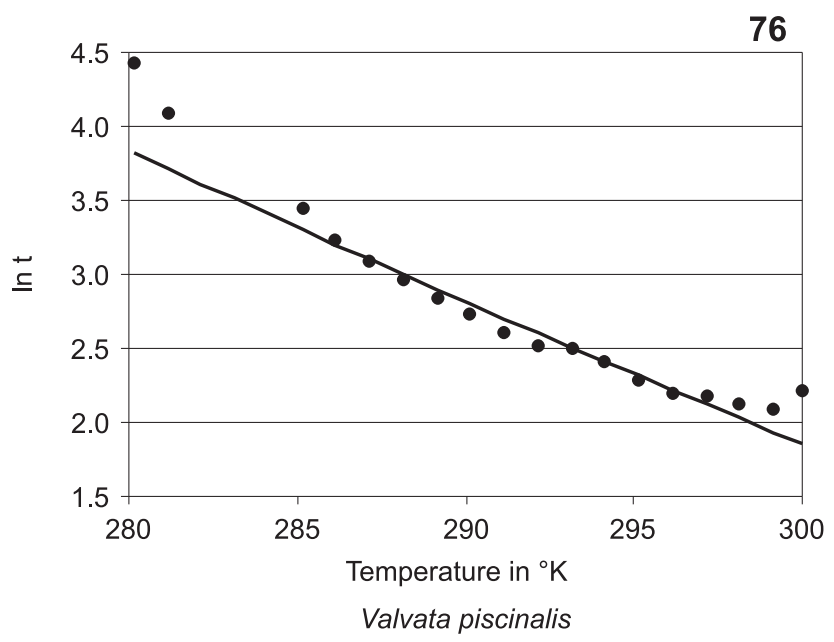

78

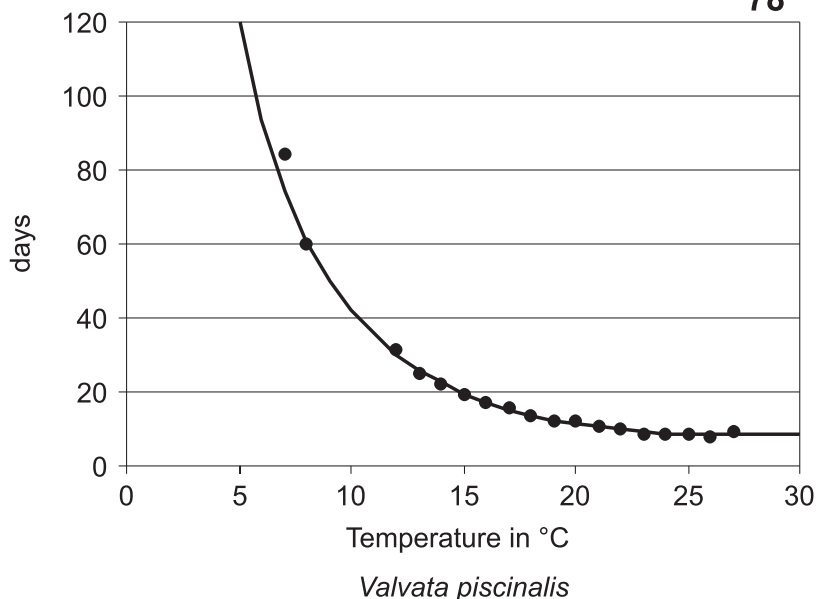

Figs 75-78. Relationship between temperature and the mean duration of embryonic development (dots); 75 - Valvata macrostoma - regression equation: $\ln \mathrm{t}=8,947.1 / \mathrm{T}-28.089 ; 76-$ Valvata piscinalis - regression equation: $\ln \mathrm{t}=8,333.7 / \mathrm{T}$ - 25.921 (ln t - natural logarithm of the mean duration of embryonic development in days; $\mathrm{T}$ - temperature in ${ }^{\circ} \mathrm{K}$ ); $77-$ Valvata macrostoma - regression equation: $\mathrm{t}=824 / \mathrm{Tc}-52+1.046 \times \mathrm{Tc} ; 78-$ Valvata piscinalis - regression equation: $\mathrm{t}=$ $838 / \mathrm{Tc}-53+1.118 \times \mathrm{Tc}\left(\mathrm{t}-\right.$ mean duration of embryonic development in days, $\mathrm{Tc}-$ temperature in $\left.{ }^{\circ} \mathrm{C}\right)$ 
in the other two species. The protoconch boundary in $V$. cristata is usually clearly marked while in $V$. macrostoma and $V$. piscinalis it is as a rule hidden among the radial striae. According to BINDER (1967) the width of the intial part of the first whorl is species-specific in Valvata. In the studied species this is explained by forming of the shell apex inside the unbroken external envelope of the egg (MYZYK 2002: Fig. 47). Both inter- and intraspecific differences in this parameter can be explained by the variation in egg size (mainly diameter).

In the laboratory in the best food conditions the time from hatching to female maturity is rather short in all the studied species: for $V$. cristata ca. 3 months (minimum 55 days), for $V$. macrostoma 3-4 months (minimum 60 days), for $V$. piscinalis ca. 2 months (minimum 42 days). With deteriorating food conditions the time can extend even to $1-2$ years. The relative duration of juvenile period is much varied and partly dependent on food conditions (Table 8). The ranges of variation are: for $V$. cristata $7.8-79.3 \%$ lifetime, for $V$. macrostoma 7.5-61.9\% lifetime, for $V$. piscinalis 13.4-82.2\% (sporadically even 100\%) lifetime. The timing of the beginning of reproduction is influenced by the season in which the animal attained maturity and by the copulation. Snails hatched in the spring often deposit their first cocoon already at the end of summer. For most snails kept in pairs (groups) in various food conditions the time between hatching and the first cocoon is: V. cristata 90-750 days (mean 368), V. macrostoma 76-414 days (mean 169), V. piscinalis 51-235 days (mean 118). Depending on the life span, reproduction in $V$. cristata lasts 1-3 seasons, in $V$. macrostoma 1-3 seasons (sporadically 4 ), in $V$. piscinalis 1-2 seasons. Better food conditions have a positive effect on the intensity of production of vitellogenic oocytes. Dependence between the number of eggs deposited during lifetime and the intensity of feeding is rather complicated because of the life span shortening with improvement of feeding conditions. The maximum numbers of cocoons and eggs deposited during lifetime by snails which could copulate are: for $V$. cristata 105 cocoons/353 eggs, for V. macrostoma 166 cocoons/1,436 eggs, for V. piscinalis 113 cocoons/2,862 eggs.

Snails kept singly, with no possibility to copulate, deposit much fewer cocoons and eggs than those kept in pairs or groups (except the uniparental V. cristata). Besides, eggs produced by them are often deformed (in V. cristata 55.3\%, in V. macrostoma $45.5 \%$, in $V$. piscinalis $34.4 \%$ ). Successful uniparental reproduction was observed only once, in V. cristata (eggs deposited in the second reproductive season). In a few other eggs deposited by other $V$. cristata the development stopped at the end of the egg phase. In the eggs of $V$. macrostoma and $V$. piscinalis produced by snails kept singly cleavage occurrs only rarely and the development stops at the latest after a few intial divisions.

In the laboratory in unfavourable food conditions the life span of $V$. cristata is for $73 \%$ snails ca. 2 years, for $25 \%$ ca. 3 years. With improving food conditions the mean life span decreases and with intense feeding amounts to ca. 1 year. The life span of $V$. macrostoma in very unfavourable food conditions is rather varied and amounts to: for $30 \%$ snails ca. 1 year, for $35 \%$ ca. 2 years and for $35 \%$ ca. 3 years. Like in V. cristata, in better food conditions the mean life span becomes shorter and for intensely feeding snails it is ca. 1 year. The life span of $V$. piscinalis fed mainly with periphyton is $1-1.5$ year (rarely somewhat longer, and in very unfavourable food conditions even slightly more than 2 years). Snails fed intensely with filamentous diatoms have a life span of ca. 6 months, and only few live to be ca. 11 months old.

The shell variation in $V$. cristata is rather small. The whorls are usually in one plane, the apex being slightly depressed. Very rarely the apex is slightly elevated and protrudes above the younger whorls. However, infection with trematode larvae results in the increasing whorl being distinctly descending and sometimes completely tucked under. Typical shells of $V$. macrostoma have a fairly low spire and wide umbilicus.

Table 7. Comparison of embryonic shells size

\begin{tabular}{lccc}
\hline & V. cristata $(\mathrm{n}=565)$ & V. macrostoma $(\mathrm{n}=444)$ & V. piscinalis $(\mathrm{n}=607)$ \\
\cline { 2 - 4 } & mean $\pm \mathrm{SD}$ & mean $\pm \mathrm{SD}$ & mean $\pm \mathrm{SD}$ \\
\hline shell diameter in mm & $0.377 \pm 0.040$ & $0.492 \pm 0.047$ & $0.465 \pm 0.054$ \\
shell height in mm & $0.222 \pm 0.016$ & $0.286 \pm 0.023$ & $0.267 \pm 0.029$ \\
number of whorls & $0.57 \pm 0.14$ & $0.74 \pm 0.10$ & $0.70 \pm 0.13$ \\
\hline
\end{tabular}

Table 8. Comparison of the relative duration of juvenile stage (days from hatching to maturity/days of life span ratio)

\begin{tabular}{lccc}
\hline \multirow{2}{*}{ Food conditions } & V. cristata & V. macrostoma & V. piscinalis \\
\cline { 2 - 4 } & mean $\pm \mathrm{SD}$ & mean $\pm \mathrm{SD}$ & mean \pm SD \\
\hline less favourable & $42.7 \% \pm 14.6 \%$ & $21.1 \% \pm 8.4 \%$ & $39.4 \% \pm 18.3 \%$ \\
more favourable & $25.4 \% \pm 11.8 \%$ & $26.8 \% \pm 12.6 \%$ & $29.7 \% \pm 13.1 \%$ \\
\hline
\end{tabular}


Joining in pairs snails with similar shells results in progeny with either planispiral or high-spired shells (spire higher than aperture), with a narrow umbilicus. Food conditions have little effect on the shell shape and proportions (in unfavourable conditions the shells are smaller and slightly more flattened compared to those of snails kept in better conditions). Shells of $V$. piscinalis are the most variable among the studied species. Their shape, proportions and size are influenced by both food conditions and individual variation (large differences are observed even among snails hatched from the same cocoon and kept in similar conditions).

The operculum is sinistral (contrary to the dextral shell). In juveniles the opercula are as a rule difficult to distinguish, greater differences are found in adults. Opercula of adult $V$. cristata resemble those of $V$. macrostoma though at the same number of whorls they reach a smaller size (different whorl width). Opercula of $V$. piscinalis are usually somewhat more flat and have a very wide last whorl (sometimes also the penultimate) with characteristic sculpture (very rarely found in $V$. macrostoma). The number of opercular whorls (including embryonic whorls) in $V$. piscinalis is ca. twice greater than the number of shell whorls, in $V$. cristata and V. macrostoma ca. three times greater.

According to the currently accepted classification the studied species are included in different subgenera within Valvata: V. (Valvata) cristata, V. (Tropidina) macrostoma and V. (Cincinna) piscinalis. My observations show clear differences in the bionomics of $V$. cristata compared to the other two species (smaller eggs and embryonic shells, different cocoon structure, uniparental reproduction). The differences between $V$. macrostoma and $V$. piscinalis are smaller and pertain, for example, to the course of embryonic development, operculum structure and effect of food conditions on life span.

\section{ACKNOWLEDGEMENTS}

I am grateful to Prof. dr hab. BEATA M. POKRYSZKO who has translated the text into English, and to my brother KAZIMIERZ MYZYK for his help when preparing this paper. My thanks go to Prof. dr hab. ANDRZEJ WITKOWSKI and to Dr Brygida WAWRZYNIAK-WYDROWSKA from the University of Szczecin for identification of the diatoms used as food for the snails.

\section{REFERENCES}

BINDER E. 1967. La coquille embryonnaire des Valvatidae (Moll. Gastropoda). Arch. Moll. 96: 21-24.

Cleland D. M. 1954. A study of the habits of Valvata piscinalis (Müller), and the structure and function of the alimentary canal and reproductive system. Proc. Malac. Soc. Lond. 30: 167-203.

FALNIOWSKI A. 1989a. Przodoskrzelne (Prosobranchia, Gastropoda, Mollusca) Polski. I. Neritidae, Viviparidae, Valvatidae, Bithyniidae, Rissoidae, Aciculidae. Zeszyty Naukowe Uniwersytetu Jagielońskiego, CMX, Prace Zoologiczne 35: 1-148.

FALNIOWSKI A. 1989b. A critical review of some characters widely used in the systematics of higher taxa of freshwater prosobranchs (Gastropoda, Prosobranchia) and a proposal of some new, ultrastructural ones. Folia Malacol. 3: 73-94.

FALNIOWSKI A. 1990. Anatomical characters and SEM structure of radula and shell in the species-level taxonomy of freshwater prosobranchs (Mollusca, Gastropoda, Prosobranchia): a comparative usefulness study. Folia Malacol. 4: 53-142.

FRETTER V., GRAHAM A. 1962. British prosobranch molluscs. Their functional anatomy and ecology. Ray Society, London.

FRÖMMING E. 1956. Biologie der mitteleuropäischen Süsswasserschnecken. Berlin.

Girod A., BiAnchi I., Mariani M. 1980. Gasteropodi, 1 (Gastropoda: Pulmonata, Prosobranchia: Neritidae, Viviparidae, Bithyniidae, Valvatidae). Consiglio Nazionale delle Ricerche $\mathrm{AQ} / 1 / 44$. Guide per il riconoscimento delle specie animali delle acque interne Italiane, 7, Verona.

MYZYK S. 2002. Life cycle of Valvata cristata O. F. Müller, 1774 (Gastropoda: Heterobranchia) in the laboratory. Folia Malacol. 10: 47-75.

MYZYK S. 2004. Life cycle of Valvata macrostoma Mörch, 1864 (Gastropoda: Heterobranchia) in the laboratory. Folia Malacol. 12: 111-136.

PIECHOCKI A. 1979. Mięczaki (Mollusca). Ślimaki (Gastropoda). Fauna Słodkowodna Polski 7. PWN, Warszawa-Poznań.

RATH E. 1986. On the anatomy and development of the Valvatidae (Gastropoda: Streptoneura). Abstracts, Ninth International Malacological Congress, Edinburgh.

RATH E. 1988. Organization and systematic position of the Valvatidae. Malac. Rev., Suppl. 4: 194-204.

WessenBERG-Lund C. 1939. Biologie der Süsswassertiere. Julius Spinger Verl., Wien.

Received: March 27th, 2007 Accepted: October 1st, 2007 